UNIVERSIDADE DE SÃO PAULO

ESCOLA DE EDUCAÇÃO FÍSICA E ESPORTE

DETERMINAÇÃO DA POTÊNCIA AERÓBIA

DE CRIANÇAS E ADOLESCENTES A PARTIR DE

AJUSTES ALOMÉTRICOS

GUSTAVO ANDRÉ BORGES

SÃO PAULO

2009 


\section{DETERMINAÇÃO DA POTÊNCIA AERÓBIA DE CRIANÇAS E ADOLESCENTES A PARTIR DE \\ AJUSTES ALOMÉTRICOS}

\section{GUSTAVO ANDRÉ BORGES}

Tese apresentada à Escola de Educação Física e Esporte da Universidade de São Paulo, como requisito parcial para obtenção do título de Doutor em Educação Física. 


\section{AGRADECIMENTOS}

Depois de uma longa e cansativa, e ainda sim prazerosa, jornada de estudos, não me furtaria a agradecer a todas as pessoas que contribuíram direta e indiretamente para a conclusão desta tese.

Ao Prof. Dr. Valdir José Barbanti, não apenas o orientador, mas um importante conselheiro, amigo, irmão e, muitas vezes, pai. Sem a sua total confiança desde o início de tudo, no mestrado, este estudo não seria possível. Não haverá palavras para agradecer por toda a sua generosidade, sabedoria, lucidez e muita paciência durante toda a minha formação. Tenho a certeza de que no futuro ainda precisarei muito de sua incondicional orientação;

A Capes, por ter concedido a bolsa de estudos;

Ao Colegiado do Curso de Educação Física da Unioeste, por permitir o afastamento integral de minhas funções e por acreditar na minha formação;

Aos diretores das escolas de Marechal Cândido Rondon - Paraná, por terem cedido o espaço e o tempo escolar e, também, por acreditarem no projeto de pesquisa;

A todos os professores de Educação Física que cederam suas aulas e por se envolverem, estimulando seus alunos a participar desta pesquisa. São eles: Marquinho, Juliano, Kelly, Gleyson, Marcel, Miro, Renan, Robson, Roberto, Karl, Cristiane, Valterncir, Yara e Márcia;

Às crianças e aos adolescentes, por terem participado com tanto empenho e motivação das avaliações. Não há como agradecer tamanha generosidade;

Aos estagiários do curso de Educação Física da Unioeste, Ângela Elly Glass, Cezar Barbosa Santolin e Maiara Cristina Tadiotto. Sem as contribuições deles, as avaliações não teriam sido possíveis;

Ao Prof. Davi Felix Schreiner, por seu empenho na concretização deste projeto de pesquisa, não medindo esforços para garantir os recursos e a infra-estrutura necessária à realização das avaliações;

A Sergio Cyriaco, funcionário da biblioteca da Escola de Educação Física e Esporte da Universidade de São Paulo, que mesmo à distância se preocuparam em buscar e enviar o material teórico necessário a complementação desta tese;

A Ilza Benedita dos Santos e Márcio Aparecido do Nascimento, funcionários da Comissão de Pós-Graduação da Escola de Educação Física e Esporte da USP, por sua atenção e dedicação nesses anos, por sempre providenciarem a documentação necessária para a conclusão deste curso mas, sobretudo, por suas amizades;

A Sergio Nascimento (Técnico da Inbrasport - RS), por todo o seu auxílio técnico durante a utilização do analisador de gazes, sempre que lhe foi solicitado;

Aos amigos para toda uma vida, Raymundo, Reynaldo, Dalmo, Enrico, Abdallah, Sergio e Marquinhos, por estarem ao meu lado nos momentos de dificuldades e de alegria, incentivando-me a avançar cada passo com a serenidade e a confiança necessárias para conclusão deste curso;

A Selma, companheira de todas essas horas e muitas outras que virão. Sem a sua compreensão, paciência, abnegação, incentivo e, acima de tudo muito amor, esse trabalho não seria possível. Amo você! 
SUMÁRIO

Página

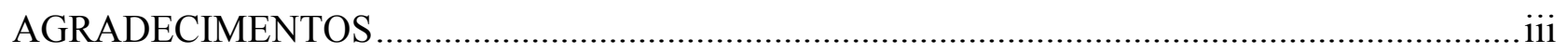

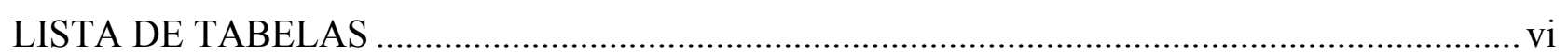

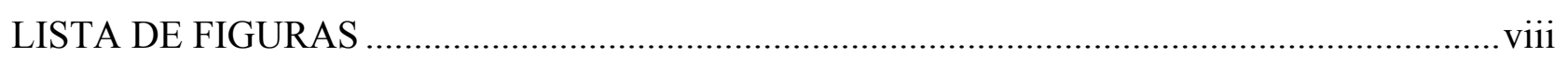

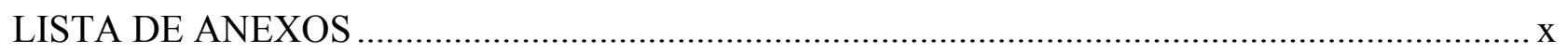

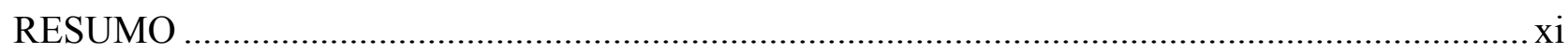

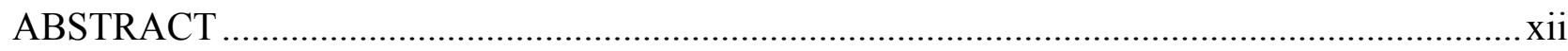

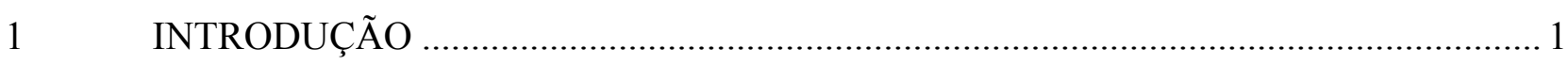

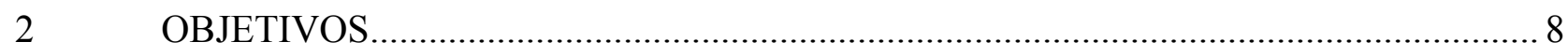

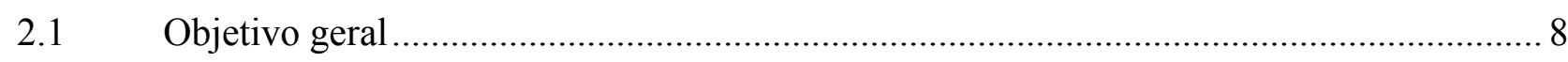

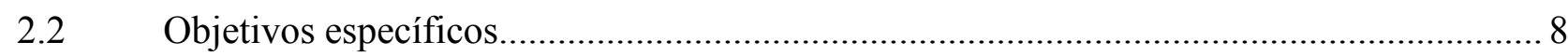

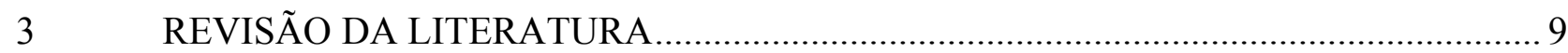

3.1 Desenvolvimento da potência aeróbia $\left(\mathrm{VO}_{2}\right)$ de crianças e adolescentes ......................... 9

3.2 Determinação do $\dot{\mathrm{V}}_{2}$ máx de crianças e adolescentes ................................................. 18

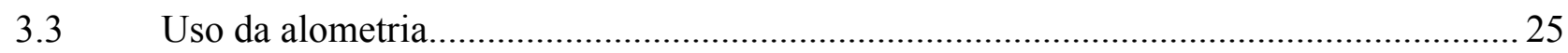

3.4 Ajustes alométrico no $\dot{\mathrm{VO}}_{2}$ de crianças e adolescentes................................................ 34

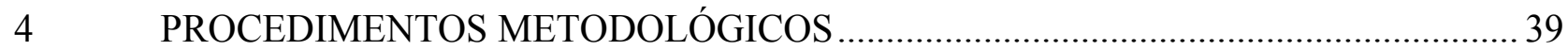

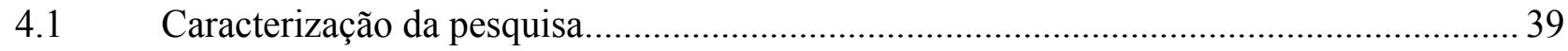

4.2 Localização e características humanas do Município de Marechal Cândido

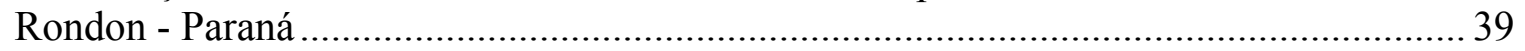

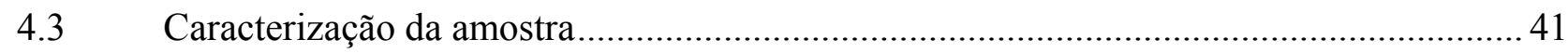

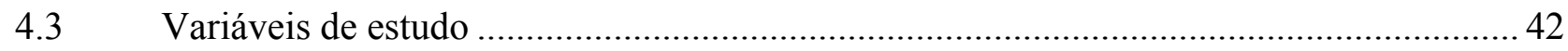

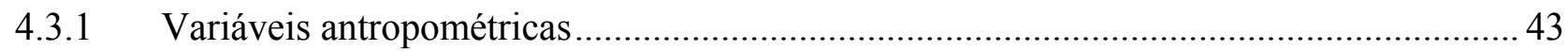

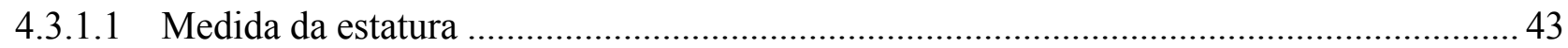

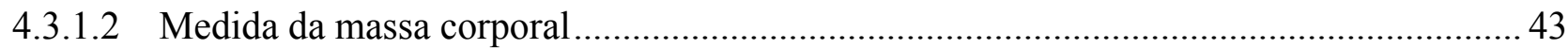

4.3.2 Medida das espessuras de dobras cutâneas ....................................................................... 43

4.3.2.1 Medida da dobra cutânea tricipital .................................................................................... 44

4.3.1.1 Medida da dobra cutânea subescapular........................................................................ 44

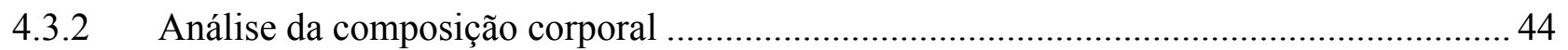

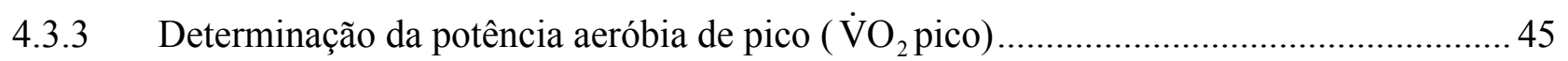




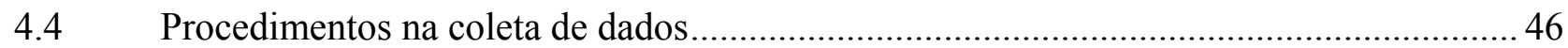

4.5 Procedimentos do teste cardiopulmonar de esforço ....................................................... 47

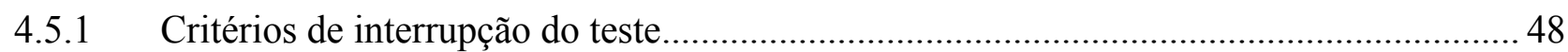

4.5.2 Critérios de determinação do $\dot{\mathrm{V}}_{2}$ pico .................................................................. 48

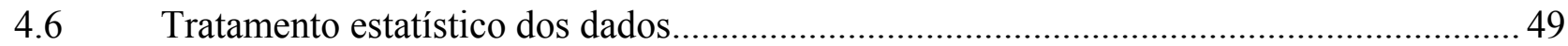

4.6.1 Descrição do comportamento das variáveis do estudo.................................................... 50

4.6.2 Determinação da regressão alométrica............................................................................ 50

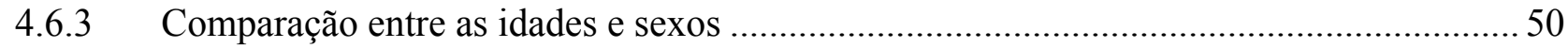

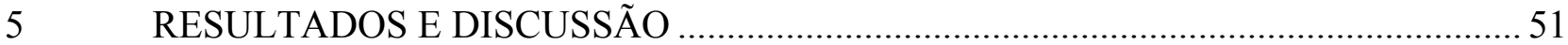

5.2 Características do crescimento físico e da composição corporal .................................... 52

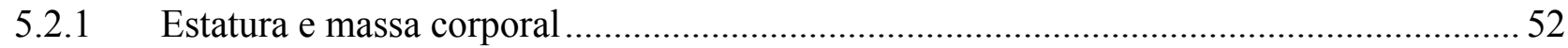

5.2.2 Gordura corporal absoluta $\left(\sum \mathrm{DC}\right)$ e relativa $(\% \mathrm{G})$, massa corporal magra $(\mathrm{MCM}) \ldots \ldots . . .59$

5.3 Características do teste de esforço e dos parâmetros ventilatórios .................................. 69

5.3.1 Tempo de corrida (TC), freqüência cardíaca (FC) e quociente respiratório (QR) ............69

5.3.2 Parâmetros ventilatórios: ventilação, potência aeróbia absoluta e relativa....................... 78

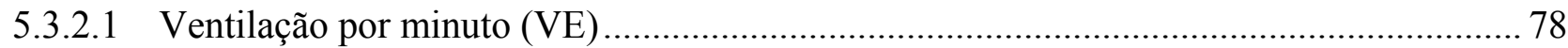

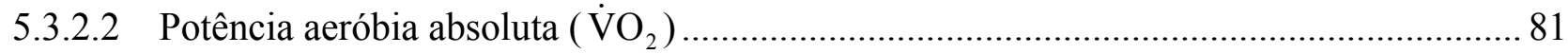

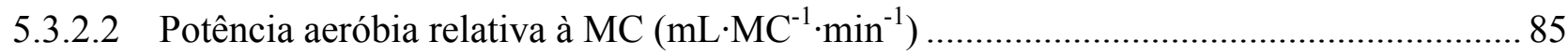

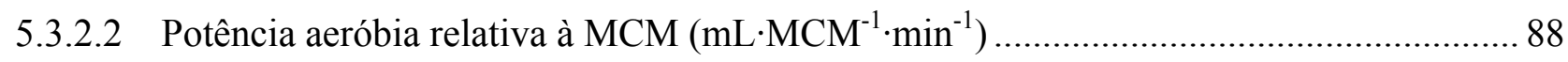

5.3.3 Potência aeróbia relativa: ajustes alométricos.............................................................. 89

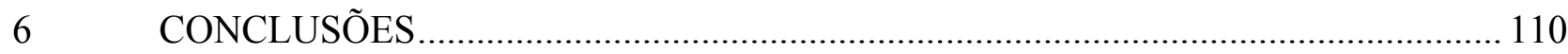

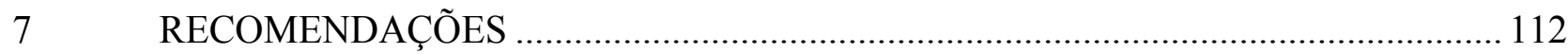

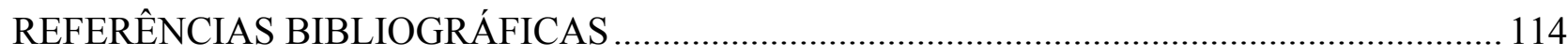

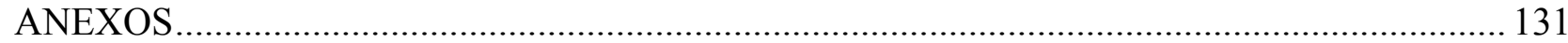




\section{LISTA DE TABELAS}

Página

TABELA 1 - Valores das constantes $C$ descritas por Boileau et al. (1985) utilizadas segundo a idade e sexo, no modelo de estimativa da gordura corporal relativa $(\% \mathrm{G})$.

TABELA 2 - Protocolo do teste cardiopulmonar de esforço (Balke adaptado) para crianças e adolescentes ativas.

TABELA 3 - Número de escolares, valores médios, desvios-padrão, mínimo e máximo por sexo e idade milesimal de crianças e adolescentes pertencentes ao estudo.

TABELA 4 - Valores médios e desvios-padrão para a estatura $(\mathrm{cm})$ e massa corporal $(\mathrm{kg}) \mathrm{de}$ crianças e adolescentes de ambos os sexos.

TABELA 5 - Coeficientes de correlação entre as variáveis morfológicas e a idade milesimal de crianças e adolescentes de ambos os sexos.

TABELA 6 - Valores médios e desvios-padrão para a somatória de dobras $(\mathrm{mm})$, gordura corporal relativa $(\%)$ e massa corporal magra $(\mathrm{kg})$ de crianças e adolescentes de ambos os sexos.

TABELA 7 - Valores médios e desvios-padrão da umidade relativa do ar (\%) e da temperatura do laboratório $\left({ }^{\circ} \mathrm{C}\right)$ durante o teste cardiopulmonar de esforço de crianças e adolescentes de ambos os sexos.

TABELA 8 - Coeficientes de correlação entre as variáveis ventilatórias e o tempo de corrida, idade, estatura e MC de crianças e adolescentes de ambos os sexos.

TABELA 9 - Valores dos coeficientes de variação $\left(\mathrm{CV}_{\mathrm{xy}}\right)$ e de correlação linear $\left(\mathrm{r}_{\mathrm{xy}}\right)$ para a potência aeróbia e MC relativo a idade e sexo, de crianças e adolescentes

TABELA 10 - Valores dos coeficientes de variação $(C V)$ e de correlação linear $\left(\mathrm{r}_{\mathrm{xy}}\right)$ para a potência aeróbia e MCM relativo à idade e ao sexo, de crianças e adolescentes.

TABELA 11 - Valores dos coeficientes de variação $(C V)$ e de correlação linear $\left(\mathrm{r}_{\mathrm{xy}}\right)$ da potência aeróbia, MC e MCM relativos à idade para crianças e adolescentes de ambos os sexos.

TABELA 12 - Equações de regressão alométrica entre a potência aeróbia e a MC relativa à idade e ao sexo de crianças e adolescentes. 
TABELA 13 - Equações de regressão alométricas entre a potência aeróbia e a MC para diferentes grupos etários de crianças e adolescentes.

TABELA 14 - Equações de regressão alométricas entre a potência aeróbia e a MCM relativa a idade de crianças e adolescentes de ambos os sexos. 


\section{LISTA DE FIGURAS}

Página

FIGURA 1 - Localização do Município de Marechal Cândido Rondon - Brasil, no extremo oeste do estado do Paraná.

FIGURA 2 - Curvas de distância para os valores médios da estatura de crianças e adolescentes de ambos os sexos.

FIGURA 3 - Curvas de distância para os valores médios da estatura e massa corporal de crianças e adolescentes de ambos os sexos.

FIGURA 4 - Curvas de distância dos valores médios e desvios-padrão da gordura corporal relativa $(\% \mathrm{G})$ de crianças e adolescentes de ambos os sexos.

FIGURA 5 - Tempo médio de corrida para o teste cardiopulmonar de esforço de crianças e adolescentes de ambos os sexos.

FIGURA 6 - Percentual de crianças e adolescentes, de ambos os sexos, que atingiram o $\mathrm{VO}_{2}$ pico em cada estágio de inclinação da esteira com relação ao tempo de corrida.

FIGURA 7 - Percentual de crianças e adolescentes, de ambos os sexos, que atingiram o $\mathrm{VO}_{2}$ pico no período recomendado de 8 a 12 minutos durante o teste.

FIGURA 8 - Curvas de distância e valores do percentual de alcance da FCpico acima de 95\% da máxima prevista para a idade de crianças e adolescentes de ambos os sexos.

FIGURA 9 - Curvas de distância e valores do percentual de alcance do QRpico $\geq 1$ de crianças e adolescentes de ambos os sexos.

FIGURA 10 - Curvas de distância dos valores médios e desvio-padrão da ventilação por minuto - VE $\left(\mathrm{L} \cdot \mathrm{min}^{-1}\right)$ de crianças e adolescentes de ambos os sexos.

FIGURA 11 - Curvas de distância $\mathrm{VO}_{2}\left(\mathrm{~L} \cdot \mathrm{min}^{-1}\right)$ de crianças e adolescentes de ambos os sexos.

FIGURA 12 - Curvas de distância do $\mathrm{VO}_{2}\left(\mathrm{~mL} \cdot \mathrm{kg}^{-1} \cdot \mathrm{min}^{-1}\right)$ de crianças e adolescentes de ambos os sexos.

FIGURA 13 - Curvas de distância para o $\mathrm{VO}_{2}\left(\mathrm{~mL} \cdot \mathrm{MCM}^{-1} \cdot \mathrm{min}^{-1}\right)$ de crianças e adolescentes de ambos os sexos. 
FIGURA 14 - Curvas de distância para os valores médios do $\mathrm{VO}_{2}$ relativo à $\mathrm{MC}$ em uma escala de potência de 0,67 e 0,75 de crianças e adolescentes de ambos os sexos.

FIGURA 15 - Curvas de distância para os valores médios e desvio-padrão do $\mathrm{VO}_{2}$ relativo a $\mathrm{MC}^{0,91}$ e $\mathrm{MC}^{0,82}$ para rapazes e moças, respectivamente

FIGURA 16 - Curvas de distância e valores médios e desvio-padrão do $\mathrm{VO}_{2}$ relativo à $\mathrm{MC}^{0,85}$ para ambos os sexos de crianças e adolescentes. 98

FIGURA 17 - Curvas de distância para os valores médios e desvios-padrão do $\mathrm{VO}_{2}$ relativo a $\mathrm{MCM}^{1,0}$ para rapazes e $\mathrm{MC}^{1,01}$ e para as moças.

FIGURA 18 - Curvas de distância para os valores médios e desvios-padrão do $\mathrm{VO}_{2}$ relativo a $\mathrm{MCM}^{1,02}$ para ambos os sexos. 


\section{LISTA DE ANEXOS}

Página

ANEXO I - Carta de Autorização da Direção da Escola.........................................................131

ANEXO II - Carta de Intenção de Pesquisa..........................................................................133

ANEXO III - Termo de Consentimento.............................................................................134

ANEXO IV - Termo de Aprovação do Comitê de Ética em Pesquisa.......................................135

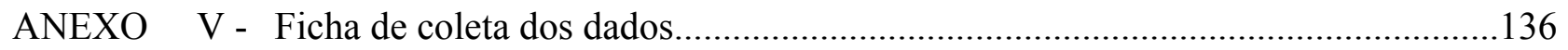


RESUMO

\title{
DETERMINAÇÃO DA POTÊNCIA AERÓBIA DE CRIANÇAS E ADOLESCENTES A PARTIR DE AJUSTES ALOMÉTRICOS
}

\author{
Autor: GUSTAVO ANDRÉ BORGES \\ Orientador: PROF. DR. VALDIR JOSÉ BARBANTI
}

O objetivo do estudo foi determinar e analisar o comportamento da potência aeróbia $\left(\mathrm{VO}_{2}\right.$ pico $)$ em valores absolutos e relativos por meio de expoentes lineares e alométricos, em crianças e adolescentes de 10 a 16 anos de Marechal Candido Rondon - Paraná. A amostra foi intencionalmente composta por 248 indivíduos, sendo 124 rapazes e 124 moças. Medidas de estatura, massa corporal (MC) e dobras cutâneas foram realizadas. A gordura corporal e a massa corporal magra (MCM) foram determinadas pela equação de Boileau et al. (1986) para ambos os sexos. A potência aeróbia foi determinada diretamente por meio de teste cardiopulmonar de esforço em esteira, segundo o protocolo modificado de Balke, para ambos os sexos. Medidas ventilatórias (VE, $\mathrm{VO}_{2}, \mathrm{QR}$ ) e homodinâmicas (FC) foram obtidas através do analisador metabólico de gazes VO2000 e do transmissor Polar, a cada 10 segundos. No tratamento estatístico dos dados, foi utilizada a estatística descritiva e as diferenças entre os sexos foram verificadas pelo teste "t" para amostras independentes. Os expoentes alométricos foram determinados através de uma regressão log-linear. Os resultados demonstraram que dos 10 aos 16 anos, os ganhos na potência aeróbia absoluta foram de $107 \%$ para os rapazes $\left(1,67\right.$ para $\left.3,46 \mathrm{~L} \cdot \mathrm{min}^{-1}\right)$ e $66 \%$ para as moças $\left(1,57\right.$ para 2,61 L· $\left.\mathrm{min}^{-1}\right)$, com diferenças a partir dos 14 anos. Os ganhos da potência aeróbia relativa à massa corporal foram de $12 \%\left(48,8\right.$ para $\left.54,5 \mathrm{~mL} \cdot \mathrm{kg}^{-1} \cdot \mathrm{min}^{-1}\right)$ e $1 \%(42,9$ para $\left.43,3 \mathrm{~mL} \cdot \mathrm{kg}^{-1} \cdot \mathrm{min}^{-1}\right)$, com diferenças significantes entre os sexos em todas as idades, enquanto que relativos à $\mathrm{MCM}$ foram de $8 \%\left(58,0\right.$ para $\left.62,9 \mathrm{~mL} \cdot \mathrm{MCM}^{-1} \cdot \mathrm{min}^{-1}\right)$ e $6 \%\left(53,3\right.$ para $56,3 \mathrm{~mL} \cdot \mathrm{MCM}^{-}$ ${ }^{1} \cdot \min ^{-1}$ ) para rapazes e moças respectivamente, com diferenças significantes entre os sexos a partir dos 12 anos. Os expoentes nos diferentes grupos etários e sexos variaram de 0,30-0,94 para a MC e de 0,44-1,32 para a MCM. No ajuste alométrico da $\mathrm{MC}$, o expoente $0,91(\mathrm{r}=0,88)$ foi obtido para todos os rapazes, $0,82(\mathrm{r}=0,85)$ para todas as moças e $0,85(\mathrm{r}=0,81)$ para ambos os sexos. $\mathrm{O}$ ajuste da MCM gerou o expoente $1,00(\mathrm{r}=0,94)$ para os rapazes, $1,01(\mathrm{r}=0,87)$ para as moças e 1,02 $(\mathrm{r}=0,89)$ para ambos os sexos. Concluiu-se que a potência aeróbia de crianças e adolescentes foi adequadamente ajustada pela $\mathrm{MCM}^{1,0}$ e alométricamente pela $\mathrm{MC}^{0,85}$.

PALAVRAS-CHAVE: Alometria; Potência aeróbia; Composição Corporal; Crianças; Adolescentes. 
ABSTRACT

\title{
DETERMINATION OF THE AEROBIC POWER IN CHILDREN AND ADOLESCENTS BY SCALING
}

\author{
Author: GUSTAVO ANDRÉ BORGES \\ Adviser: VALDIR JOSÉ BARBANTI, PhD
}

The aim of this study was to determine and analyze the absolute e and relative aerobic power ( $\mathrm{VO}_{2}$ peak) by mean of linear and allometric exponents in children and adolescents, ages 10 to 16 years from Marechal Cândido Rondon - Paraná. Body mass (BM), height end skinfold thickness were measure in an intentional sample of 248 schoolchildren (124 boys and 124 girls). Body fat and lean body mass (LBM) were estimated by the equation suggested by Boileau et al. (1982) in both sexes. Aerobic power was determinate directly using a treadmill by mean of a modified Balke protocol and a VO2000 portable metabolic system and heart rate by Polar transmission, each ten seconds. Descriptive statistics were use for all data. The difference between sexes was determined by " $t$ " test, and the allometric exponents by log-linear regression. The gain in $\mathrm{VO}_{2}$ peak absolute was $107 \%$ in boys $\left(1,67\right.$ to $\left.3,46 \mathrm{~L} \cdot \mathrm{min}^{-1}\right)$ and $66 \%$ in girls $\left(1,57\right.$ to $\left.2,61 \mathrm{~L} \cdot \mathrm{min}^{-1}\right)$ from 10 to 16 years old. Absolute $\mathrm{VO}_{2}$ peak was similar for boys and girls in ages 10, 11, 12 and 13 years old. The gain was $12 \%\left(48,8\right.$ to $\left.54,5 \mathrm{~mL} \cdot \mathrm{kg}^{-1} \cdot \mathrm{min}^{-1}\right)$ and $1 \%\left(42,9\right.$ to $\left.43,3 \mathrm{~mL} \cdot \mathrm{kg}^{-1} \cdot \mathrm{min}^{-1}\right)$ to $\mathrm{VO}_{2}$ peak relative to BM and $8 \%\left(58,0\right.$ to $\left.62,9 \mathrm{~mL} \cdot \mathrm{MCM}^{-1} \cdot \mathrm{min}^{-1}\right)$ and $6 \%\left(53,3\right.$ to $\left.56,3 \mathrm{~mL} \cdot \mathrm{MCM}^{-1} \cdot \mathrm{min}^{-1}\right)$ relative to $\mathrm{LBM}$, for boys and girls respectively. The differences in $\mathrm{VO}_{2}$ peak relative to $\mathrm{BM}$ were significant in all ages, with boys showing higher values. Boys also showed significantly higher values in $\mathrm{VO}_{2}$ peak relative to $\mathrm{LBM}$ from ages 12 to 16 years. Allometry applied to $\mathrm{VO}_{2}$ peak relative to $\mathrm{BM}$ determinate an exponent of 0.91 for boys, 0.82 for girls and 0.85 for both sexes. Allometry applied to $\mathrm{VO}_{2}$ peak relative to LBM revealed an exponent of 1.00 for boys, 1.01 for girls and 1.02 for the both sexes. The data suggest that $\mathrm{VO}_{2}$ peak were better adjust linearly by LBM and by $\mathrm{MC}^{0,85}$.

KEYWORDS: Allometry; Aerobic power; Body composition; Children; Adolescents. 
O crescimento físico constitui-se em um dos mais importantes períodos do desenvolvimento dos seres humanos. Durante aproximadamente os vinte primeiros anos da vida, o corpo humano aumenta continuamente a sua substância viva (intra e extracelular), provocando inequívocas mudanças em suas estruturas anatômica e funcional (filogenia), e em suas formas e tamanhos (ontogenia). Todas as transformações concorrem para tornar o indivíduo biologicamente maduro. Ainda que cada uma das estruturas possua a sua particularidade e independência no crescer e desenvolver-se, todas influenciam-se reciprocamente. Esse período da vida distingue-se especialmente dos demais por ser muito sensível às influências das condições ambientais (particularmente as sociais e culturais) na formação integral do indivíduo adulto.

O crescimento físico é analisado sob diferentes olhares, nos diversos campos de investigação auxológica, tais como a fisiologia, a anatomia, a pediatria, a neurologia, a antropologia, a psicologia, a biomecânica, etc. Em cada um desses campos, tornou-se imprescindível realizar estudos nos diferentes grupos populacionais, a fim de identificar as semelhanças, sobretudo as vicissitudes ambientais que influem e caracterizam as sutis diferenças em cada grupo populacional ao longo da vida.

Dentre os diferentes indicadores autólogos do crescimento físico, como a massa corporal e a estatura conjuntamente (crescimento somático), são as mais representativas, principalmente quando se observam suas mudanças ao longo do tempo. Para TANNER (1987), são três as razões principais que impulsionam os estudos auxológicos. A primeira delas refere-se ao desejo mais simples de conhecer o modo particular de "como" e "quanto" $a(s)$ criança(s) cresce $(m)$. A segunda surge por uma razão socialmente orientada, na medida em que mulheres e homens (os pais) buscam entender o crescimento de suas crianças como um indicador das boas condições de vida da sociedade em que se inserem e à qual estão suscetíveis. A terceira razão reside na necessidade clínica ou sanitária - realizada pelos agentes de saúde -, da monitoração do crescimento da criança com relação ao crescimento esperado para o sexo e idade, assegurando que seu desenvolvimento seja o melhor possível. Portanto, tratando-se de crianças e adolescentes, essas duas informações são imprescindíveis na compreensão do seu desenvolvimento biológico. 
A avaliação de qualquer um desses indicadores em um único momento no tempo tem pouco significado no conjunto de transformações observadas nos indivíduos ao longo dos anos, contudo é extremamente útil quando se destina à avaliação do estado nutricional. Pela avaliação em um único momento no tempo, geralmente procura-se identificar o estado de desnutrição ou de obesidade infantil, considerando, para tanto, os valores da estatura para a idade ou da massa corporal para a estatura (MARCONDES, 1989).

Porém, as medidas somáticas orientam, mas não refletem necessariamente as outras características do desenvolvimento biológico, fundamentalmente aquelas associadas aos aspectos funcionais e motores, como a quantidade relativa de gordura corporal e a da potência aeróbia. Essas medidas apenas estabelecem uma visão macroscópica do crescimento anatômico, resultante das interferências genéticas e suas interações socioculturais em um grupo de pessoas estudadas dentro de um universo populacional específico.

Em termos de avaliação do crescimento para representação da população de qualquer país, alguns estudos descreveram o crescimento de grupos populacionais com faixas etárias que variam do nascimento à idade adulta. O estudo de HAMILL, DRIZD, JOHNSON, REED, ROCHE e MOORE (1979), que abordou o desenvolvimento de indivíduos do nascimento aos 19 anos, serviu, até o final dos anos de 1990, de base para o acompanhamento do crescimento de crianças estadunidenses, além de ser a referência para outros grupos populacionais no mundo. No Brasil, o estudo de MARCONDES (1989) passou a ser a referência do comportamento da normalidade do crescimento somático paras as crianças e adolescentes brasileiros.

Os aspectos funcionais do crescimento têm sido analisados, em grande parte, pelas características motoras no desenvolvimento, sendo inerente a esse processo a avaliação por meio de testes de desempenho motor. Alguns estudos procuraram descrever o crescimento em diferentes grupos populacionais, culturais e sociais, incluindo idades que variam de sete a 17 anos (GUEDES e GUEDES, 1994; BÖHME, 1995), e sete a 14 anos (BARBANTI, 1983; GONÇALVES, 1995).

Durante o período de crescimento, marcado cronologicamente, os ganhos no desempenho motor também são resultado dos exercícios regulares praticados pelas crianças e adolescentes. Ou seja, quando a crianças cresce, sua capacidade de se exercitar também cresce, devido ao simples fato de que quando a ela se torna maior, também se tornam maiores a suas 
pernas e braços, coração, pulmões e músculos. Essas mudanças não são apenas quantitativas, mas substancialmente qualitativas (ASMUSSEN e HEEBOLL-NIELSEN, 1955).

Embora os resultados do desempenho motor nos testes de campo sejam importantes indicadores do desenvolvimento psicomotor da criança, eles ainda não refletem todas as transformações, biológicas e psicossociais, ocorridas no período, pois existem diferenças entre o resultado visível do crescimento - em relação à idade cronológica e a maturação - e aqueles observados no comportamento das variáveis funcionais. Entre as variáveis funcionais que podem sofrer alterações durante o processo de crescimento, sem dúvida alguma a potência aeróbia se destaca entre as mais importantes, pois ela agrega as variações sofridas pelos aspectos comportamentais, sociais, morfológicos e fisiológicos, simultaneamente. No caso dos adultos, a importância da potência aeróbia está associada à prática regular de exercícios físicos que contribuem para o melhoramento ou manutenção da saúde cardiovascular ao longo da vida, ou para o desempenho esportivo, fundamentalmente entre as modalidades esportivas de longa duração e de média a baixa intensidade.

No caso da saúde de crianças, a maior parte dos estudos sobre o desenvolvimento aeróbio contempla os seus efeitos no combate às doenças cardíacas e pulmonares ocorridas durante a própria infância. Neste caso, este conhecimento deverá auxiliar os especialistas em saúde infantil no planejamento de programas de exercícios físicos de prevenção ou reabilitação apenas durante este período da vida (ROWLAND, 2002), mas com repercussão na fase adulta, estimulando a sua manutenção mediante a participação nas práticas esportivas.

Embora as investigações sobre o desenvolvimento biológico de crianças e adolescentes sejam valiosas, o conhecimento sobre as alterações na potência aeróbia não está muito claro, pois há inúmeros fatores de interferência, entre os quais destacam-se os aspectos morfológicos (indiscutivelmente o da massa corporal) que podem agir tanto positivamente quanto negativamente. Nesse sentido, é necessária uma maior compreensão dos efeitos do crescimento físico, fundamentalmente a partir das alterações somáticas, pois isso pode revelar a medida certa dessas modificações no âmbito da capacidade funcional, exigindo dos pesquisadores, portanto, um conhecimento mais aprofundado sobre os seus efeitos.

Para TURLEY, ROGERS, KUJAWA, HARPER e WILMORE (1995) a avaliação da potência aeróbia é importante durante o crescimento porque as comparações com base nas dimensões corporais podem ser feitas inter e intraindivíduos, e produzem informações quanto aos padrões de normalidade dessa variável. 
No Brasil ainda há inúmeras dificuldades na obtenção de valores de potência aeróbia por procedimentos diretos, devido ao elevado custo financeiro dos aparelhos envolvidos na medida, além do elevado tempo dependido para cada avaliação, apresentando-se inadequado para a realização de com um grande número de indivíduos nos espaços esportivos destinados às escolas. Portanto, a maioria dos estudos tem sido determinada mediante testes indiretos, privilegiando os testes de campo como a corrida e/ou caminhada, com diferentes distâncias ou tempo de corrida (BARBANTI, 1983; BÖHME, 1994; GUEDES, 1994; GUEDES e BARBANTI, 1995; GUEDES e GUEDES, 1993; LORENZI, 2006; OLIVEIRA, 1982) por serem mais baratos e envolverem simultaneamente um grande número de jovens. Entretanto, os resultados dos testes de campo apenas servem como indicadores de capacidade aeróbia. Mais recentemente o teste de corrida de vai-e-vem de 20 metros tem se apresentado como uma alternativa (HOBOLD, 2003; VASQUES, SILVA e LOPES, 2007) aos testes em laboratório que envolveu o cicloergômetro (DUARTE e DUARTE, 1989). Todos mediram indiretamente a potência ou capacidade aeróbia.

A dificuldade de realizar medidas laboratoriais se dá pelo elevado custo de alguns tipos de ergômetros - tais como a esteira rolante ou a bicicleta -, e de aparelhos como o analisador metabólico de gases. Poucos estudos foram realizados no Brasil utilizando o método direto em crianças e adolescentes, sendo estes recentes e em grupos populacionais específicos (CAPUTO, STELLA, MELLO e DENADAI, 2003; LORENZI, 2006; VIDAL FILHO, HERRERA e BOTTARO, 2003).

Os resultados encontrados nos estudos brasileiros são, no geral, semelhantes àqueles observados em estudos estrangeiros, com os rapazes apresentando resultados médios mais elevados às moças em todas as idades. O tipo de teste escolhido, de campo ou de laboratório, pode influenciar os resultados entre os sexos para uma mesma idade. Também o tipo de estudo utilizado, na sua maioria do tipo transversal, reflete parcialmente na qualidade das informações obtidas quando os jovens não apresentam experiências anteriores nos testes utilizados. Quando as crianças e adolescentes não desempenham o máximo que era esperado para cada tipo de teste, os valores observados podem ser subestimados.

Segundo ROWLAND (2002), embora o conhecimento sobre as diferenças nos tipos de testes tenha fornecido algumas soluções, por exemplo, na utilização de testes mais válidos, alguns aspectos do desenvolvimento da potência aeróbia na criança e no adolescente ainda precisam ser mais bem esclarecidos. Entre eles, o quanto as variáveis morfológicas 
interferem nas características fisiológicas, fundamentalmente em relação a um crescimento possivelmente não-linear, que pode influenciar nos resultados dos testes motores.

Para WINTER (1996), não há dúvidas de que durante o crescimento físico as crianças também melhoram os indicadores de desempenho. O que não está claro é o quanto esses aumentos no tamanho do corpo contribuem para a melhora qualitativa dos tecidos e estruturas orgânicas, conduzindo a melhoras funcionais. Considerando que os resultados da potência aeróbia podem ser avaliados com base em comparações entre ou intra-indivíduos, principalmente mediante as suas diferenças de tamanho, é essencial que a ela seja expressa relativamente a alguma variável de tamanho para representar as diferenças corporais entre os indivíduos e os sexos.

No que diz respeito às crianças e adolescentes, as variáveis associadas ao crescimento físico, como a estatura e a massa corporal, pois representam os melhores indicadores do crescimento. Convencionalmente, a potência aeróbia é ajustada pela massa corporal do indivíduo, sendo expresso, normalmente, por $\mathrm{mL} \cdot \mathrm{kg}^{-1} \cdot \mathrm{min}^{-1}$, que freqüentemente representam os valores de normalidade para os diferentes grupos populacionais. (WELSMAN, ARMSTRONG, NEVILL, WINTER e KIRBY, 1986). Os possíveis efeitos do crescimento nas variáveis de desempenho, que apontam para um aumento em uma capacidade motora em produzir efeitos qualitativos no desenvolvimento das crianças já foram discutidos por ASMUSSEN e HEEBOLL-NIELSEN (1995).

No caso da potência aeróbia, também é de se esperar que durante o crescimento ela aumente em ambos os sexos; contudo, avaliar as diferenças apenas pela massa corporal pode não ser a forma mais adequada. TANNER (1949) já alertava estudar as variáveis funcionais com base na massa corporal poderia produzir grandes distorções nos resultados, uma vez que o modelo de regressão estatística adotado interpreta as variáveis apenas como medidas com elevado grau de relação. A adoção deste modelo estatístico tende a desfavorecer pessoas mais pesadas, porque o aumento da massa corporal conduz a uma relação inversamente proporcional.

Ao contrário, quando se analisa o resultado da potência aeróbia na forma absoluta, percebe-se que entre os sexos existem poucas diferenças que são ainda menores durante a infância e adolescência. Contudo, ainda há a necessidade de se descrever os resultados, para melhor compreender as diferenças, quando estas existirem. Considerando o a teoria das similaridades geométricas, é possível ajustar variáveis como o $\mathrm{VO}_{2}$ máx a partir da 
compreensão das similaridades geométricas do corpo humano, quando desempenha atividades motoras em que uma dimensão corporal pode influenciar outra. Para verificar essas influências, alguns pesquisadores começaram a estudar as relações, procurando estabelecer as influências com ajustes das variáveis de forma a produzir um modelo de regressão matemático mais específico, chamada regressão alométrica.

Diversos estudos foram desenvolvidos destacando a regressão alométrica da massa corporal para potência aeróbia de idosos (DAVIES, DALSKY e VANDERBURGH, 1995) e de adultos jovens (BATTERHAM, VANDERBURGH, MAHAR e JACKSON, 1989; NEDER, LERARIO, CASTRO, SACHS e NERY, 2001); ajustes alométricos da massa muscular sobre a força em adultos sedentários e atletas (VANDERBURGH, MAHAR e CHOU, 1995; VANDERBURGH, KATCH, SHOENLEBER, BALABINIS e ELLIOTT, 1996; BATTHERHAM e GEORGE, 1997); efeitos da massa corporal na potência aeróbia submáxima (DAVIES, MAHAR e CUNNUNGHAM, 1997); a potência anaeróbia de adultos de ambos os sexos (BATTERHAM e BIRCH, 1996); a influência das espessuras de dobras cutâneas sobre a massa de gordura central e periférica (BECQUE, HATTORI, KATCH e ROCCHINI, 1992); efeito relativo da massa corporal sobre a massa ventricular esquerda em adultos de ambos os sexos (BATTERHAM, GEORGE e MULLINEAUX, 1997).

Os estudos variam de acordo com o objetivo, havendo aqueles que verificaram as influências da massa corporal nos testes de desempenho motor que envolve o deslocamento, como no caso do teste de flexão dos braços em suspensão na barra modificada (VANDERBURGH e EDMONDS, 1997). Em crianças e adolescentes estes estudos têm ocorrido com mais freqüência, pois os efeitos do crescimento podem ser evidenciados nas diferenças inter e intra-sexos.

Em todos estes estudos, diferentes expoentes alométricos foram encontrados para determinar as influências da massa corporal sobre essas variáveis. Contudo, não há indicações de que esses resultados sejam definitivos e expliquem as variações para todos os grupos populacionais, uma vez que nem todos os estudos verificaram se o ajustamento alométrico seria a melhor forma de explicar as diferenças entre os adultos.

Os estudos sobre ajustes alométricos realizados entre crianças e adolescentes requerem maior atenção nos resultados das relações alométricas entre a potência aeróbia e a massa corporal. Alguns deles utilizaram informações associadas à idade cronológica (ASMUSSEM e HEEBOLL-NIELSEN, 1985; PATERSON, McLELLAM, STELLA e 
CUNNINGHAM, 1987; EISENMANN, PIVARNIK e MALINA, 2001), maturação pelo pico de velocidade do crescimento (BEUNEN, BAXTER-JONES, MIRWALD, THOMIS, LEFREVE, MALINA e BAILEY, 2002) e a maturação sexual (ARMSTRONG, KIRBY, MACMANUS e WELSMAN, 1995; BEUNEN, ROGERS, WOYNAROWSKA e MALINA, 1997; ROWLAND, VANDERBURGH e CUNNINGHAM, 1997; THOMIS, ROGERS, BEUNEN, WOYNAROWSKA e MALINA, 2000).

Embora alguns estudos tenham gerados seus próprios expoente alométricos, outros optaram por adotar um ajuste para a massa corporal com os expoente alométrico fixo em $0,67\left(\mathrm{~m}^{0,67}\right)$ ou $0,75\left(\mathrm{~m}^{0,75}\right)$, utilizados muito freqüentemente na fisiologia comparada dos animais (ROGERS et al., 1995; MACHADO, GUGLIELMO e DENADAI, 2002). Neste caso, o mais adequado seria que os expoentes pudessem ser criados com base nas próprias variações observadas durante o crescimento. Porém também há aqueles estudos que procuraram adotar expoentes para ajustar a massa corporal a potência aeróbia com base nas variações observadas nos próprios indivíduos (COOPER, WEILER-RAVELL, WHIPP e WASSERMAN, 1984; PATERSON et al., 1987; ARMSTRONG et al., 1995). Este modo evitaria que ajustes subestimados ou superestimados pudessem ocorrer e trataria o grupo populacional com base nas suas próprias particularidades.

Assim, considerando que não há um estudo amplo no Brasil que tenha determinado o comportamento da potencia aeróbia em crianças e adolescentes pelo método direto, há necessidade de se determinar um ajuste das variáveis morfológicas para potência aeróbia desses indivíduos. 
Este estudo tem como objetivo analisar as alterações na potência aeróbia $\left(\mathrm{VO}_{2}\right.$ máx $)$ relativas às variáveis morfológicas durante $\mathrm{o}$ crescimento, em crianças $\mathrm{e}$ adolescentes de 10 a 16 anos de idade, de ambos os sexos.

2.2 Objetivos específicos

- descrever e comparar o comportamento das variáveis somáticas e morfológicas, relativas à idade e sexo;

- descrever e comparar o comportamento dos valores ventilatórios e da potência aeróbia, com base em medidas diretas, relativas à idade e sexo;

- examinar a influência da massa corporal na potência aeróbia relativa, baseada na idade e sexo;

- descrever e comparar o comportamento da potência aeróbia, com base em expoentes alométricos fixos;

- determinar os expoentes alométricos para o $\mathrm{VO}_{2}$ pico com base nas diferenças sexuais e de idade. 
Nos esforços de longa duração, o fornecimento de energia ocorre predominantemente através do metabolismo aeróbio e, dependendo do tipo de esforço empregado, pode representar um nível cerca de 20 vezes maior que aquele observado no repouso nos indivíduos adultos jovens. A potência aeróbia pode ser definida como "a mais alta captação de oxigênio que o indivíduo pode alcançar durante um trabalho físico, respirando ar (sic) ao nível do mar" por unidade de tempo (ASTRAND e RODAHL, 1982, p.292). A medida da potência aeróbia é de extrema importância no estudo de desempenho humano, pois revela a eficiência de um indivíduo quando submetido a algum tipo de esforço, fundamentalmente o de longa duração, exigindo uma maior adaptação entre os sistemas respiratório, circulatório e muscular.

O organismo eleva a sua capacidade de utilizar energia pela via aeróbia, desde o nascimento, por meio de um processo de maturação do sistema muscular, até aproximadamente os 20 anos de idade, onde se inicia um processo de diminuição dessa capacidade. Evidentemente o processo de aumento ou diminuição dessa capacidade está intimamente relacionado às características morfológicas de cada indivíduo, considerando a sua aptidão física e o seu estado geral de saúde. Todas elas são influenciadas pelo contexto sociocultural em que o sujeito está inserido, tornando mais rápido ou lento o aumento ou diminuição dos níveis da potência aeróbia. No caso de homens e mulheres, independentemente da idade, as diferenças observadas entre os sexos parece ser mais em uma dimensão quantitativa (com maior vantagem dos homens), do que em uma dimensão qualitativa (por exemplo na economia de movimento), sendo que os ganhos e perdas na potência aeróbia descrevem um mesmo comportamento em ambos os sexos ao longo da vida (ASTRAND e RODAHL, 1982).

Quando são analisadas as diferenças entre rapazes e moças na infância e adolescência, em valores absolutos e relativos, elas não ocorrem tão acentuadamente até os 12 anos. Aos 14 anos são por volta de $25 \%$ e aos 16 anos por volta de $50 \%$, sempre favoravelmente aos meninos nos valores absolutos; no entanto, em valores relativos, a média entre os meninos é praticamente estável dos 6 aos 16 anos e entre as meninas, o valor médio 
diminui no mesmo período etário. Há uma diferença pequena (1,5\%) aos 6 anos de ambos os sexos, alcançando a sua maior diferença entre eles (36\%) aos 16 anos (KRAHENBUHL, SKINNER e KORTH, 1985). Avaliar a potência aeróbia é importante para compreender as diferenças que ocorrem entre os sexos durante o período do crescimento.

É preciso diferenciar, no entanto, a aplicação dos termos potência e capacidade aeróbia quando se trata de avaliação do consumo máximo de oxigênio. A expressão "consumo máximo de oxigênio" é empregada para determinar a mais alta quantidade de oxigênio que um organismo pode extrair da atmosfera e consegue transportar para os tecidos. Potência aeróbia, por outro lado, refere-se a uma medida quantitativa do consumo máximo de oxigênio que pode ser obtido pelos tecidos de um indivíduo, por unidade de tempo (geralmente por minuto), durante um esforço progressivo que o conduza à exaustão (THODEN, 1990). Quando a potência aeróbia é expressa em termos de consumo de oxigênio, ela é normalmente escrita como máximo volume por minuto $(\dot{\mathrm{V}})$ de oxigênio $\left(\mathrm{O}_{2}\right)$, sendo abreviado por ' $m a ́ x$ '. Na prática, a potência aeróbia máxima deverá coincidir com um platô no nível do consumo de oxigênio, sendo este medido em um teste de esforço progressivo. O platô, quando alcançado, é expresso pelo termo 'máximo' ( $\dot{\mathrm{VO}}_{2}$ máx), mas nem sempre é alcançado em crianças nos testes de esforço progressivo. Quando os valores máximos não são obtidos em qualquer tipo de teste progressivo, o maior valor encontrado é determinado como pico ( $\dot{\mathrm{VO}}_{2}$ pico), uma vez que ele está muito perto do que seria o valor máximo (LÉGER, 1996).

O termo capacidade aeróbia deve ser empregado quando uma fração da potência aeróbia máxima $\left(\% \dot{\mathrm{VO}_{2}}\right.$ máx) for utilizada durante um intervalo de tempo (KISS, COLANTONIO, REGAZZINI, BARROS e REGAZZINI, 2003). Ou seja, a capacidade aeróbia pode ser medida em teste submáximo, com seus valores sendo obtidos nas crianças e adolescentes em termos de distância percorrida (metros), para um teste padronizado com tempo fixo (corrida/caminhada de 9/12 minutos), ou tempo obtido (minutos), quando o teste utilizar uma distância fixa (MALINA, BOUCHARD e BAR-OR, 2004).

Os exercícios aeróbios de longa duração provocam um gasto energético relativamente alto e a quantidade de oxigênio necessária e utilizada determina a maior ou menor capacidade do indivíduo consumir oxigênio. A partir de uma análise sobre o comportamento do $\dot{\mathrm{V}}{ }_{2}$ máx durante o crescimento, MALINA e BOUCHARD (1991) 
verificaram que o $\mathrm{V}_{2}$ máx sofre uma grande variação por faixa etária, o que compromete enormemente uma análise ampla do comportamento desta variável entre os sexos.

A maioria dos estudos desenvolvidos sobre esse tema envolveu mais freqüentemente os rapazes, e os ergômetros e protocolos de avaliação do $\mathrm{V}_{2}$ máx - em ciclos ou esteiras - diferem enormemente seus resultados, dificultando sua comparação para diferentes grupos amostrais. Os valores absolutos de $\dot{\mathrm{VO}}_{2}$ máx são mais baixos nas idades iniciais da vida, refletindo um comportamento esperado devido às condições de maturação do sistema cardiorrespiratório. Com o passar dos anos, eles tendem a aumentar em ambos os sexos, sendo mais acentuado no período pubertário. Contudo, quando se analisa esse mesmo comportamento por valores relativos à massa corporal, estes decrescem no mesmo período (BRADEN e STRONG, 1989).

$\mathrm{Na}$ comparação de valores absolutos $\left(\mathrm{L} \cdot \mathrm{min}^{-1}\right)$ ou relativos $\left(\mathrm{mL} \cdot \mathrm{kg}^{-1} \cdot \mathrm{min}^{-1}\right)$ entre os sexos, BRADEN e STRONG (1989) observaram que o $\dot{\mathrm{VO}}_{2}$ máx se apresenta estável entre os rapazes com o passar dos anos, enquanto diminui levemente entre as moças. Tais considerações são reavaliadas quando o $\dot{\mathrm{VO}}_{2}$ máx é analisado relativamente à massa corporal, indicando que pode aumentar com o passar dos anos, entre os rapazes, e manter-se estável entre as moças, diferindo do que foi apontado anteriormente.

Quando os valores médios do $\mathrm{VO}_{2}$ de crianças são comparados aos dos adultos, estes se apresentam mais baixos nos valores absolutos $\left(\mathrm{L} \cdot \mathrm{min}^{-1}\right)$, sendo por volta de 25 a $30 \%$ mais baixo nas crianças com idades inferiores a 14 anos. Entretanto, quando estes valores são relativos à massa corporal $\left(\mathrm{mL} \cdot \mathrm{kg}^{-1} \cdot \mathrm{min}^{-1}\right)$, as suas médias são semelhantes aos dos adultos (entre 45 a $50 \mathrm{~mL} \cdot \mathrm{kg}^{-1} \cdot \mathrm{min}^{-1}$ ) para ambos os grupos etários (LÉGER, 1996).

Segundo MALINA e BOUCHARD (1991), os valores de $\dot{\mathrm{VO}}_{2}$ analisados de forma relativa são mais úteis para avaliar as diferenças adequadamente, quando elas existirem, não somente para determinar as diferenças entre os sexos, mas, sobretudo, com relação ao próprio crescimento. Ou seja, ao analisarem alguns estudos longitudinais em crianças e adolescentes de diferentes regiões, os autores verificaram que o $\mathrm{V}_{2}$ dos rapazes crescia até os 16 anos, e das moças, apenas até os 13 anos de idade, aproximadamente.

Essas diferenças relativas entre os sexos no $\dot{\mathrm{VO}}_{2}$ podem ser atribuídas a vários fatores mas, sem dúvida, a mais importante é a variação da massa corporal. Considerando que 
a energia gasta entre as crianças é maior que nos adultos, e também que a superfície corporal infantil é proporcionalmente maior, as atividades físicas influenciadas pela massa corporal deverão, sem dúvida, ser analisadas mediante valores relativos à massa corporal (LÉGER, 1996).

Tudo indica que o pouco aumento observado em ambos os sexos com o passar dos anos, sempre com menos intensidade entre as moças, deve-se ao fato da massa corporal variar mais rapidamente do que o próprio $\dot{\mathrm{VO}}_{2}$ entre as crianças e os adolescentes. Ou seja, se ele varia positivamente com o passar dos anos, a massa corporal varia ainda mais, conduzindo a uma queda nos valores máximos relativos para ambos os sexos. Durante a adolescência, os rapazes possuem, em média, uma maior massa corporal para todas as idades em relação às meninas que, em contrapartida, apresentam uma maior massa de gordura em relação aos rapazes (MALINA et al., 2004). Outro aspecto a ser observado entre os sexos é que os rapazes produziriam uma maior quantidade de energia durante os esforços físicos por possuírem uma maior massa corporal. Assim, estando o $\dot{\mathrm{VO}}_{2}$ fortemente associado à massa livre de gordura, a maior massa corporal poderia explicar parcialmente as diferenças de resultado entre os sexos; entretanto as diferenças tendem a desaparecer quando o $\dot{\mathrm{V}}_{2}$ é relacionado à massa corporal total.

Segundo BRADEN e STRONG (1989), em qualquer idade as moças têm o $\dot{V}_{2}$ mais baixo que os rapazes, sendo que uma menor diferença ocorre apenas próxima aos 5 anos de idade. Em sua revisão, os autores sugerem, com base em alguns estudos, que as moças tendem a diminuir o seu $\dot{\mathrm{V}}_{2}$ com o passar dos anos devido um maior aumento na massa de gordura; diferentemente do observado entre os rapazes, que tendem a aumentar os seus valores porque sua massa corporal varia um pouco menos. Mas as razões pelas quais isso acontece ainda não estão totalmente esclarecidas. Entre os rapazes, os valores absolutos de $\dot{\mathrm{VO}}_{2}$ continuam a aumentar com o passar dos anos, mas entre as moças esses valores médios começam a alcançar um platô por volta dos 12 anos de idade. Contudo, no período pubertário esses níveis baixos são aumentados significativamente, apresentando um comportamento nãolinear, de acordo com a idade cronológica (ROWLAND, 2002).

Com o objetivo de avaliar as respostas metabólicas durante o exercício em função do crescimento somático, COOPER et al. (1984) avaliaram 109 indivíduos com idades 
variando de 6 a 17 anos, sendo 58 rapazes e 51 moças. Foi utilizado um teste de rampa em cicloergômetro para obter os valores de $\dot{\mathrm{VO}}_{2}$ máx, limiar anaeróbio (LA), eficiência do trabalho e respostas metabólicas quanto ao tempo de obtenção do $\dot{\mathrm{VO}}_{2}$. Para tanto, cada gênero foi subdividido em grupos por nível de maturação. Os autores encontraram como resultado principal o resultado de o LA estar altamente correlacionado com a massa corporal, em ambos os sexos, provavelmente associado ao período do crescimento físico, pois quando ao mesmo tempo em que crianças e adolescentes aumentaram seus valores médios de LA, também aumentaram a sua massa corporal.

Em um estudo longitudinal, PATERSON et al. (1987) acompanharam o $\dot{\mathrm{V}}_{2}$ máx e o limiar ventilatório de 18 atletas masculinos durante 5 anos (dos 11 aos 15 anos de idade). Como resultado geral, foi observado que o $\dot{\mathrm{VO}}_{2}$ máx, em valores absolutos, aumentou por volta de $83,7 \%$, enquanto em valores relativos $\left(\mathrm{mL} \cdot \mathrm{kg}^{-1} \cdot \mathrm{min}^{-1}\right)$ os ganhos foram mais modestos (por volta de 11,8\%), demonstrando, neste caso, que pode ter havido efeito negativo da massa corporal durante o período estudado, o que contribuiu para um aumento no $\dot{\mathrm{VO}}_{2}$ máx na ordem de $70 \%$, abaixo dos valores absolutos.

A potência aeróbia pode ser influenciada por diferentes fatores, sobretudo em crianças e adolescentes, que são mais sensíveis às variações do período do crescimento, bem como às condições ambientais em que estão envolvidas. Os fatores podem ser intrínsecos aqueles que não podem ser alterados, pois envolvem a natureza biológica do indivíduo, tais como herança genética, dimensões corporais, idade, sexo e regulação hormonal (maturação) ou extrínsecos - associados aos aspectos ambientais em que a criança ou adolescente está envolvido, tais como os nutricionais, socioculturais e dos níveis de atividade física. Para MALINA et al. (2004), os fatores intrínsecos são compreendidos como fatores regularizadores do crescimento e os extrínsecos seriam os fatores que interagem com os intrínsecos durante o crescimento em geral, e a potência aeróbia, em particular. Estes últimos podem ser caracterizados como os mais relevantes no desenvolvimento da potência e capacidade aeróbia pelas inúmeras influências exercidas na criança e no adolescente ao longo do seu desenvolvimento ontológico, desde que elas alcancem o seu desenvolvimento biologicamente esperado.

A importância do fator genético no desempenho aeróbio é discutida por BOUCHARD, DIONNE, SIMONEAU e BOULAY (1992), podendo ser abordada por duas 
diferentes perspectivas. A primeira é chamada de perspectiva da genética epidemiológica, que procura abordar os aspectos relacionados tradicionalmente à composição familiar e aos estudos de herança genética. A segunda perspectiva está alicerçada na compreensão e composição molecular do tecido, envolvendo a compreensão, transcrição e tradução dos mecanismos regularizadores das respostas agudas ao exercício e treinamento, a partir de estudos com animais. No caso de crianças e adolescentes, fica evidente que o tipo de estudo genético preconiza a primeira perspectiva, principalmente no que diz respeito às diferenças individuais causadas pela grande variação de combinações do ADN (ácido desoxirribonucléico), nos diferentes grupos populacionais.

Dentre os tipos de estudos epidemiológicos em genética, que abordam a potência aeróbia de crianças e adolescentes, segundo BOUCHARD et al. (1992), aqueles envolvendo 'semelhança familiar', ou estudo 'familiar nuclear' (CZERWINSKI e TOWNE, 2004) são os mais recomendados. A característica desses estudos é abranger todas as partes envolvidas na possível herança genética da criança para a potência aeróbia, como a combinação de pais/herdeiros, marido/esposa, irmão/irmão, parentes/herdeiros.

Um estudo importante com essas características foi o "Canada Fitness Survey", que obteve uma amostra de aproximadamente 10.000 sujeitos pertencentes a milhares de domicílios distribuídos em todo o país. O teste de banco foi adotado para avaliar a capacidade aeróbia com base na freqüência cardíaca de $150 \mathrm{bpm}\left(\mathrm{PWC}_{150}\right)$. Os resultados demonstraram que houve uma semelhança nos resultados entre pais e filhos para o desempenho aeróbio; contudo, esses resultados também foram semelhantes quando observada a relação de pais e filhos adotivos (BOUCHARD et al., 1992), demonstrando que, nesse estudo, parece haver uma influência dos hábitos de vida dos pais tão importante quanto as características genéticas herdadas pelos filhos biológicos. Com base em uma análise de outros estudos, os autores verificaram que houve uma relação significante entre os resultados de potência aeróbia entre pais e filhos, sem qualquer relação significante com outros parentes, inclusive com resultados semelhantes entre irmãos gêmeos.

O "Heritage Family Study" foi considerado como o mais abrangente estudo de família nuclear, tendo investigado a função genotípica nas respostas cardiovasculares, metabólicas e hormonais no treinamento aeróbio, cuja amostra contemplava 429 sujeitos de 86 núcleos familiares (MALINA et al., 2004). Foram empregados dois testes de esforço máximo 
em dias separados, com 48 horas de diferença entre os testes. A variância para o $\dot{\mathrm{VO}}_{2} \max$ (ajustado para a idade, sexo, peso corporal e composição corporal) foi 2,72 vezes maior entre as famílias do que dentro das famílias. Como resultado, encontrou-se uma probabilidade máxima de estimação da influência genética no $\dot{\mathrm{V}}_{2}$ máx de $50 \%$, considerando casais, pais e filhos e irmãos. Quando foi considerada apenas a influência genética dos pais sobre os filhos, esta probabilidade ficou abaixo de 50\% (MALINA et al., 2004), resultado semelhante ao revisado por BOUCHARD et al. (1992), que foi de 40 a $60 \%$ em diferentes estudos para a potência aeróbia. Nesse caso, parece que o efeito genético herdado pelos filhos sobre a potência aeróbia é mais importante nas dimensões corporais, e no próprio crescimento, que modula os valores de $\dot{\mathrm{V}}_{2}$. A interação com o ambiente, evidenciada nas respostas ao treinamento, é ainda mais relevante quando considerado outro fator influenciador na potência aeróbia de crianças e adolescentes.

O período pubertário é caracterizado como uma fase de grande aceleração no crescimento em estatura e peso, como conseqüência da ebulição hormonal que ocorre em ambos os sexos. Este período relaciona o tempo biológico com o tempo cronológico. $\mathrm{O}$ crescimento biológico da criança não ocorre necessariamente no mesmo tempo cronológico, uma vez que um grupo de crianças do mesmo sexo e mesma idade cronológica poderá ter variações no nível de maturidade biológica alcançado. Dentro de um determinado grupo de mesma idade, algumas crianças poderão ser biologicamente avançadas relativamente a suas idades cronológicas, e outras crianças poderão estar atrasadas em relação à sua idade cronológica.

Nesse sentido, os agentes biológicos transformadores do organismo imaturo para o estado maduro são os hormônios. Eles são divididos em vários grupos que têm papéis específicos na transformação de crianças em adultos, entre eles se destacam no crescimento os hormônios hipotalâmicos-pituitários, os hormônios do crescimento $(\mathrm{GH})$, os tireodianos, os paratireodianos, os adrenais e corticais, os sexuais, os gonadais, e as gonadotrofinas, que incluem o hormônio folículo-estimulante - FSH - e o hormônio luteinizante - LH, juntamente com o estradiol - E2, para a regularização da ovulação e ciclo menstrual (MALINA et al., 2004). Contudo, do ponto de vista exclusivamente biológico, o período pubertário é caracterizado pela maturação das características sexuais secundárias, pela obtenção da capacidade reprodutiva e o estirão do crescimento somático (MALINA et al., 2004). 
Fatores extrínsecos ou ambientais, bem como as condições socioculturais podem provocar influências na potência aeróbia de crianças e adolescentes sobre vários aspectos. Entre eles, o mais determinante é a alimentação e a sua consequência no estado nutricional desses jovens.

Durante os primeiros anos de vida, o requerimento nutricional para o crescimento é elevado, principalmente nos dois primeiros anos (MALINA et al., 2004). Isso significa que a quantidade e a qualidade de energia fornecida à criança dependem, respectivamente, de nível social e cultural adequados. Famílias de baixa renda têm dificuldade de fornecer quantidade de alimento adequada ao desenvolvimento de seus filhos, e esse fato é aliado à baixa escolarização dos pais, o que provoca um oferecimento de quantidade de alimento, quando adequada, com uma baixa qualidade nutricional. Ou seja, tanto a quantidade como a qualidade dos alimentos requer dos pais uma atenção especial nos primeiros anos de vida, pois caso isso seja negligenciado, pode ter como conseqüência um desenvolvimento infantil abaixo do esperado, ou incor em subnutrição, quando a criança não ganha peso e estatura esperados para a idade (MALINA et al., 2004). Por outro lado, quando crianças são superalimentadas, uma conseqüência também frequente, principalmente observada nos grandes centros urbanos, é a de excesso de peso (KAUR, HYDER e POSTON, 2003).

Em ambos os sexos, quando a criança inicia o seu período pubertário, o requerimento energético torna-se importante novamente, embora o custo energético total destinado ao crescimento esteja por volta de $2 \%$ do total ingerido por dia (MALINA et al. , 2004), devido ao desenvolvimento dos diferentes tecidos corporais, dentre eles a massa óssea e a muscular. Nesse sentido, um efeito direto do excesso de peso da criança e do adolescente é a diminuição da potência aeróbia máxima obtida em valores relativos ao peso corporal, mesmo quando os valores absolutos são semelhantes a uma criança com peso esperado para a idade.

Outro fator importante associado ao desempenho da potência aeróbia da criança e adolescente é o nível de atividade física habitual. Vários são os estudos que procuram descrever os níveis de atividade física com o passar dos anos em ambos os sexos, por meios de diferentes métodos de avaliação, na tentativa de explicar os resultados obtidos nos testes.

Do ponto de vista dos indicadores de morbidade e mortalidade, o impacto favorável dos níveis elevados de atividade física e da capacidade aeróbia ao longo do tempo sobre indivíduos adultos já está bem conhecido; no entanto entre crianças e adolescentes esses índices ainda não estão claramente definidos (MORROW e FREEDSON, 1994). 
No Brasil, alguns estudos têm mostrado, por diferentes métodos, que os níveis de atividade física de crianças e adolescentes têm caído com o passar dos anos, para ambos os sexos, sendo que os rapazes ainda demonstram ser mais ativos que as moças para todas as idades (FARIAS e SALVADOR, 2005; GUEDES, GUEDES, BARBOSA e OLIVEIRA, 2001; PIRES, DUARTE, PIRES e SOUZA, 2004).

Em uma ampla revisão envolvendo mais de 100 estudos sobre o mesmo tema, SALLIS, PROCHASKA e TAYLOR (2000) analisaram as relações entre os níveis de atividade física habitual de crianças e adolescentes de ambos os sexos. Os autores dispuseram de um sofisticado meio de interpretação dos resultados, observando todas as possibilidades de relações com variáveis biológicas (idade, sexo, índice de massa corporal - IMC), psicológicas (auto-estima, auto-eficácia, imagem corporal), comportamentais (uso de cigarros, uso de álcool, ingestão calórica) e socioculturais (atividade física dos pais, participação conjunta de pais e filhos em atividade física). De maneira geral, os resultados observados na revisão sugerem que há uma diminuição dos níveis de atividade física com o passar dos anos para todas as idades e sexos, e que nenhuma das relações explicou esse fenômeno. Isso sugere que os níveis de atividade física constituem um comportamento complexo que deve ser determinado por múltiplos fatores. A principal característica observada nos resultados dos estudos foi a irrefutável diferença entre os sexos, sendo o masculino mais ativo que o feminino em mais de $80 \%$ dos casos, como observados pelos estudos com crianças e adolescentes brasileiros.

Contudo, os níveis de atividade física e os níveis de potência não podem estabelecer uma possível relação de causa e efeito. Em uma revisão, realizada por MORROW e FREEDSON (1994), de estudos sobre a relação dos níveis da atividade física e a potência e capacidade aeróbia de adolescentes, foram encontrados 53 diferentes coeficientes de correlação obtidos entre atividade física habitual e $\dot{\mathrm{V}} \mathrm{O}_{2} \max$, sendo que apenas 49 coeficientes diferentes de zero foram obtidos entre elas, com média de $r=0,17\left(\mathrm{r}^{2}=0,03 \approx 3 \%\right)$. Dos resultados disponíveis, os autores comentam os 37 coeficientes mais expressivos, dos quais apenas 17 sugerem alguma relação enquanto os demais coeficientes (20 do total) estabeleceram não haver nenhuma. Os autores concluem que nenhuma relação foi obtida entre níveis de atividade física habitual e o $\dot{\mathrm{VO}}_{2}$ máx, em ambos os sexos, uma vez que a relação mais provável entre as variáveis não explicava $3 \%$ delas. 
No Brasil, um estudo semelhante procurou abordar a associação dos níveis de atividade física habitual e aptidão física relacionada à saúde de adolescentes de 15 a 18 anos (GUEDES et al., 2002). Os autores dividiram os adolescentes em grupos, por níveis de atividade física (inativos, de baixa intensidade e de moderada a intensa) com base nos valores de gasto energético, analisado por descrição das atividades por formulário de autorrecordatório em 24 horas. Como resultado, os coeficientes de correlação mais elevados ocorreram entre atividade física moderada e vigorosa (0,192 e 0,282 respectivamente), os quais não explicaram uma variação de 4 e $8 \%$ para moças e rapazes, respectivamente.

Determinação do $\dot{\mathrm{V}} \mathrm{O}_{2}$ máx de crianças e adolescentes

$\mathrm{O} \dot{\mathrm{V}}_{2}$ máx é conhecido como a maior capacidade que o indivíduo pode atingir para captar, transportar e utilizar oxigênio durante o esforço máximo. Conhecer os valores de $\dot{\mathrm{V}}_{2}$ máx de crianças e adolescentes é importante porque pode refletir um bom estado geral de saúde, como também revelar uma capacidade maior de realizar tarefas do cotidiano com menos fadiga. Para LÉGER (1996), de modo geral, as crianças alcançam um $\dot{V}_{2}$ máx em condições semelhantes aos adultos, ou seja, no comportamento evolutivo em uma prova de esforço individual, a criança deverá alcançar um platô nas mesmas condições do teste realizado para adultos.

Para DUNCAN, MAHON, HOWE e CORRAL (1996), o conceito de platô é baseado na suposição de que há um ponto durante o esforço no qual ocorre um incremento na intensidade, sem necessariamente ocorrer um aumento nos valores de $\dot{\mathrm{V}}_{2}$, significando um nivelamento (achatamento) da curva projetada entre a intensidade em função do tempo. Contudo, tanto as crianças como os adolescentes podem atingir uma exaustão durante o teste sem necessariamente alcançar um platô. E, mesmo aqueles que alcançaram um platô podem não ter atingido os valores mais elevados de $\dot{\mathrm{VO}}_{2}$ máx (ARMSTRONG, KIRBY, MCMANUS e WELSMAN, 1995).

Segundo RIVERA-BROWN e FRONTERA (1998), os indicadores determinantes da potência aeróbia, comumente utilizados como critério de determinação do $\dot{\mathrm{V}}_{2}$ em esforço máximo de jovens são: a) a razão das trocas respiratórias ou quociente respiratório $(\mathrm{QR}) \geq 1$; 
b) a frequência cardíaca igual ou superior a 95\% da máxima prevista para a idade; 3) um aumento no $\dot{\mathrm{VO}} 2$ inferior a $2,1 \mathrm{~mL} \cdot \mathrm{kg}^{-1} \cdot \mathrm{min}^{-1}$, com um concomitante aumento na intensidade do esforço, quando se procura verificar se ocorreu um platô. Para ROWLAND, et al. (1997) no entanto, a freqüência cardíaca exigida como critério de determinação do $\dot{\mathrm{VO}}_{2}$ máx/pico foi considerada apenas como superior a $190 \mathrm{bpm}$.

Por outro lado, DUNCAN et al. (1996) sugerem que, além dos critérios anteriores, um aumento do $\dot{\mathrm{VO}}_{2}$ inferior a $150 \mathrm{~mL}$ (sobre os valores absolutos) ou um incremento de $2,5 \%$ na intensidade do teste (velocidade da esteira) sem uma correspondente elevação do $\dot{\mathrm{V}}_{2}$, como também um aumento no $\dot{\mathrm{V}}_{2}$ inferior a 2 desvios-padrão da média das alterações do $\dot{\mathrm{VO}}_{2}$ durante o teste com o aumento da sua intensidade, são critérios que também devem ser levados em consideração, uma vez que caracterizam um alcance de platô.

Para ARMSTRONG et al. (1995), os critérios de interrupção do esforço e conseqüente interpretação do maior valor de $\dot{\mathrm{V}} \mathrm{O}_{2}$ obtido são semelhantes aos observados em adultos, como por exemplo, os sinais de fadiga representados pelas perturbações ou confusão no pensamento, desequilíbrio ou falta de coordenação de movimento durante a corrida na esteira. No entanto, se todos esses critérios não puderem ser percebidos e, ainda assim, a criança atingir a fadiga, o maior valor de $\dot{\mathrm{V}}_{2}$ observado deverá ser considerado pico ( $\dot{\mathrm{VO}}_{2}$ pico).

Há também uma discussão sobre o emprego mais adequado dos resultados observados para o $\dot{\mathrm{VO}}_{2}$. Segundo RIVERA-BROWN e FRONTERA (1998), os testes de esforço realizados em esteira ou cicloergômetro são os mais comuns e confiáveis para a obtenção de valores de $\dot{\mathrm{V}}_{2}$ de crianças e adolescentes. A discussão é centrada no tipo de protocolo utilizado, pois dificilmente uma criança alcançará um platô durante o teste, mesmo quando o $\dot{\mathrm{V}}_{2}$ for medido diretamente. Nesse estudo foi identificada a mesma coerência do platô nos resultados do teste de $\dot{\mathrm{VO}}_{2}$ máx para dois diferentes ergômetros. Os resultados demonstraram que, de maneira geral, menos de 50\% dos sujeitos alcançaram o platô nos diferentes ergômetros, sendo que entre eles, o ciclo foi o que apresentou índices mais baixos (em torno de $25 \%$ ). Nesse sentido, o maior valor alcançado durante o teste, de fato, deverá ser chamado de $\dot{\mathrm{VO}}_{2}$ pico. 
$\mathrm{Na}$ tentativa de encontrar os resultados do alcance de platô no $\dot{\mathrm{VO}}_{2}$ de moças, PIVARNIK, DWYER e LAUDERDALE (1996) determinaram a fidedignidade e reprodutibilidade das medidas de potência aeróbia em esteira, tanto em valores absolutos como relativos à massa corporal $\left(\mathrm{mL} \cdot \mathrm{kg}^{-1} \cdot \mathrm{min}^{-1}\right)$. A idade do grupo variava entre 10 e 16 anos. Os resultados da fidedignidade (teste-reteste) apontaram para um coeficiente de correlação superior a $0,90(r>0,90)$ e nenhuma diferença estatisticamente significante foi observada nos valores de $\dot{\mathrm{VO}}_{2}$ absolutos e relativos para ambas as tentativas. Com relação ao alcance do platô, ficou evidenciado que ele também não ocorreu nas duas tentativas do estudo.

Estes achados demonstraram que também para as moças os maiores valores de $\dot{\mathrm{VO}}_{2}$ foram determinados independentemente da observação de um platô por meio dos critérios anteriormente estabelecidos, sendo estes resultados determinados como $\dot{\mathrm{V}}_{2}$ pico. Com relação aos aspectos metodológicos de obtenção do $\dot{\mathrm{VO}}_{2}$, ARMSTRONG et al. (1995) advogam que eles são menos seguros do que aqueles tradicionalmente utilizados em adultos, e a adequada análise e interpretação dos dados coletados entre crianças e adolescentes são ainda problemáticas.

Com o objetivo de responder às questões sobre a determinação do $\dot{\mathrm{VO}}_{2}$, DUNCAN et al. (1996) analisaram se ocorreria um platô do $\dot{\mathrm{V}}_{2}$ máx de rapazes a partir do tempo do teste em esteira, uma vez que o platô não era observado em outros estudos porque havia um incremento na intensidade do teste, até se alcançar a exaustão. Cada indivíduo repetiu o teste duas vezes, a fim de assegurar a confiabilidade dos protocolos. Considerando todos os critérios necessários, os resultados indicaram que apenas $40 \%$ dos sujeitos alcançaram um platô no primeiro teste, enquanto que no segundo foram apenas $28 \%$. Como conclusão, os autores sugerem que o alcance de um platô é independente do tipo do protocolo, pois não houve diferenças nos valores de $\dot{\mathrm{VO}}_{2}$ observados em ambos os testes, independentemente de terem ou não alcançado o platô.

No estudo de ARMSTRON, WELSMAN e WINSLEY (1995), três diferentes testes de esforço máximo foram realizados com meninos e meninas de 10 anos de idade. Cada teste requisitava esforços mais elevados, e o objetivo foi verificar a ocorrência ou não do platô. Também foram três os diferentes critérios para determinação do platô: aumento inferior a 2 $\mathrm{mL} \cdot \mathrm{kg}^{-1} \cdot \mathrm{min}^{-1},<5 \%$ e $<150 \mathrm{~mL} \cdot \mathrm{min}^{-1}$ no $\dot{\mathrm{V}} \mathrm{O}_{2}$ ao final de cada estágio. Os resultados 
demonstraram que no primeiro critérios apenas 39 e $35 \%$ de meninas e meninos respectivamente, atingiram um platô nos três testes; 50 e $65 \%$ respectivamente para o segundo; e 56 e 76\% para o terceiro. Não houve diferenças estatisticamente significantes entre os resultados de pico ou máx (absoluto ou relativo) nos três testes e nos dois grupos de indivíduos. Os autores concluíram que o primeiro critério foi o mais rigoroso entre os demais, contudo foram ainda muito baixos para serem considerados adequados para a população estudada.

Com relação às possíveis diferenças entre crianças de ambos os sexos, prépúberes (estágio 1 dos pelos pubianos de Tanner), ARMSTRONG et al. (1995) avaliaram dois dos diferentes critérios de determinação do platô (aumento inferior a $2 \mathrm{~mL} \cdot \mathrm{kg}^{-1} \cdot \mathrm{min}^{-1}$ e a $5 \%$ do $\dot{\mathrm{V}}_{2}$ ). Entre as meninas, $35,8 \%$ apresentaram platô pelo primeiro critério, enquanto que apenas 26,4\% apresentaram platô a partir do segundo. Entre os meninos, os resultados foram de $24,3 \%$ e $20,7 \%$ para o primeiro e segundo critérios respectivamente. Apenas $24,5 \%$ das meninas e $18 \%$ dos meninos alcançaram um platô exibindo simultaneamente os critérios utilizados. Ou seja, aproximadamente $64 \%$ das meninas e $75 \%$ dos meninos não apresentaram um platô, sendo o $\dot{\mathrm{VO}}_{2}$ determinado pelo pico. Com relação aos meninos que não obtiveram um platô por qualquer um dos critérios, ficou evidenciado que eles estavam entre os mais velhos do grupo (por volta dos 11 anos) e tinham um $\dot{\mathrm{VO}}_{2}$ mais elevado em valores relativos à massa corporal; entre as meninas não foi verificada nenhuma influência da idade ou da massa corporal na obtenção $\dot{\mathrm{V}} \mathrm{O}_{2}$ por platô ou pico.

Considerando as possíveis variações entre os resultados de diferentes ergômetros para a determinação da potência aeróbia de crianças, TURLEY et al. (1995) analisaram as respostas do $\dot{\mathrm{V}}_{2}$ durante um teste em esteira e ciclo, tanto em valores absolutos quanto relativos à massa corporal e à superfície corporal (BSA - Body Superficie Area), uma vez que os valores médios de estatura e massa corporal eram idênticos em ambos os sexos. Os resultados demonstraram que o $\dot{\mathrm{VO}}_{2}$ foi mais elevado no teste de esteira, tanto nos valores absolutos quanto relativos, para ambos os sexos. Foi demonstrado que o teste em ciclo apresentou-se mais confiável e reprodutível do que em esteira, embora os resultados sejam sempre mais baixos que os valores registrados em esteira. 
Essa observação se deve ao fato do teste ser realizado em uma posição sentada, com uma sobrecarga menor do peso corporal durante o esforço, conduzindo as crianças e adolescentes a um desempenho mais satisfatório até entrar em fadiga por elevação da carga. No geral, os valores absolutos e relativos de $\dot{\mathrm{V}}_{2}$ máx foram sempre mais elevados na esteira. Na tentativa de definir se havia alcance de platô nos diferentes ergômetros, a realização do reteste indicou que poucos adolescentes alcançaram um platô nos diferentes estudos (TURLEY et al., 1995; RIVERA-BROWN e FRONTERA, 1998). Nesse sentido, ARMSTRONG et al. (1995) defendem que a terminologia apropriada para a utilização com crianças e adolescentes, na quantificação do $\dot{\mathrm{V}}_{2}$ deverá ser pico $\left(\dot{\mathrm{V}}_{2}\right.$ pico), pois é o mais alto valor obtido na criança até que ela alcance a exaustão, sendo tão reprodutível e confiável entre as crianças quanto o platô entre os adultos.

Outra análise a ser feita sobre os resultados obtidos da potência aeróbia de crianças e adolescentes, independentemente de ser em valores máximos ou de pico, é com relação aos protocolos de teste adotados pelos pesquisadores. Considerando apenas os diferentes protocolos utilizados, podemos perceber que não há um consenso entre os procedimentos adotados. Houve estudos que descreveram, por exemplo, a utilização de aquecimento prévio, variando normalmente entre 2 e 5 minutos, antes do início do teste em esteira (ARMSTRONG et al, 1995; DIBELLA, JOHNSON e CABRERA, 2002; DUNCAN et al., 1996; FREDRIKSEN, INGJER, NYSTAD e THAULOW, 1998; LOFTIN, STRIKMILLER, WARREN, MYERS, SCHROTH, PITTMAN, HARSHA e SOTHERN, 1998; RIVERA-BROWN, RIVERA e FRONTERA, 1995; RIVERA-BROWN e FRONTERA, 1998; ROWLAND et al., 1997), do teste em ciclo (BEUNEN et al., 1997; COOPER et al., 1984; JUNG, NIEMAN e KERNODLE, 2001; KATHLEEN, BURNS, WITT e MAHONEY, 1998; MALINA, BEUNEN, LEFEVRE e WOYNAROWSKA, 1997; RIVERA-BROWN e FRONTERA, 1998; THOMIS et al., 2000).

Houve também estudos que não fazeram qualquer referência sobre a utilização do aquecimento em esteira (ARMSTRONG et al., 1999; BEUNEN et al., 2002; KEMPER e VERSCHUUR, 1981; NEVILL, HOLDER, BAXTER-JONES, ROUND e JONES, 1998; PIVARNIK, TAYLOR e CUMMINGS, 1988; PIVARNIK, DWYER e LAUDERDALE, 1996; ROGERS et al., 1995) ou em ciclo (ROWLAND, KLINE, GOFF, MARTEL e FERRONE, 1999). 
Contudo, o procedimento do aquecimento é mencionado na maioria dos estudos, tanto em testes na esteira como em cicloergômetro, indicando sua importância para a realização de um bom teste. Outro aspecto importante sobre o aquecimento é que, nos minutos iniciais do teste em esteira, a criança ou adolescente parece criar um efeito de familiarização, tornando-os mais tranqüilos e confiantes para continuarem o teste, principalmente se considerar que nos minutos seguintes serão exigidas velocidades ou inclinações mais elevadas.

Ao ser considerado apenas o protocolo apresentado pelos pesquisadores para teste em esteira, para se obter os valores de $\dot{\mathrm{V}}_{2}$ mais elevados e, portanto, representativos do desempenho, foi verificado que a maioria não são idênticos ou em alguns casos apenas parecidos. Quando os protocolos diferiram muito dos demais, isto se deveu pela existência de características amostrais muito específicas, com base na constituição etária ou do nível de atividade física, como por exemplo ser do tipo rampa ou escalonado.

Entre os protocolos de rampa, as suas características variam com uma velocidade constante a $9 \mathrm{~km} / \mathrm{h}$, sendo a inclinação da esteira elevada em $2 \%$ a cada minuto até a exaustão (LOFTIN et al., 1998), ou com uma velocidade constante em $8 \mathrm{~km} / \mathrm{h}$, e inclinação da esteira em 2,5\% a cada minuto até a exaustão (DUNCAN et al., 1996). Já nos protocolos escalonados, percebem-se inúmeras maneiras de realização. Entre elas, há aquela em que a velocidade de corrida permanece constante em $8 \mathrm{~km} / \mathrm{h}$ e a inclinação da esteira eleva-se em 2,5\%, a cada dois minutos (DUNCAN et al., 1996). Há também o protocolo de Bruce adaptado para jovens, no qual a velocidade inicial é de $2,7 \mathrm{~km} / \mathrm{h}$ com a inclinação em $10 \%$, elevando-se velocidade e inclinação em $1,3 \mathrm{~km} / \mathrm{h}$ e $2 \%$, respectivamente, a cada dois minutos (DIBELLA et al., 2002), ou a cada três minutos no protocolo de Bruce padrão (FREDRIKSEN et al., 1998).

Há protocolo com a inclinação constante em $0 \%$ e a velocidade de corrida aumentando a cada três minutos, iniciando em $4,8 \mathrm{~km} / \mathrm{h}$ até a velocidade final de $19,2 \mathrm{~km} / \mathrm{h}$ (BEUNEN et al., 2002). Também houve aqueles com velocidade constante de $5,6 \mathrm{~km} / \mathrm{h}$ e a inclinação inicial de $8 \%$, posteriormente elevando-se em $2 \%$ a cada dois minutos até a exaustão (ROWLAND et al., 1997); ou um protocolo misto com velocidade constante entre 8 e $10 \mathrm{~km} / \mathrm{h}$, dependendo da habilidade e aptidão de cada sujeito e a cada minuto a esteira inclinava em $1 \%$ até o máximo de $10 \%$, ou até a criança atingir a exaustão (ROGERS et al., 1995). 
Uma alternativa de teste escalonado foi desenvolvida para crianças de 9 e 10 anos, no qual a velocidade inicial de $6 \mathrm{~km} / \mathrm{h}$ passava a ser aumentada em $1 \mathrm{~km} / \mathrm{h}$ a cada três minutos, até ser alcançada a velocidade final de $10 \mathrm{~km} / \mathrm{h}$, com a inclinação fixa em $0 \%$. Caso a criança não alcançasse a exaustão, a intensidade de esforço era aumentada apenas com a inclinação da esteira, sendo elevada em 3\% a cada três minutos, com a velocidade fixa em 10 $\mathrm{km} / \mathrm{h}$ (ARMSTRONG et al., 1995). Outro protocolo com as mesmas particularidades (teste misto) estabeleceu a velocidade inicial de $4 \mathrm{~km} / \mathrm{h}$ e a inclinação em $0 \%$, sendo a velocidade aumentada a cada minuto em $0,8 \mathrm{~km} / \mathrm{h}(0,5 \mathrm{mph})$ até ser alcançada a velocidade de $6 \mathrm{~km} / \mathrm{h}$, sendo a partir deste momento a inclinação elevada em 3\% a cada minuto (PIVARNIK et al., 1996).

Outro tipo de teste escalonado estabeleceu a velocidade fixa mais elevada (11 $\mathrm{km} / \mathrm{h}$ ), sendo aumentada em 2,5\% a cada dois minutos (RIVERA-BROWN et al., 1995), mas foi específico para adolescentes bem treinados, não sendo recomendado para crianças e adolescentes apenas ativos. O protocolo de Balke modificado, recomendado por ROWLAND (1993), foi realizado por KEMPER e VERSCHUUR (1981), onde a velocidade da esteira foi fixada em $8 \mathrm{~km} / \mathrm{h}$ sem inclinação no início do teste, e a cada dois minutos sendo elevada em $2,5 \%$, até a criança ou adolescente atingir a exaustão voluntária.

Em uma revisão ainda mais ampla, será possível encontrar muitas diferenças entre os protocolos adotados. Contudo, entre crianças e adolescentes, parece que um protocolo escalonado - que proporciona uma velocidade fixa da esteira - com o incremento das cargas mediante apenas a elevação da inclinação entre 2 e 2,5\%, se tornou mais aceito e seguro, garantido que tanto o $\dot{\mathrm{V}} \mathrm{O}_{2}$ máx quanto o de $\dot{\mathrm{VO}}_{2}$ pico pudessem ser alcançados em um tempo relativamente curto, ou entre 8 e 12 minutos de teste.

Finalmente, outra discussão tão importante quanto a da terminologia do resultado final obtido ( $\dot{\mathrm{V}} \mathrm{O}_{2}$ máx ou $\dot{\mathrm{V}} \mathrm{O}_{2}$ pico), ou mesmo do protocolo empregado no teste, seria sobre o comportamento da criança ou adolescente durante o teste. Ou seja, a motivação envolvida durante o teste para se alcançar o melhor desempenho.

Se as crianças e adolescentes não estiverem motivados durante a realização do teste, dependendo do ergômetro utilizado, não haverá garantias da possibilidade de determinação do valor máximo da potência aeróbia mediante um platô, como observado em adultos, ou até mesmo o valor de pico. Entre os dois principais ergômetros utilizados, se 
considerarmos que a manutenção do ritmo do ciclo de pedaladas desenvolvidas nos testes em cicloergômetros é mais difícil, pela sua inconstância, parece interessante que para adolescentes e, sobretudo, para crianças, a escolha da esteira seja mais adequada para testes de potência máxima.

Uso da alometria

O estudo das alterações da função a partir das alterações do tamanho e forma do corpo é conhecido como alometria, ou seja, uma relação de escala de potência (REISS, 1989). A alometria procura descrever a existência de uma relação entre duas variáveis x e y. A relação alométrica não surge acidentalmente, devendo-se levar sempre em conta o seu conceito fundamental (demonstrando uma importante propriedade do fenômeno a ser estudado): a sua autossimilaridade (BARENBLATT, 2003).

A questão capital sobre as escalas de medidas dentro de um corpo em constante processo de crescimento, passa pela compreensão da geometria euclidiana, pois é a partir desse conhecimento matemático específico que se pode compreender a necessidade de correções ou ajustes em variáveis a partir dos modelos de regressão alométricas (ABERNETHY, KIPPERS, MACKINNON, NEAL e HARAHAN, 1997).

O campo das correções ou ajustes por "escalas de potência" - relacionado especificamente às dimensões corporais de tamanho, como a estatura ou massa corporal -, é fundamental no estudo do crescimento do ser humano, pois algumas medidas funcionais, como o $\dot{\mathrm{V}}_{2}$ máx, se alteram, na maioria das vezes, proporcionalmente a algumas das dimensões ou tamanhos do próprio corpo. Alguns pesquisadores procuraram adotaram novos procedimentos estatísticos para oferecer comparações mais adequadas das características morfofuncionais humanas, mediante a utilização de regressões lineares (KATCH e KATCH, 1974; TOTH, GORAN, ADES, HOWARD e POEHLMAN, 1993), seguindo o modelo geral abaixo:

$$
\mathrm{Y}=c+b \mathrm{X}
$$

Onde b e c são constantes. 
A discussão de diferentes modelos de regressão não teve um amplo campo de investigação e utilização nas diferentes populações, porque as diferenças no desempenho não são simplesmente atribuídas por características morfológicas. Neste caso, também há diferenças qualitativas tanto interindivíduos quanto intraindivíduos, entre tamanhos dos segmentos corporais envolvidos nas provas de esforço, tais como o volume ou área muscular, que podem ser alterados ao longo do tempo.

Sob essa perspectiva, HEUSNER (1983) advoga que no campo da fisiologia comparada, os animais podem ser descritos em termos de suas propriedades físicas, químicas, geométricas e biológicas, podendo diferir-se uns dos outros tanto quantitativa quanto qualitativamente. Do ponto de vista das características descritivas, os animais devem ser analisados sob duas perspectivas: por suas propriedades 'extensivas' e 'intensivas'. As extensivas referem-se às propriedades dependentes do tamanho, tais como a massa corporal, superfície corporal, volume, metabolismo e produção de energia. As propriedades intensivas, por outro lado, são independentes do tamanho, mas dependente da forma dos animais. O termo aditivo "e", portanto, determina que todas as análises descritivas da fisiologia entre os animais sejam feitas necessariamente sob essas duas abordagens, pois as diferenças entre grupos de indivíduos não podem ser apresentadas apenas pelas dimensões quantitativas do tamanho, mas também pela sua forma. Contudo, essa premissa da fisiologia comparada trata prioritariamente das diferenças morfofuncionais entre os animais, mas não se referem aos seres humanos.

Em se tratando de seres humanos, as diferenças entre os indivíduos eram tratadas tradicionalmente por ajustes lineares. Nesse sentido, TANNER (1949) já havia alertado que haveria muitos equívocos na avaliação de algumas variáveis de desempenho físico quando utilizasse ajustes lineares. Num estudo relatado pelo autor, foi demonstrado que o volume de ejeção sistólica corrigido pela massa corporal (mediante um modelo linear), para homens e mulheres adultos, desvantagem mais os sujeitos pesados e diagnosticava os mais leves como portadores de hipercinemia ${ }^{1}$. Neste caso, ele chamou a atenção para o fato que regressões lineares induziriam a conclusões insatisfatórias nos resultados de ajustes de variáveis funcionais por morfológicas, que não seriam justificadas pelos próprios dados.

Ele sugeria que há uma forma de verificar a validade das relações lineares nos ajustes de dados funcionais usando os coeficientes de correlação linear como critério. Ele

\footnotetext{
${ }^{1}$ Aumento excessivo do volume cardíaco durante o repouso, em posição supina.
} 
explica que o uso de modelos lineares para os ajustes funcionais deviam satisfazer obrigatoriamente a condição de igualdade entre o coeficiente de correlação $r_{x y}$ e o quociente entre os coeficientes de variação $(\mathrm{CV})$ de $x\left(\mathrm{~S}_{\mathrm{x}} / \mathrm{X}_{\mathrm{x}} \cdot 100\right)$ e de $y\left(\mathrm{~S}_{\mathrm{y}} / \mathrm{X}_{\mathrm{y}} \cdot 100\right)$, dado pelo modelo matemático abaixo:

$$
\frac{\frac{S_{x}}{\bar{X}_{x}} \cdot 100}{\frac{S_{y}}{\bar{X}_{y}} \cdot 100} \Rightarrow \frac{C V_{x}}{C V_{y}}=r_{x y}
$$

Caso contrário, o modelo linear apresentará ajustes equivocados ou espúrios. $\mathrm{Ou}$ seja, se este critério não é atingido, a magnitude das distorções aumenta na mesma proporção da discrepância entre as variáveis. Ainda segundo TANNER (1949), quando ocorrer variações tanto intra quanto inter-indivíduos, este modelo sempre favorecerá aos indivíduos mais leves em relação aos mais pesados, quando ambos tiverem os mesmos valores absolutos de potência aeróbia. Mas que essa regra ainda seja garantida, o uso de regressão linear no ajustes das variáveis funcionais a partir de variáveis morfológicas, somente seria válido se a linha de origem do modelo matemático, representada por um ponto de intercepto na abscissa, for igual a zero (letra $c$ no modelo matemático). Porém isso normalmente não ocorre com variáveis como a potência aeróbia e a massa corporal. Somente com este entendimento sobre as variações observadas entre as variáveis funcionais e de tamanho, em um mesmo grupo de indivíduos, poder-se-iam justificar a utilização de novos ajustes para determinação da potência aeróbia, incluindo até mesmo os modelos alométricos.

Para compreender esse processo de escala de potência com base nas similaridades geométricas, deve-se tomar como exemplo um quadrado. A regra matemática estabelece que, se observarmos atentamente este quadrado, o comprimento de cada um dos seus lados cresce proporcionalmente quando apenas um lado altera a sua dimensão. De qualquer forma, ele não alteraria a sua forma original, embora tenha uma nova dimensão.

Com base na regra das similaridades geométricas, a área de um objeto com diferentes tamanhos pode ser relacionada com a área de qualquer outro objeto de forma semelhante pelo quadrado das suas dimensões lineares, enquanto o volume deverá variar de acordo com o cubo dessas dimensões. Entre os animais é possível aplicar os mesmos 
princípios teóricos, baseado na hipótese de que algumas das suas dimensões corporais são lineares e outras são de volume. No caso da potência aeróbia, claramente sendo esta uma medida de volume, ela também deverá ser expressa em uma dimensão cúbica (DOCHERTY, 1996).

ABERNETHY et al. (1996) explicaram essas relações, demonstrando que se a medida de comprimento altera em um dos lados, os demais lados terão sido alterados em uma relação de 1:2 (L). Neste caso, as alterações se dão em uma mesma dimensão, identificada como linear por se tratar apenas do comprimento. Por outro lado, na observação de um quadrado como uma área de superfície pode-se perceber que a alteração em um dos lados (comprimentos) provocará um aumento proporcional em toda a sua área, obtendo-se uma relação de 1:4. Essa relação é conhecida como quadrática $\left(\mathrm{L}^{2}\right)$. Quando este quadrado se transforma em uma figura de três dimensões, um cubo, qualquer alteração em uma medida de qualquer de um dos lados ou face deste cubo provocará uma alteração proporcional nas outras 6 faces desta mesma figura, obtendo-se uma relação de 1:8, uma relação cúbica $\left(\mathrm{L}^{3}\right)$. A área do quadrado pelo seu volume é da pela relação 1:2/3. Assim podemos expressar essas relações matemáticas na direção das variações em escalas de superfície e de volume.

Usando as relações das similaridades geométricas, a área de superfície e o volume podem ser expressos como segue:

$$
\begin{aligned}
& \mathrm{C}=\mathrm{L} \\
& \mathrm{A}=\mathrm{L}^{2} \\
& \mathrm{~V}=\mathrm{L}^{3} \\
& \mathrm{~A}=\mathrm{V}^{2 / 3}
\end{aligned}
$$

Onde C é comprimento, A é a área de superfície, V é o volume e L é uma medida linear.

A expressão alométrica, que estabelece uma relação entre as diferentes partes de um organismo, se expressa pelo modelo matemático abaixo: 


$$
\mathrm{Y}=a \cdot \mathrm{X}^{\mathrm{b}}
$$

Onde Y é a variável dependente (a ser predita), 'a' é uma constante de correção, $\mathrm{X}$ é a variável independente (preditora), normalmente uma variável de tamanho, e ' $\mathrm{b}$ ' é o expoente da razão de potência entre as relações (CALDER III, 1984; SCHIMIDT-NIELSON, 1984).

Segundo SCHIMIDT-NIELSON (1984), há muito mais a ser revelado nesse modelo alométrico (que correspondente a uma linha de regressão linear) do que apenas a exploração das relações entre duas variáveis, pois o modelo tem dois importantes atributos que não podem ser observados separadamente: o coeficiente de proporcionalidade 'a' (o ponto de intercepto no eixo X) e o expoente 'b' (a inclinação da linha de regressão). Ambos têm diferentes significados e respondem questões interdependentes e, portanto, complementares, na relação entre as duas variáveis.

Ou seja, mesmo quando dois grupos de indivíduos possuam o mesmo expoente 'b', mas com diferentes coeficientes de proporcionalidade, a única semelhança entre eles é que o mesmo princípio governa as suas relações. Neste caso, o coeficiente de proporcionalidade revela a magnitude das diferenças entre esses dois grupos, a partir das diferenças do tamanho e da forma. Outro aspecto sobre a equação alométrica para o qual SCHIMIDT-NIELSON (1984) chama a atenção, é como os valores da relação foram obtidos. Para ele, dois importantes fatores devem ser levados em consideração. $O$ primeiro radica nos erros de medida, que podem ser sistemáticos ou aleatórios; o segundo na forma de obtenção da amostra para cada grupo de indivíduos (intencional ou aleatória). Pequenos grupos de sujeitos obtidos de forma intencional podem muito dizer sobre os expoentes e coeficientes de proporcionalidade gerados na equação. Também a forma de obtenção das medidas pode comprometer os resultados, fundamentalmente se não há controle das variáveis que interferem na avaliação.

No caso da potencia aeróbia, ROWLAND (2003) também evidencia essa premissa, pois o nível de aptidão física ou o pequeno número de sujeitos envolvidos podem produzir ajustes equivocados para a potência aeróbia e nas medidas de tamanho, fundamentalmente em se tratando de crianças e adolescentes em constante processo de crescimento. Entretanto, NEVILL (1994) identificou os dois principais aspectos a favor do uso 
das técnicas alométricas, independentemente do fator tamanho da amostra. O primeiro: um modelo linear não é sempre apropriado. Segundo: o erro-padrão de estimativa da regressão não é necessariamente uma constante, podendo inclusive ser um número multiplicativo. $\mathrm{Ou}$ seja, o erro aumenta na mesma magnitude do aumento da variável independente.

Segundo WINTER e NEVILL (1996), há a necessidade de uma transformação para a nova expressão matemática, que poderia resultar na obtenção de um expoente que não seria necessariamente um número inteiro, mas poderia ser uma fração (número menor ou maior que 1). Essa expressão seria facilmente alterada por expressões logarítmicas $\left(\log ^{*}\right)$ de cada variável e regressão em $\log X$ e $\log Y$ (expressão $\log$-log). Ela produzirá uma relação chamada de log-linear, apresentada da seguinte forma:

$$
\log \mathrm{Y}=\log a+b \cdot \log \mathrm{X}
$$

Este modelo poderia apresentar uma nova representação gráfica dos resultados que poderiam ser apresentados no formato de curvas. Segundo SCHMIDT-NIELSEN (1984), essa equação estabelece uma simples asseveração de que quando duas variáveis são plotadas em coordenadas logarítmicas, $\log \mathrm{Y}$ em função do $\log \mathrm{X}$ produzem uma linha reta com uma inclinação em função de ' $b$ '. Na biologia ou fisiologia comparada, um grande número de variáveis funcionais ajustadas pelo tamanho e transformadas logaritmicamente produzem um expoente "b" (no modelo log-linear acima). Esses expoentes podem assumir qualquer valor, inclusive negativos. Por exemplo, se a variável dependente, potência aeróbia, aumenta mais lentamente que a variável preditora, massa corporal, a linha de regressão terá uma inclinação maior que zero e menor que $1(0<\mathrm{b}<1)$. Ao contrário, se a variável dependente aumentar mais rapidamente que a preditora, a linha de regressão terá uma inclinação maior que 1 (b > 1). Se for obtido um valor de $b=1$, em uma relação entre essas variáveis, essa relação será conhecida como isométrica (CALDER III, 1984).

Por outro lado TANNER (1949) estabeleceu que comparações entre grupos com base nas proporções também são equivocadas, porque elas envolvem algumas dificuldades estatísticas. Nas comparações entre indivíduos de diferentes tamanhos, ou para avaliar as séries de mudanças nos períodos longitudinais, é essencial que o $\mathrm{VO}_{2}$ máx seja expresso com

\footnotetext{
* Onde log é um logaritmo natural.
} 
relação ao fator que poderá contar com as diferenças de crescimento. Considerando as controvérsias e incertezas existentes, se faz necessário rever os modelos determinantes de modelagem da expressão do $\dot{\mathrm{VO}}_{2}$.

ROGERS et al. (1995) advogam que o expoente 0,67 é utilizado por considerar que as variações nas dimensões corporais são proporcionais às leis da superfície corporal, e que no corpo há comprimentos, áreas e volumes. Os segmentos corporais são proporcionais ao seu comprimento (L), a superfície corporal é proporcional à área que é obtida pelo quadrado do comprimento $\left(\mathrm{L}^{2}\right)$, e o volume corporal é proporcional ao cubo $\left(\mathrm{L}^{3}\right)$. Como a potência aeróbia é uma medida de volume de $\mathrm{O}_{2}$ consumido por unidade de tempo $\left(\mathrm{L}^{3}\right)$, o tempo é uma medida de comprimento (L), então a relação de potência aeróbia por unidade de tempo se daria da seguinte forma:

$$
\frac{\mathrm{L}^{3}}{\mathrm{~L}} \Rightarrow \mathrm{L}^{3} \times \mathrm{L}^{-1} \Rightarrow \mathrm{L}^{3-1}=\mathrm{L}^{2}
$$

A explicação do expoente 0,67 é dada da seguinte forma: no caso da massa corporal ser utilizada no ajustamento do $\dot{\mathrm{VO}}_{2}$, a relação deve ser assim considerada:

$$
\frac{\dot{\mathrm{VO}}_{2}}{\text { Massa Corporal }}
$$

Finalmente, a expressão do $\dot{\mathrm{VO}}_{2}$ seria relativa a um expoente de 0,67 quando incluída a massa corporal, pois:

$$
\frac{\mathrm{L}^{2}}{\mathrm{~L}^{3}} \Rightarrow \mathrm{L}^{2 / 3}=\mathrm{L}^{0,67}
$$


Se for considerado que todo o modelo de similaridade geométrica utiliza as relações de área e volume, indicado pelo expoente 0,67 , ele se iguala ao expoente teórico da lei de superfície.

$$
\frac{\mathrm{A}}{\mathrm{V}} \Rightarrow \frac{\mathrm{L}^{2}}{\mathrm{~L}^{3}} \Rightarrow \mathrm{L}^{2 / 3}=\mathrm{L}^{0,67}
$$

Quando ocorre no crescimento físico, nele também poderia ser incluída a estatura (que é uma medida de comprimento L). O resultado do expoente anterior saltaria de 0,67 para 0,75, obtido da seguinte expressão:

$$
\text { Estatura } x \frac{\dot{\mathrm{VO}}_{2}}{\text { Massa Corporal }}
$$

ou seja,

$$
\frac{\mathrm{L} \times \mathrm{L}^{2}}{\mathrm{~L} \times \mathrm{L}^{3}} \Rightarrow \frac{\mathrm{L}^{1+2}}{\mathrm{~L}^{1+3}} \Rightarrow \frac{\mathrm{L}^{3}}{\mathrm{~L}^{4}} \Rightarrow \mathrm{L}^{3 / 4}=\mathrm{L}^{0,75}
$$

Para NEVILL (1994), vários são os modelos de regressão alométricos que poderiam ser utilizados para o ajustamento de variáveis fisiológicas, dependendo basicamente do grupo de indivíduos analisado e da variável avaliada. Um dos exemplos apresentados pelo autor, envolvendo as medidas de potência aeróbia, é presumivelmente proporcional a um expoente de 0,67 . Mas este expoente poderá subestimar os resultados quando se despreza outra covariante dentro do mesmo grupo - a estatura.

Nesse sentido, considerando então essa nova variável, a estatura, este modelo alométrico será semelhante ao modelo descrito por ABERNETHY et al. (1997), pois oferece uma explicação matemática para o uso do expoente 0,75 . Contudo, qualquer expoente utilizado ainda não justifica o seu uso, pois a maioria das medidas lineares, de área e de 
volume obtidas no indivíduo também pode variar desproporcionalmente, principalmente no período do crescimento. Neste caso, para tentar resolver esse conflito, todos os sujeitos deveriam ser homogêneos filogeneticamente para que pudesse ser utilizado o modelo alométrico anterior $\left(\mathrm{m}^{0,67}\right)$. A descrição de variáveis que se interpõem ao ajuste da potência aeróbia, somente poderia ser encontrada com base em um estudo utilizando relações loglineares, para que então se determinassem os expoentes para o grupo populacional estudado.

Os expoentes alométricos podem ser obtidos considerando a ontogenia e a filogenia dos seres humanos. Para tentar explicar essas diferenças, ROWLAND (2003) advoga que na análise ontogenética considerada-se a expressão fenotípica do mesmo material genético ao longo do tempo. Já na análise filogenética o tempo não é considerado, além de o expoente alométrico ser oriundo de diferentes grupos de indivíduos. Ou seja, no primeiro caso os expoentes alométricos são obtidos por meio de um estudo longitudinal, enquanto que no segundo, por meio de um estudo transversal. Em ambos os casos, os expoentes obtidos por meio desses dois tipos de estudo não explicam o mesmo fenômeno, mesmo que envolvam crianças e adolescentes durante o crescimento.

$\mathrm{Na}$ fase de crescimento, a força da explicação de uma relação função/tamanho, por meio de um expoente alométrico, não está radicada inteiramente no tipo do estudo: ontogenético ou filogenético. Apesar de o estudo ontogenético envolver os mesmos sujeitos ao longo do tempo, sua maior desvantagem está na quantidade de medidas obtidas. Ou seja, o número de indivíduos envolvidos e a quantidade de avaliações deveriam ser proporcionais à quantidade de alterações atribuídas às variáveis envolvidas, permitindo aumentar a sensibilidade do modelo de regressão alométrico. Essa desvantagem poderia ser minimizada nos estudos transversais, por envolver, em primeiro lugar, uma maior quantidade de indivíduos para cada grupo etário; em segundo lugar, uma faixa etária mais ampla e em menor tempo de estudo. Contudo, neste caso, os indivíduos não seriam os mesmos e os diferentes estágios de desenvolvimento também poderiam afetar os resultados para cada grupo etário. Para ROWLAND (2003), ainda é difícil emitir qualquer conclusão a respeito das relações entre as escalas alométricas ontogenéticas e filogenéticas para a potência aeróbia de crianças e adolescentes, ou até mesmo de indivíduos adultos, principalmente se as informações forem limitadas por envolver amostras pequenas, ou por não controlarem adequadamente as diferenças sexuais, de composição corporal e da própria aptidão física, fundamentalmente nos estudos longitudinais. As comparações entre os expoentes alométricos obtidos nos diferentes 
tipos estudos devem ser feitas com cautela, conforme sugere CALDER III (1984), pois eles são mais descritivos do que conceituais, ainda que possam ser mais utilizados vantajosamente nas comparações fisiológicas.

Obter valores de $\dot{\mathrm{VO}}_{2}$ relativos à massa corporal, sem um devido ajuste considerando as diferenças nas proporcionalidades, poderá causar uma interpretação equivocada das diferenças entre os indivíduos, desfavorecendo os indivíduos mais pesados em relação aos mais leves (TANNER, 1949). Nesse sentido, o procedimento estatístico linear pode induzir os erros que se tornam ainda mais graves quando se referem às crianças e adolescentes.

$\mathrm{Na}$ literatura, apesar de este ser um tema em grande debate, ainda são poucos os estudos que apresentaram dados empíricos. Os estudos que utilizam um ajuste alométrico, em sua maioria, partem de um pressuposto teórico determinado, no qual o expoente que trata da correção da potência aeróbia é fixo em 0,67 ou 0,75 . Realizando uma verificação dos estudos que utilizaram ajustes alométricos com base nos expoentes fixos para crianças e adolescentes, observamos que sua utilização é recente e ainda distante de uma solução definitiva. Por outro lado, alguns autores identificaram em seus estudos novos expoentes específicos para ajustes na potência aeróbia, colocando em suspeita a utilização de um expoente fixo, fundamentalmente no período do crescimento físico.

Um aspecto a ser observado no conjunto das contribuições morfológicas durante o crescimento na potência aeróbia de rapazes e moças é o período maturacional, pois ele ocorre em momentos e intensidades diferentes em cada indivíduo, tornando a interpretação do crescimento cada vez mais difícil e específica para os grupos etários estudados.

Com o objetivo de compreender as diferenças entre os sexos na potência aeróbia de crianças pré-púberes, ARMSTRONG et al. (1995) observaram que os rapazes eram significantemente mais altos e pesados que as moças para a mesma idade. Os valores médios do $\dot{\mathrm{VO}}_{2}$ máx foram analisados de quatro diferentes formas: a) valores absolutos; b) relativos à massa corporal; c) relativos à massa corporal corrigida por expoentes em 0,67 e d) corrigidos 
a 0,75 . Os resultados mostraram que, em todas as formas, os rapazes apresentaram valores médios mais elevados em relação às moças, mas os autores alertam que o uso dos expoentes pode não ser adequado para crianças e adolescentes (devido ao processo de crescimento envolvido nos dois grupos), sendo talvez adequado aos indivíduos adultos.

Em outro estudo semelhante, ROGERS et al. (1995) avaliaram a potência aeróbia máxima e submáxima de 42 crianças pré-púberes (idades entre 7 e 9 anos). Os resultados demonstraram que em velocidade submáxima de corrida em esteira, tanto os meninos quanto as meninas apresentaram os resultados estatisticamente iguais, nos valores absolutos e nos relativos à massa corporal ajustada a 0,67 e 0,75 . As diferenças somente apareceram quando foram obtidos os valores máximos, sendo os valores médios dos meninos sempre maiores que os das meninas. Quando os autores ajustaram os valores de $\dot{\mathrm{VO}}_{2}$ máx a uma potência de 0,67 e 0,75 da massa corporal, os rapazes apresentaram valores crescentes e maiores aos das moças, enquanto que entre elas os valores continuaram estáveis com o passar dos anos, em todas as formas de interpretação. Considerando uma avaliação da composição corporal e obtendo os valores da massa corporal magra para ser substituída a massa corporal total para os diferentes tipos de ajustes, os resultados foram semelhantes aos já observados anteriormente, para ambos os sexos.

Uma adequada compreensão dos resultados encontrados na potência aeróbia, considerando o tipo de ajuste adotado (alométrico ou linear) ao longo do crescimento, também pode ser obtida a partir do tipo do estudo, como o tamanho da amostra. Estudos longitudinais são consideradas os mais confiáveis quando e deseja compor uma análise sobre o efeito do crescimento no comportamento aeróbio de uma população jovem. Nessa perspectiva, PATERSON et al. (1987) realizaram um estudo longitudinal da potência aeróbia apenas com rapazes ao longo de cinco anos. Os autores observaram que o $\mathrm{V}_{2}$ máx em valores absolutos aumentou $83,7 \%$ no período, enquanto os ganhos nos valores relativos foram menos expressivos, sendo por volta de $12 \%$. Para os autores, esse resultado demonstrou que somente a massa corporal estabeleceu um efeito mais negativo do que positivo ao longo do crescimento no que diz respeito ao $\dot{\mathrm{V}}_{2}$ máx, pois no mesmo período ela cresceu aproximadamente $70 \%$ para o grupo estudado.

Por outro lado, quando os autores procuraram ajustar alometricamente os valores de $\dot{\mathrm{V}}_{2}$ máx pela massa corporal, um expoente de $1,02(\mathrm{r}=0,94, \mathrm{p}<0,05)$ foi encontrado, 
diferentemente daqueles utilizados em outros estudos $(0,67$ ou 0,75$)$, demonstrando que o período maturacional pode ter exercido uma influência ainda não identificada totalmente. Nesse particular, PATERSON et al. (1987) advogam que os expoentes de 0,67 e 0,75 parecem não ser adequados para crianças e adolescentes (pelo menos em rapazes), pois o $\mathrm{V}_{2}$ máx aumenta mais lentamente do que a massa corporal, quando analisado em valores relativos.

ROWLAND et al. (1997) avaliaram longitudinalmente 11 rapazes e 9 moças por cinco anos (dos 9 aos 13 anos), sem considerarem as mudanças maturacionais, acompanhando apenas os níveis de atividade física habitual. Os resultados para os expoentes alométricos foram demonstrados tanto longitudinalmente quanto transversalmente. No primeiro caso, os expoentes obtidos para rapazes e moças foram 1,10 e 0,78 respectivamente. No segundo caso, a cada ano foi gerado um expoente para cada um dos grupos, variando de 0,40 a 0,70 respectivamente para os rapazes aos 9 anos e para as moças aos 12 anos. A média dos expoentes foi de 0,53 para rapazes e 0,65 e para as moças.

Em outro estudo, BEUNEN et al. (1997) analisaram o $\dot{\mathrm{VO}}_{2}$ máx de crianças por quatro anos. Houve uma divisão no grupo de indivíduos por nível maturacional, na intenção de avaliarem mais adequadamente os efeitos do crescimento e da maturação sobre o $\dot{\mathrm{V}}_{2}$ de jovens. Nesse estudo, os autores encontraram 16 diferentes expoentes alométricos, utilizando tanto a massa corporal quanto a estatura como covariantes em todos os níveis maturacionais observados. Contudo, alguns dos expoentes apresentaram melhor ajuste aos resultados de $\dot{\mathrm{VO}}_{2}$, principalmente entre os rapazes mais velhos. Os expoentes variaram entre 0,53 a 0,79, valores próximos aos expoentes 0,67 e 0,75 adotados anteriormente como os mais adequados.

Considerando apenas o estágio maturacional, dentre os possíveis estágios sugeridos na literatura, ARMSTRONG et al. (1995) identificaram um expoente alométrico de 0,66 para rapazes pré-púberes, estando bem próximo ao expoente padrão de 0,67 . Sobre a inclusão da estatura como uma nova covariante no modelo para o grupo estudado, os autores consideraram que não seria necessário, considerando o período maturacional dos indivíduos, em que a estatura ainda não se estabeleceu, sendo uma variável em crescente elevação com o passar dos anos, o que poderia elevar artificialmente o expoente alométrico, mas sem implicação com o resultado do $\dot{\mathrm{VO}}_{2}$. 
Segundo COOPER et al. (1984), a mesma tendência nos resultados foi observada quando os autores corrigiram alometricamente o $\dot{\mathrm{VO}}_{2}$ de rapazes e moças, encontrando um expoente de 0,92. Nesse mesmo estudo, os autores preocupam-se em corrigir os resultados de limiar anaeróbio (LA), sendo bem diferentes para ambos os sexos, mas sempre com expoentes superiores para os rapazes nos dois grupos etários (expoente de 0,95 e 0,76;1,12 e 1,02, para rapazes e moças respectivamente). Com esses resultados, os autores avaliaram que o fator alométrico foi mais baixo para o LA do que para o $\mathrm{V}_{2}$, mas as diferenças não eram estatisticamente significantes. No caso de crianças, uma relação entre o crescimento e o exercício parece ser adequada durante essa fase da vida, em que a massa corporal pareceu não ser um bom fator de ajuste alométrico para interpretar os resultados entre as diferentes faixas etárias e sexo.

Na tentativa de avaliar os efeitos da idade cronológica e da maturação sobre o $\dot{\mathrm{VO}}_{2}$ de crianças brasileiras, MACHADO et al. (2002) realizaram um estudo envolvendo 40 rapazes com idades entre 10 e 15 anos, dividindo-os em dois grupos maturacionais. O primeiro grupo se encontrava nos estágios de 1 a 3 enquanto o segundo grupo estava nos estágios 4 e 5 - para a pilosidade pubiana. Eles concluíram que a idade cronológica e a maturação determinaram um aumento nos valores absolutos do $\dot{\mathrm{VO}}_{2}$ máx, mas não foram observados aumentos para os valores relativos com o passar dos anos. Embora não tenha sido objetivo do estudo, os autores realizaram uma correção dos valores de massa corporal ajustadas alometricamente pelo expoente $0,67\left(\mathrm{~mL} \cdot \mathrm{kg}^{-0,67} \cdot \mathrm{min}^{-1}\right)$ e observaram que a maturação exerceu uma influência positiva nos valores relativos de $\dot{\mathrm{V}}_{2}$ entre os rapazes.

Em um estudo transversal mais recente, LORENZI (2006) avaliou direta e indiretamente a aptidão cardiorrespiratória de 96 crianças e adolescentes brasileiras, de ambos os sexos (46 rapazes e 50 moças), de 10 a 14 anos, mediante um teste cardiopulmonar de esforço e outros de campo. O objetivo foi estabelecer uma relação entre os dois tipos de desempenho e obter o expoente que melhor ajustava aquele avaliado diretamente. No que diz respeito à relação aos testes de campo (seis e nove minutos), o melhor coeficiente de correlação foi obtido entre o teste de 9 minutos e a potência aeróbia relativa à massa corporal $\left(\mathrm{mL} \cdot \mathrm{kg}^{-1} \cdot \mathrm{min}^{-1} ; \mathrm{r}=0,632, \mathrm{p}<0,05\right)$, provavelmente por este ser mais longo que o anterior e depositar uma maior relação com a potência mensurada diretamente; por outro lado, essa 
mesma relação aumentou quando o $\dot{\mathrm{V}} \mathrm{O}_{2}$ foi ajustado a expoente teórico de $0,67(\mathrm{r}=0,704 \mathrm{e}$ 0,728, $\mathrm{p}<0,05)$. Ao avaliarem a relação alométrica da potência aeróbia e a massa corporal, o expoente obtido para ambos os sexos foi de 0,87 , enquanto que para os rapazes o expoente foi mais elevado $(b=0,88)$ que o das moças $(b=0,69)$. Estes apresentaram a melhor correlação com os desempenhos no teste de campo para ambos os sexos, demonstrando que os expoentes teóricos de 0,67 e 0,75 não se aplicaram a esse grupo etário de jovens brasileiros.

Diante dos resultados observados, nota-se que os estudos longitudinais são freqüentes e adequados para revelar o comportamento evolutivo do $\dot{\mathrm{VO}}_{2}$ de crianças e adolescentes, principalmente quando se objetiva avaliar os efeitos da massa corporal ao longo do crescimento. Para tanto, a técnica da regressão alométrica foi indicada para estabelecer o melhor ajuste para a potência aeróbia a partir de variáveis morfológicas como a estatura e a massa corporal. De modo geral, os rapazes apresentaram um aumento significante no $\dot{\mathrm{V}} \mathrm{O}_{2}$ máx enquanto as moças apresentaram um discreto aumento com o passar dos anos.

A utilização indiscriminada de expoentes alométricos fixos em 0,67 ou 0,75 pode ainda não representar o melhor ajuste do $\dot{\mathrm{V}}_{2}$ ao longo do crescimento físico, pois tanto o nível maturacional como os níveis de atividade física podem influenciar os valores observados, sobretudo em moças, pois a atividade física não se dá no mesmo nível que os rapazes nessa fase do crescimento. Com esse argumento, qualquer um dos expoentes fixos utilizados nessa área de investigação poderá não traduzir as verdadeiras transformações nos diferentes tecidos corporais, sendo necessário obter expoentes específicos para cada grupo etário estudado, inclusive nos estudos transversais. 
Este estudo é caracterizado como descritivo, do tipo transversal, e procurou apresentar as características da potência aeróbia de crianças e adolescentes de ambos os sexos, além de propor ajustes alométricos nos valores da massa corpora e massa corporal magra na potência aeróbia ( $\dot{\mathrm{V}}_{2}$ pico), com base na idade e sexo.

4.2 Localização e características humanas do Município de Marechal Cândido Rondon - Paraná

O município de Marechal Cândido Rondon está localizado no oeste do Paraná, na microrregião do município de Toledo, a 491,4 km da capital Curitiba, tendo a sua sede localizada entre as coordenadas de $24^{\circ} 26^{\prime}$ e $24^{\circ} 46^{\prime}$ latitude sul e $53^{\circ} 57^{\prime}$ e $54^{\circ} 22^{\prime}$ ' longitude oeste, com uma área total de $670.800 \mathrm{~m}^{2}$ (FIGURA 1). O município tem uma altitude de $410 \mathrm{~m}$ do nível do mar, possuindo suas características climáticas e de vegetação incluída na zona tropical e subtropical úmida, de clima quente e chuvoso; com temperaturas médias anuais de $20,3^{\circ} \mathrm{C}$, com médias mais elevadas nos meses de janeiro e fevereiro $\left(24,1^{\circ} \mathrm{C}\right)$ e as mais baixas nos meses de junho e julho $\left(15,8^{\circ} \mathrm{C}\right)$, com uma umidade relativa do ar média de $85 \%$ /ano (PFLUCK, 2007).

O município foi criado em 1960, emancipando-se do município de Toledo, e foi colonizado por agricultores imigrados dos estados do Rio Grande do Sul e Santa Catarina, ainda no período dos anos de 1950. As migrações foram iniciadas nos anos de 1940 para o município de Toledo e, por sua extensão, ao antigo distrito e hoje município de Marechal Cândido Rondon. 


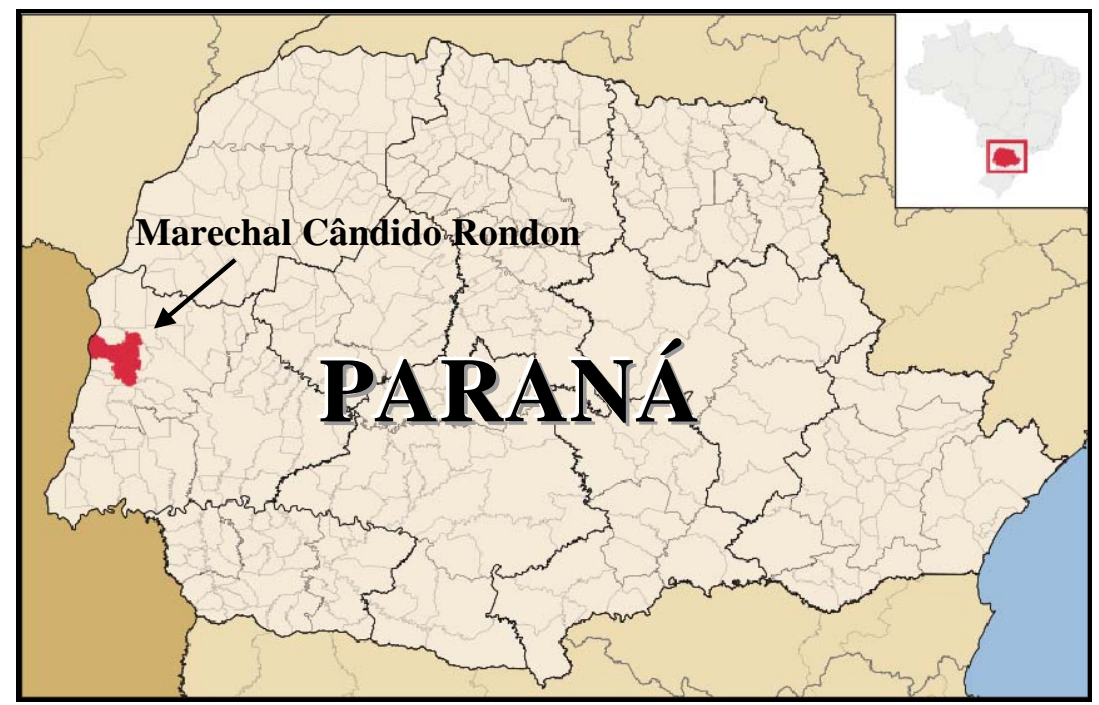

FIGURA 1 - Localização do Município de Marechal Cândido Rondon - Brasil, no extremo oeste do estado do Paraná.

Para tanto, a empresa colonizadora responsável pela venda de lotes de terras, assentou famílias, consideradas "trabalhadoras" (SCHREINER, 1997), cujas origens étnicas descendiam predominantemente dos imigrantes alemães, e em menor parte de poloneses e italianos daqueles estados. No caso específico do assentamento dos colonos rondonenses, atribuiu-se ao município a condição da cidade mais germânica do Paraná, característica que hoje ainda prevalece. Portanto, a característica etnogênica caucasiana é superior a 95\% da população, sendo aproximadamente $85 \%$ de descendentes de alemães, 5\% de poloneses, 5\% de italianos e 5\% de outras regiões do Brasil e do mundo (HOBOLD, 2003).

A população rondonense foi estimada em 44.562 mil habitantes, sendo que destes, por volta de 30 mil habitam a região urbana (74\%) e 15 mil na região rural $(26 \%)$ (IBGE, 2007). A taxa de urbanização, apesar de ser predominante, coloca o município com uma densidade demográfica baixa $\left(61,1 \mathrm{hab} / \mathrm{km}^{2}\right)$. A taxa de escolarização em nível fundamental da população jovem é elevada, pois mais de $60 \%$ da população tem até 7 anos de escolarização, para jovens de 15 a 24 anos. A porcentagem de matrícula de crianças de 7 a 14 anos de idade é de 99,4\%, e no ensino médio de $80 \%$ para as idades de 15 a 17 anos (PNUD, 2007).

A renda per capita média, avaliada em 2002, era de R\$ 9.801,00/ano (IBGE, 2006), com uma taxa de pobreza inferior a $15 \%$ da população (renda inferior a $\mathrm{R} \$ 75,5 / \mathrm{mês}$ ). 
Considerando as condições de vida, mediante uma avaliação do acesso a serviços básicos no município, 99\% das casas têm água encanada, 99,4\% possuem luz elétrica e 97,1\% têm coleta de lixo; no caso dos itens de bens de consumo nas residências, o censo revelou que 98,3\% das casas têm geladeira, 95,5\% com ao menos uma televisão, $38,3 \%$ possuem um telefone fixo e, à época, 12,4\% das casas tinham um computador (IBGE, 2006).

Esses resultados têm proporcionado aos moradores deste município um elevado Índice de Desenvolvimento Humano (IDH), sendo o valor global de 0,829 ( $8^{\circ}$ mais elevado do estado do Paraná, ano de 2000), o IHD-Educação de 0,932, o IDH-Longevidade de 0,808 e o IDH-Renda de 0,747 (PNUD, 2007), índices que podem ser traduzido em satisfatórios indicadores do crescimento físico, mediante as medidas de estatura e massa corporal.

A amostra foi constituída por 248 crianças e adolescentes de forma nãoprobabilística (por conveniência), sendo 124 rapazes e 124 moças, com idades variando de 10 a 16 anos de idade. A idade dos sujeitos da amostra foi determinada pelo método milesimal, seguindo os procedimentos propostos mediante o uso da tabela com frações para cada dia do mês. Ou seja, obtinha-se a fração do dia para do mês no ano da avaliação e subtraia-se o valor da fração do dia do mês no ano do nascimento. Cada grupo etário foi agrupado considerandose a idade inferior a partir da fração 0,501 e a superior na fração até 0,499 (ROSS e MARFELL-JONES, 1982).

Para participar da amostra, todas as crianças estavam matriculadas em escolas públicas e/ou privadas de Marechal Cândido Rondon (Paraná). O procedimento adotado para o convite dos escolares de ambos os sexos foi primeiramente visitar as escolas que permitiram a visitação aos estudantes, seguido da aprovação dos professores de Educação Física, pois foram nessas aulas que se fizeram o convite. Após as direções e professores das escolas autorizarem a visita (Anexo 1), nos dias das aulas de educação física sugeridos pelos professores(as) destas disciplinas, foram dadas as explicações dos objetivos das avaliações (envolvendo as medidas antropométricas e o teste de corrida na esteira). Todas estavam cientes de que a sua participação era voluntária. Após rapazes e moças manifestarem-se favoravelmente à participação na pesquisa, receberam um envelope contendo duas cartas. Foi-lhes explicado que 
a primeira delas era dirigida aos pais ou responsáveis - Carta de Intenção de Pesquisa (Anexo 2) e a segunda continha uma solicitação de autorização dos pais - Termo de Consentimento Esclarecido (Anexo 3), conforme modelo sugerido por TOMASSONI (1993).

Após a autorização para a participação do estudo, foram marcadas as avaliações individualmente, nas instalações do Laboratório de Avaliação do Desempenho no Esporte (LADESP), da Universidade Estadual do Oeste do Paraná (UNIOESTE). Para os que não condições financeiras para o transporte até a Unioeste, foi providenciado um transporte. Os testes foram predominantemente realizados no período da tarde, sendo as crianças e adolescentes estudantes do período matutino. O número de crianças e adolescentes convidados a participarem da amostra foram suficientes até atingirem o mínimo estabelecido de 15 sujeitos por sexo e idade.

Não fizeram parte do estudo as crianças e adolescentes que:

- Não tiveram a autorização dos pais para participar;

- Não se adaptaram à caminhada ou corrida sobre a esteira;

- Estavam doentes ou tinham apresentado doenças agudas ou crônicas recentes, mediante entrevista, que recomendaram a não realização do teste;

- Possuíam ou contraíram alguma lesão física (muscular ou articular) que os impediram de desempenharem o esforço máximo progressivo na esteira.

Todos os procedimentos foram aprovados pelo Comitê de Ética em Pesquisa da Universidade Estadual do Oeste do Paraná em 30/0802007 (Parecer 227/2007-CEP, Ata 008/2007 - CP, CR n. 21.449/2007 - Anexo 4).

4.3 Variáveis de estudo

As variáveis de estudo foram divididas em antropométricas e de potência aeróbia. As variáveis antropométricas foram: massa corporal; estatura e espessuras de dobras cutâneas (tricipital e subescapular). Os valores de potência aeróbia $\left(\mathrm{V}_{2}\right.$ pico) foram obtidos conjuntamente com as seguintes informações ventilatórias:

- VE $\left(\mathrm{L} \cdot \mathrm{min}^{-1}\right)$ - Ventilação Pulmonar por minuto;

- $\quad \dot{\mathrm{VO}}_{2}\left(\mathrm{~L} \cdot \mathrm{min}^{-1}\right)-$ Volume de Oxigênio por minuto; 
- QR - Quociente Respiratório (Razão das Trocas Respiratórias $\left.\mathrm{VCO}_{2} \cdot \dot{\mathrm{VO}}_{2}^{-1}\right)$, por minuto.

\subsubsection{Variáveis antropométricas}

\subsubsection{Medida da estatura}

Para a medida da estatura, foi utilizado um estadiômetro padrão, construído em madeira especialmente para este fim, envolvendo uma precisão de medidas de $0,1 \mathrm{~cm}$, onde o avaliado manteve-se em uma posição ereta, pés unidos e sem calçados na base da plataforma, e olhar voltado para frente, no Plano de Frankfurt (GORDON, CHUNLEA e ROCHE, 1988). A medida foi registrada três vezes, no momento de uma inspiração máxima do avaliado para cada uma delas, para minimizar o efeito do horário do dia sobre a sua estatura. O maior valor mensurado foi considerado para a estatura.

\subsubsection{Medida da massa corporal}

Para a obtenção da medida da massa corporal foi utilizada uma balança eletrônica, com precisão de 0,50 gramas, da marca Toledo, onde o indivíduo se posicionou sobre a plataforma com os pés unidos e o tronco ereto e braços relaxados no prolongamento do corpo, com o mínimo de roupa possível (GORDON, CHUNLEA e ROCHE, 1988). Foi tomada uma única medida do avaliado.

\subsubsection{Medida das espessuras de dobras cutâneas}

Para a determinação das espessuras de dobras cutâneas das crianças e dos adolescentes, recorreu-se a utilização de um compasso de dobras cutâneas da marca Harpenden (Harpenden Skinfold Caliper, John Bull, British Indicators Ltd., Bedfordshire UK), com precisão de $0,2 \mathrm{~mm}$ e com pressão constante de suas hastes de $10 \mathrm{~g} / \mathrm{mm}^{2}$ para qualquer abertura. O mesmo avaliador realizou as mensurações das duas dobras cutâneas. 
Todas elas foram mensuradas na forma de uma seqüência direta das três medidas, iniciando pela dobra de tríceps (DCTR) e em seguida a subescapular (DCSB). Caso houvesse discrepância superior a $1 \mathrm{~mm}$ nos valores de duas das três medidas, uma nova seqüência de três medidas era iniciada. Após o registro das três medidas, o valor intermediário foi determinado como o valor da dobra cutânea, em milímetros (mm).

\subsubsection{Medida da dobra cutânea tricipital}

A medida da dobra cutânea tricipital foi obtida na linha média da face posterior do braço direito flexionado, sobre o músculo tríceps, em uma linha longitudinal imaginária, no ponto médio entre a borda lateral do processo do acrômio e o ponto mais inferior do olécrano, sendo ela tomada com o braço na posição relaxada (HARRISON, BUSKIRK, CARTER, JOHNSTON, LOHMAN, POLLOCK, ROCHE e WILMORE, 1988).

\subsubsection{Medida da dobra cutânea subescapular}

A dobra cutânea subescapular foi obtida em uma linha imaginária em diagonal, sendo a dobra destacada abaixo da escápula, aproximadamente $1 \mathrm{~cm}$ do ângulo inferior da escápula, com o sujeito relaxado e seus braços estendidos ao lado do corpo (HARRISON et al., 1988).

\subsubsection{Análise da composição corporal}

Os valores de percentual de gordura $(\% \mathrm{G})$ foram obtidos segundo o modelo matemático proposto por BOILEAU, LOHMAN e SLAUGHTER (1985), abaixo:

$$
\% \mathrm{G}=1,35 \cdot(\mathrm{TR}+\mathrm{SB})-0,012 \cdot(\mathrm{TR}+\mathrm{SB})^{2}-C
$$

onde C é a constante (intercepto) do modelo matemático, sendo apresentadas conforme o sexo e a idade na TABELA 1. 
TABELA 1 - Valores das constantes $C$ descritas por Boileau et al. (1985) utilizadas segundo a idade e sexo, no modelo de estimativa da gordura corporal relativa $(\% \mathrm{G})$.

\begin{tabular}{cc}
\hline & Sexo \\
\cline { 2 - 2 } Faixa Etária (anos) & Rapazes \\
\hline 6 a 11 & 3,4 \\
12 a 14 & 4,4 \\
15 a 17 & 5,4 \\
\hline 6 a 10 & Moças \\
\cline { 2 - 2 } 11 a 13 & 1,4 \\
14 a 15 & 2,4 \\
16 a 17 & 3,4 \\
\hline
\end{tabular}

A massa corporal magra (MCM) foi obtida pela relação aritmética, envolvendo a diminuição da massa gorda (MG) na massa corporal, segundo os modelos abaixo:

$$
\begin{gathered}
\mathrm{MG}=\text { Massa Corporal } \cdot(\% \mathrm{G} \cdot 100)^{-1} \\
\mathrm{MCM}=\text { Massa Corporal }-\mathrm{MG}
\end{gathered}
$$

4.3.3 Determinação da potência aeróbia de pico ( $\dot{\mathrm{V}}_{2}$ pico $)$

Para determinação do $\dot{\mathrm{VO}}_{2}$ pico, foi utilizado um analisador metabólico de gases VO2000 ${ }^{\circledR}$, Portable Metabolic Testing System, MEDGRAPHICS (Medical Graphics Corporation, Saint Paul, Minnesota - USA). O analisador de gazes VO2000 ${ }^{\circledR}$ utiliza-se do método análise por amostragem de ar em circuito aberto, contando com uma bomba integrada com válvula para amostragem de micro-partículas para $\mathrm{O}_{2}$ e $\mathrm{CO}_{2}$, simultaneamente.

Durante o teste de corrida em esteira, o aparelho captava microfrações de oxigênio inspirado $\left(\mathrm{FO}_{2}\right)$ por meio de um sensor eletrônico de fluído de $\mathrm{O}_{2}$ (Galvanic Fuel Cell), com variação de 0 a $96 \%$ e precisão de $\pm 0,1 \%$ do $\mathrm{FO}_{2}$. As frações de dióxido de carbono $\left(\mathrm{FCO}_{2}\right)$ foram captadas pelo ar expirado e determinadas pelo método de análise por infravermelho não-dispersivo, com variação de 0 a $10 \%$ e precisão de $\pm 0,02 \%$. Para o registro das medidas de ventilatórias, o aparelho possui sensor específico para a medição de volume de ar espirado. Todos os registros foram feitos a cada 10 segundo (método do tempo fixo). 
No aparelho também há um sensor de pressão atmosférica, para as necessárias correções das frações de $\mathrm{O}_{2}$ e $\mathrm{CO}_{2}$ presentes na atmosfera da região e, consequentemente, no ambiente laboratorial. Nesse sentido, para verificar se a pressão atmosférica registrada no aparelho estava de acordo com aquela da região geográfica das dependências da Unioeste, foram solicitadas as medidas diárias dos registros da pressão na cidade de Marechal Cândido Rondon, obtida pelo Laboratório de Meteorologia Agrícola, do Curso de Agronomia da Universidade Estadual do Oeste do Paraná, Campus de Marechal Cândido Rondon. Nenhuma discrepância foi observada entre os valores mensurados no aparelho a cada calibração, e aqueles registrados diariamente pelos equipamentos do Laboratório de Meteorologia Agrícola.

Finalmente, o analisador metabólico de gazes, VO2000 ${ }^{\circledR}$, também possui um sensor eletrônico de temperatura interna, muito importante na realização dos exames metabólicos. A recomendação do fabricante é de que o parelho inicie o primeiro exame após estar aquecido, para garantir a melhor qualidade na leitura dos resultados internamente. Nesse sentido, a primeira avaliação somente era realizada depois de o aparelho estar ligado por aproximadamente 40 minutos, para garantir a qualidade das frações de ar inspirado e expirados, dentro do aparelho. Após cada exame, o aparelho foi calibrado, pelo método da autocalibração, sendo valores obtidos pelo procedimento STDP (Standard Temperature and Pressure Dry).

Para a captação dos valores ventilatórios foi utilizado um peneumatocógrafo de fluxo médio, para valores de ventilação de 20 a $180 \mathrm{~L} \cdot \mathrm{min}^{-1}$, para todos os sujeitos da amostra. Todos os valores foram registrados e plotados em gráficos em tempo real, utilizando o Software Aerograph ${ }^{\circledR}$ (Medical Graphics Corporation, Saint Paul, Minnesota - USA). Todos os valores foram marcados simultaneamente para o pico, quando atingido o maior valor absoluto de $\mathrm{V}_{2}$ pelo sujeito, antes da interrupção por fadiga voluntária e considerando os critérios de determinação.

4.4 Procedimentos na coleta de dados

A avaliação foi desenvolvida em dois momentos distintos: o primeiro envolvendo a coleta de dados antropométricos, e o segundo envolvendo a avaliação da potência aeróbia, mediante um teste de esforço graduado em esteira rolante. 
Para cada indivíduo (criança ou adolescente) foi atribuída uma ficha de registro específica (Anexo 5), que continha prioritariamente as seguintes informações:

- nome;

— data de nascimento;

- data da avaliação;

— valores antropométricos de estatura, massa corporal e dobras cutâneas;

— valores ventilatórios obtidos no software Aerograph ${ }^{\circledR}$, considerando o maior valor absoluto (pico) da potência aeróbia ( $\dot{\mathrm{V}}_{2}$ pico).

A coleta de dados foi realizada mantendo-se as mesmas condições ambientais em uma sala de $54 \mathrm{~m}^{2}$, na qual a temperatura ambiente variou entre 20 e $25^{\circ} \mathrm{C}$ e a umidade relativa do ar entre 40 e 60\%, segundo a preconização de TOMASSONI (1993).

4.5 Procedimentos do teste cardiopulmonar de esforço

Para cada criança ou adolescente, de ambos os sexos, o procedimento do teste foi o mesmo. O protocolo de Balke modificado para crianças e adolescentes ativos foi utilizado (ROWLAND, 1993). Antes de cada sujeito realizar a avaliação, foi feita uma demonstração de todas as partes do teste, envolvendo o aquecimento, a corrida, as variações na inclinação, a maneira de pedir para parar e a volta a calma. Após cada criança e adolescentes estar seguro de como o teste iria acontecer, foi feita a preparação do sujeito, que consistia na fixação da máscara e do transmissor da freqüência cardíaca, com o sujeito sentado. Após todos os acessórios terem sido ajustados, o avaliado estava autorizado a subir na esteira.

O teste iniciava com um aquecimento entre 3 a 5 minutos de caminhada em velocidade constante de $4 \mathrm{~km} / \mathrm{h}(2,5 \mathrm{mph})$, com a esteira sem inclinação (0\%), para ambos os sexos. Após esse período de aquecimento, o teste era iniciado com uma corrida em velocidade constante de $8 \mathrm{~km} / \mathrm{h}$ (5 mph). A cada 2 minutos de corrida, a inclinação da esteira se elevava em 2,5\%, até que a criança ou adolescente atingisse a exaustão voluntária ou algum dos critérios de interrupção (Tabela 2). A recuperação após a interrupção do teste durou entre 4 a 5 minutos, com uma caminhada em uma velocidade constante de $4 \mathrm{~km} / \mathrm{h}(2,5 \mathrm{mph})$, com a 
inclinação da esteira em $0 \%$, ou até que o jovem restabelecesse os parâmetros ventilatórios iniciais do teste.

TABELA 2 - Protocolo do teste cardiopulmonar de esforço (Balke adaptado) para crianças e adolescentes ativas.

\begin{tabular}{ccccc}
\hline $\begin{array}{c}\text { Idade } \\
\text { (Ambos os } \\
\text { sexos) }\end{array}$ & $\begin{array}{c}\text { Velocidade } \\
(\mathbf{k m} / \mathbf{h})\end{array}$ & $\begin{array}{c}\text { Grau } \\
\text { inicial } \\
\mathbf{( \% )}\end{array}$ & $\begin{array}{c}\text { Incremento } \\
\text { de carga } \\
\mathbf{( \% )}\end{array}$ & $\begin{array}{c}\text { Estágio } \\
\text { de duração } \\
(\mathbf{m i n})\end{array}$ \\
\hline $10-16$ & 8 & 0 & 2,5 & 2 \\
\hline
\end{tabular}

4.5.1 Critérios de interrupção do teste

O teste era interrompido toda vez que se observassa pelo menos um dos seguintes critérios (ROWLAND, 1993):

- solicitação da criança ou adolescente por meio de um sinal previamente estabelecido;

- sinais de tontura ou desequilíbrio;

— falta de coordenação ou perda do ritmo da corrida.

4.5.2 Critérios de determinação do $\dot{\mathrm{VO}}_{2}$ pico

$\mathrm{O} \dot{\mathrm{VO}}_{2}$ pico foi determinado considerando o maior valor absoluto alcançado pela criança ou adolescente, quando ao menos um de dois critérios foi alcançado:

- o Quociente respiratório (QR) ter alcançado ou ultrapassado o valor de 1,0 $(\mathrm{QR} \geq 1,00)$;

- a freqüência cardíaca (FC) atingiu ao menos $95 \%$ da FC prevista para idade, mediante o modelo proposto por TANAKA, MONAHAN e SEALS (2001), segundo a fórmula abaixo:

FCmáx $=208-0,7 *$ idade $($ anos completos $)$; 
Vale ressaltar que o modelo originalmente proposto por TANAKA et al. (2001) envolveu sujeitos com idades a partir de 18 anos, sem distinção do sexo. Contudo, considerando que o estudo de meta-análise destes autores analisou um total de 351 estudos publicados (contendo resultados de 18.721 homens e mulheres), envolvendo 492 grupos distintos de indivíduos, sendo 161 de mulheres e 331 com homens, esse modelo mostrou-se como o mais adequado para determinar a FC máxima para todas as idades, inclusive de crianças e adolescentes entre 10 e 16 anos, em detrimento do tradicionalmente modelo envolvendo o modelo FCmáx $=220$ - idade, para este mesmo fim.

Todos os avaliados foram orientados a não participarem de atividades físicas ou esportivas intensas tanto no dia anterior quanto no dia do teste, além das moças não realizarem a avaliação no seu período menstrual. $\mathrm{O}$ teste de esforço na esteira ocorreu preferencialmente no período da tarde, sempre após as 14:30 h, ou ao menos duas horas após o almoço. Quando realizados no período da manhã, estes ocorreram a partir das 10:00 h, ou pelo menos duas horas após o desjejum. Quando algumas crianças ou adolescentes não apresentavam as condições necessárias para realizarem o teste no dia marcado, como por exemplo, alguma moça estar no período menstrual, agendava-se outro dia, garantindo, neste particular, a qualidade dos resultados.

4.6 Tratamento estatístico dos dados

Para alcançar os objetivos estabelecidos no estudo, os dados foram analisados pelo pacote estatístico computadorizado "Statistica", versão 6.0 (StatSoft Incorporation. Tulsa, Oklahoma - USA) para Windows (Microsoft Windows XP. Versão Profissional 2002 Service Pack 2. Microsoft Corporation. Redmond, Washington-USA). A análise dos dados foi feita em três momentos. O primeiro obtendo-se apenas a estatística descritiva, o segundo verificou as correlações e o último recorrendo ao teste " $t$ ", para amostras independentes. 
4.6.1 Descrição do comportamento das variáveis do estudo

Para análise do comportamento do crescimento físico e da potência aeróbia de crianças e adolescentes, foi utilizada a estatística descritiva, obtendo-se valores de média e desvio-padrão de todas as variáveis estudadas.

4.6.2 Determinação da regressão alométrica

Após a determinação dos valores médios da potência aeróbia para ambos os sexos e grupos etários, uma relação log-linear entre o pico e a massa corporal foi determinada pela transformação dos valores de cada variável predita e preditora (Y e X) em logaritmos naturais (transformação log-log) em uma planilha do Microsoft ${ }^{\circledR}$ Office Excel 2003. Esta transformação permitiu fornecer os valores de ' $a$ ' e ' $b$ ', na expressão alométrica:

$$
\log \mathrm{Y}=\log a+b \cdot \log \mathrm{X}
$$

4.6.3 Comparação entre as idades e sexos

Após a definição dos expoentes alométricos no estudo para cada grupo etário e sexo, os valores absolutos do $\dot{\mathrm{VO}}_{2}$ pico foram transformados em relativos considerando o novo fator de correção alométrico, e as comparações entre os grupos etários e os sexos foi feita por teste "t", com $\mathrm{p}<0,05$. 
Foram visitadas seis escolas públicas, sendo duas do ensino fundamental, para contemplar as crianças de com idades a partir de 9,501 até 10,499 anos, e quatro do ensino médio para as demais idades. Também foram visitadas três escolas particulares do município, procurando envolver as crianças e adolescentes tanto do ensino fundamental quanto do médio. A relação do conjunto da amostra do presente estudo, envolvendo alunos de 10 a 16 anos, de ambos os sexos, está apresentada na TABELA 3.

TABELA 3 - Número de escolares, valores médios, desvios-padrão, mínimo e máximo por sexo e idade milesimal de crianças e adolescentes pertencentes ao estudo.

\begin{tabular}{|c|c|c|c|c|}
\hline Sexo & $\begin{array}{l}\text { Faixa } \\
\text { Etária }\end{array}$ & $\mathbf{N}$ & $\begin{array}{c}\text { Idade } \\
\text { (Média e dp) }\end{array}$ & $\begin{array}{l}\text { Min } \\
\text { Máx }\end{array}$ \\
\hline \multirow[t]{7}{*}{ Rapazes } & 10 & 16 & $\begin{array}{c}10,0 \\
\pm 0,245\end{array}$ & $\begin{array}{c}9,644 \\
10,471\end{array}$ \\
\hline & 11 & 17 & $\begin{array}{c}11,1 \\
\pm 0,287\end{array}$ & $\begin{array}{l}10,559 \\
11,628\end{array}$ \\
\hline & 12 & 18 & $\begin{array}{c}12,0 \\
\pm 0,287\end{array}$ & $\begin{array}{l}11,512 \\
12,480\end{array}$ \\
\hline & 13 & 17 & $\begin{array}{c}12,9 \\
\pm 0,252\end{array}$ & $\begin{array}{l}12,512 \\
13,416\end{array}$ \\
\hline & 14 & 18 & $\begin{array}{c}14,1 \\
\pm 0,225\end{array}$ & $\begin{array}{l}13,652 \\
14,436\end{array}$ \\
\hline & 15 & 18 & $\begin{array}{c}15,1 \\
\pm 0,324\end{array}$ & $\begin{array}{l}14,329 \\
15,470\end{array}$ \\
\hline & 16 & 20 & $\begin{array}{c}16,1 \\
\pm 0,317 \\
\end{array}$ & $\begin{array}{l}15,578 \\
16,483 \\
\end{array}$ \\
\hline \multirow[t]{7}{*}{ Moças } & 10 & 14 & $\begin{array}{c}10,1 \\
\pm 0,228\end{array}$ & $\begin{array}{c}9,616 \\
10,454\end{array}$ \\
\hline & 11 & 17 & $\begin{array}{c}11,1 \\
\pm 0,320\end{array}$ & $\begin{array}{l}10,630 \\
11,470\end{array}$ \\
\hline & 12 & 19 & $\begin{array}{c}12,1 \\
\pm 0,244\end{array}$ & $\begin{array}{l}11,598 \\
12,455\end{array}$ \\
\hline & 13 & 18 & $\begin{array}{c}13,1 \\
\pm 0,307\end{array}$ & $\begin{array}{l}12,513 \\
13,614\end{array}$ \\
\hline & 14 & 19 & $\begin{aligned} & 14,0 \\
& \pm 0,315\end{aligned}$ & $\begin{array}{l}13,565 \\
14,487\end{array}$ \\
\hline & 15 & 18 & $\begin{array}{c}15,0 \\
\pm 0,317\end{array}$ & $\begin{array}{l}14,556 \\
15,449\end{array}$ \\
\hline & 16 & 19 & $\begin{array}{c}16,2 \\
\pm 0,255\end{array}$ & $\begin{array}{l}15,646 \\
16,485\end{array}$ \\
\hline
\end{tabular}


Para constituir a amostra de crianças e adolescentes, algumas escolas foram escolhidas. Aquelas que apresentavam um maior número de indivíduos na faixa etária preconizada recebiam uma visita sempre no período da manhã, para que as avaliações pudessem ser realizadas no período da tarde. Foram visitadas aproximadamente 56 turmas de escolares, da $4^{\mathrm{a}}$ a $8^{\mathrm{a}}$ séries do ensino fundamental, além da $1^{\mathrm{a}}$ a $3^{\mathrm{a}}$ séries do ensino médio. A média de escolares por turma foi avaliada em 22 alunos, perfazendo uma estimativa de 1230 crianças e adolescentes que receberam informações sobre as avaliações e, portanto, foram convidados a participar do estudo. Deste total, aproximadamente 50\% interessaram-se em participar, recebendo, neste caso, um envelope contendo as cartas dirigidas aos pais ou responsáveis.

Dos interessados em participar, aproximadamente $65 \%$ devolveram o Termo de Consentimento assinado e apenas 276 avaliações completas foram realizadas. Isso porque ocorreram casos em que, apesar da devolução do Termo, o indivíduo não compareceu as avaliações no dia e horários agendados. A maior parte destes indivíduos foi contatada por telefone, entretanto, os motivos para as faltas não foram esclarecidos.

Apesar do oferecimento do transporte gratuito, a maior parte das crianças e adolescentes comparecerem ao dia agendado por condução própria (a pé, de bicicleta ou com os pais), mesmo aquelas mais novas (9 a 11 anos), indicando a disposição e facilidade em se deslocarem no município em direção às instalações da Unioeste.

A diferença de entre o número total de exames e a composição efetiva a amostra (28 indivíduos) deveu-se ao fato destes indivíduos estarem em idade superior ao determinado (acima de 16,501 anos), ou o seu baixo desempenho na corrida em esteira, nesses casos, o teste foi interrompido logo no início do teste, por receio de queda.

5.2 Características do crescimento físico e da composição corporal

5.2.1 Estatura e massa corporal

As características e o comportamento da estatura e massa corporal para os diferentes grupos etários e sexos são indicados nas FIGURAS 2 e 3 e os valores médios e desvios-padrão são apresentadas na TABELA 4. O comportamento da estatura apresentou-se 
crescente com o passar dos anos, para ambos os sexos. As moças apresentaram-se mais altas que os rapazes até os 13 anos, especialmente aos 12 e 13 de idade, em que as diferenças foram estatisticamente significantes. Ao contrário, a partir dos 14 anos de idade os rapazes apresentaram valores médios mais elevados que as moças, contudo, muito próximos entre si até os 16 anos, quando são estatisticamente mais elevados. Os ganhos em estatura dos 10 aos 16 anos foram bastante diferentes, sendo de aproximadamente 20,4\% (de 140,0 para 176,2 cm) e $14,8 \%$ (de 143,9 para $167,0 \mathrm{~cm}$ ) para rapazes e moças, respectivamente. A estatura das moças aos 10 anos representava $86 \%$ da estatura média entre elas aos 16 anos, enquanto que os rapazes apresentaram $79 \%$ no mesmo período etário.

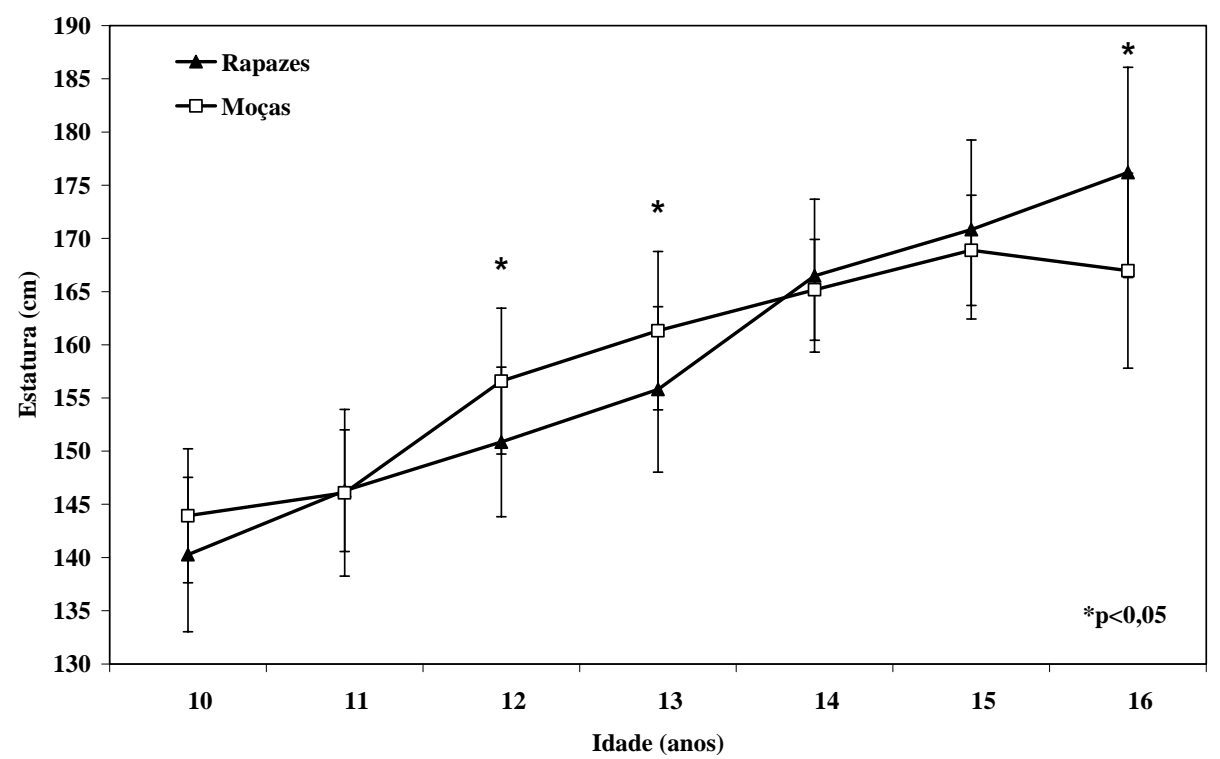

FIGURA 2 - Curvas de distância para os valores médios da estatura de crianças e adolescentes de ambos os sexos. 


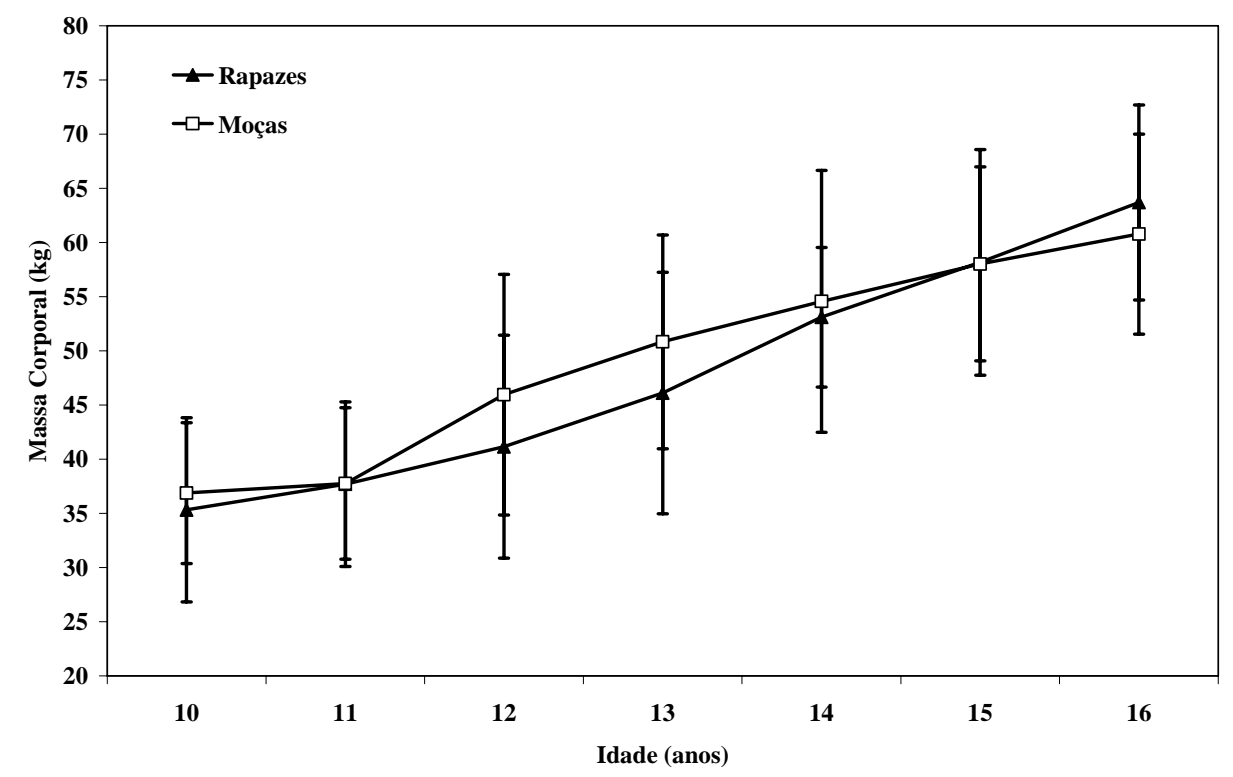

FIGURA 3 - Curvas de distância para os valores médios da estatura e massa corporal de crianças e adolescentes de ambos os sexos.

Uma característica importante do comportamento da estatura pode ser visto nos ganhos absolutos $(\mathrm{cm})$ por período etário estudado. Por exemplo, enquanto aos 10 e 11 anos as moças apresentaram uma estatura muito semelhante, com uma pequena diferença entre as médias $(2,2 \mathrm{~cm})$, aos 12 anos houve um aumento importante destas diferenças (cerca de 10 $\mathrm{cm}$ ), indicando a ocorrência de um possível salto pubertário em estatura, considerando que neste grupo etário, as moças alcançaram aproximadamente $94 \%$ que teriam aos 16 anos. A partir desta idade, os ganhos continuaram a existir, mas passaram a ser paulatinamente menores, variando de 4,7 cm aos 12-13 anos a 3,7 cm/ano aos 14-15 anos, quando as moças aparentemente atingiram a estatura adulta.

Já entre os rapazes, o comportamento foi um pouco diferente com relação aos ganhos observados entre as moças, pois o crescimento linear ocorreu por mais dois anos, entre os 10 e 13 anos, com uma diferença média nos ganhos absolutos neste período de 5,2 cm/ano. Aos 14 anos de idade ocorreu o maior ganho absoluto entre todas as diferenças das médias etárias, sendo de 10,7 cm (13-14 anos). Os ganhos absolutos também são muito semelhantes aos apresentados pelas moças aos 12 anos (11-12 anos), indicando também a ocorrência de um possível salto pubertário em estatura, considerando que, neste grupo etário, os rapazes alcançaram em torno de $94,5 \%$ da estatura final, sendo um percentual virtualmente igual ao 
das moças na idade dos 12 anos. Após os 14 anos, os ganhos médios na estatura continuaram elevados, sendo por volta de 5,0 cm/ano dos 15 aos 16 anos, demonstrando que um salto pubertário possivelmente mais longo que o observado entre as moças (TABELA 4).

TABELA 4 - Valores médios e desvios-padrão para a estatura $(\mathrm{cm})$ e massa corporal $(\mathrm{kg}) \mathrm{de}$ crianças e adolescentes de ambos os sexos.

\begin{tabular}{ccccc}
\hline & \multicolumn{2}{c}{ Estatura } & \multicolumn{2}{c}{ Massa Corporal } \\
\cline { 2 - 5 } Idade & Rapazes & Moças & Rapazes & Moças \\
\hline 10 & 140,3 & 143,9 & 35,3 & 36,9 \\
& $\pm 7,25$ & $\pm 6,30$ & $\pm 8,5$ & $\pm 6,5$ \\
11 & 146,3 & 146,1 & 37,7 & 37,8 \\
& $\pm 5,72$ & $\pm 7,83$ & $\pm 7,6$ & $\pm 7,0$ \\
12 & 150,9 & $156,6^{*}$ & 41,2 & 46,0 \\
& $\pm 7,03$ & $\pm 6,86$ & $\pm 10,3$ & $\pm 11,1$ \\
13 & 155,8 & $161,3 *$ & 46,1 & 50,8 \\
& $\pm 7,77$ & $\pm 7,44$ & $\pm 11,1$ & $\pm 9,9$ \\
14 & 166,5 & 165,2 & 53,1 & 54,6 \\
& $\pm 7,19$ & $\pm 4,74$ & $\pm 6,4$ & $\pm 12,1$ \\
15 & 170,8 & 168,9 & 58,2 & 58,0 \\
& $\pm 8,40$ & $\pm 5,18$ & $\pm 10,4$ & $\pm 9,0$ \\
16 & $176,2^{*}$ & 167,0 & 63,7 & 60,8 \\
& $\pm 9,88$ & $\pm 9,17$ & $\pm 9,0$ & $\pm 9,2$ \\
$10-16$ & 158,8 & 159,1 & 48,45 & 49,86 \\
& $\pm 14,6$ & $\pm 11,2$ & $\pm 13,50$ & $\pm 12,68$ \\
\hline (*p<0,05) & \multicolumn{3}{c}{}
\end{tabular}

No Paraná, em um estudo transversal envolvendo mais de 4.000 mil escolares de 7 a 17 anos, GUEDES e GUEDES (1997) dispuseram os índices de ganho anual de estatura e massa corporal de crianças e adolescentes londrinenses. No caso da estatura, os maiores ganhos foram observados dos 10-11 anos para as moças, com um incremento de 7,1 cm, e dos 13-14 anos para os rapazes, na ordem de 6,4 cm/ano. Ou seja, embora a diferença absoluta tenha sido maior entre as moças aos 12 anos, a duração foi menor em relação aos rapazes pois estes valores de ganho anual mantiveram-se muito próximos entre as idades de 12 a 15 anos. Em outro estudo, envolvendo mais de 1400 crianças e adolescentes mineiros, BÖHME (1995) observou que o maior ganho em estatura para as moças ocorreu aos 12 anos (11-12), sendo de aproximadamente 4,8 cm/ano e, para os rapazes, o maior ganho ocorreu aos 14 anos (13-14) 
com valor médio de 7,9 cm/ano, coincidindo o período etário para ambos os sexos com os resultados encontrados no presente estudo, mas com magnitude mais baixa.

Também buscando avaliar as diferenças entre as médias etárias na estatura, para avaliar o provável período de salto pubertário, GLANNER (2005) envolveu mais de 1400 escolares de 11 a 17 anos, do norte gaúcho e do oeste catarinense, considerando para tanto os dois grupos populacionais como um único. Isso deveu-se ao fato de haver entre esses grupos uma formação étnica, social e cultural muito semelhante entre si, ou seja, as duas regiões agregam crianças e adolescentes oriundos de imigrantes descendentes majoritariamente de alemães, italianos e poloneses, o que ocorre também com as crianças e adolescentes rondonenses que compõem este estudo. A autora observou que os maiores incrementos na estatura entre as meninas deram-se aos 13 anos (12-13 anos) e entre os meninos, aos 14 anos (13-14 anos), com diferenças entre 6,9 e 7,2 cm/ano para meninas e meninos, respectivamente. Buscando as diferenças no acréscimo da estatura de rapazes e moças, WALTRICK e DUARTE (2000) desenvolveram um estudo longitudinal-misto com 298 crianças e adolescentes de Florianópolis (SC), com idades variando de 7 a 17 anos. Os autores observaram que os maiores ganhos em estatura ocorreram aos 12 anos para as moças e aos 14 anos para os rapazes, com diferenças de 6,9 cm (11-12 anos) e de 7,9 cm (12-13 anos) respectivamente. Embora os autores tenham apresentado resultados transversais com mais de 850 crianças e adolescentes no mesmo período etário, pertencentes ao mesmo grupo escolar, os valores médios para estatura e massa corporal foram mais elevados que os do estudo longitudinal-misto. Esses achados parecem indicar uma incoerência nos resultados médios entre as duas abordagens, quando se utilizam o mesmo grupo populacional. Apesar disso, as maiores diferenças médias entre os grupos ocorreram no mesmo período etário nas duas abordagens, indicando que o comportamento das mudanças entre os sexos nos estudos transversais podem ser representativos das mudanças ocorridas no período etário analisado.

Com relação aos valores médios para a massa corporal, os resultados para ambos os sexos evidenciaram o mesmo comportamento observado para a estatura. As médias etárias mostraram que as moças são mais pesadas que os rapazes dos 10 aos 14 anos e somente a partir dos 15 anos, ocorre uma inversão, com os valores médios dos rapazes superando o das moças. Contudo, nenhuma diferença estatisticamente significante ocorreu entre os sexos para todos os grupos etários analisados, isso porque as moças continuaram a ganhar massa corporal aos 16 anos, demonstrando uma íntima relação com os ganhos na estatura, sendo os valores 
médios próximos aos dos rapazes. Esses resultados são semelhantes aos observados por HOBOLD (2003) com crianças e adolescentes rondonenses, mas são mais elevados que os observadas por ANJOS, CASTRO, ENGSTROM e AZEVEDO (2003), BÖHME (1995), GUEDES e GUEDES (1993, 1997), PIRES e LOPES (2004) e WALTRICK e DUARTE (2000), cujos estudos apontam que as diferenças entre os sexos passam a ocorrer, em sua maioria, já aos 15 anos, sempre em favor dos rapazes.

Os ganhos de massa corporal dos 10 aos 16 anos, para ambos os sexos, foram proporcionalmente mais elevados - cerca de duas vezes - que os ganhos relativos à estatura (44,6 e 39,3\% para rapazes e moças respectivamente), já que o principal salto nos valores médios entre os grupos etários mantiveram o mesmo comportamento. Ou seja, a massa corporal das moças ganhou o seu maior incremento em valores absolutos aos 12 anos $(8,2 \mathrm{~kg}$, 11-12 anos), enquanto a dos rapazes ocorreu aos 14 anos (7,0 kg, 13-14 anos), sendo o maior ganho das moças pode ser explicado pelo fato da média da massa corporal na idade dos 11 anos esteve efetivamente muito próxima aos 10 anos, o que possibilitou uma variação bem maior, contudo manteve-se acompanhando muito intimamente os resultados observados para a estatura.

No estudo com jovens londrinenses, GUEDES e GUEDES (1997) observaram também os maiores ganhos para as moças, na idade dos 11 anos (10-11 anos), sendo estes em torno de 5,5 kg/ano e, para os rapazes, na idade dos 14 anos (13-14 anos), em torno de 6 kg/ano. BÖHME (1995) igualmente assinala que os maiores ganhos ocorreram nas idades referidas para a estatura, apontando ainda que as diferenças na massa corporal somente passaram a ser significantes a partir dos 16 anos, em favor dos rapazes. Para os resultados de GLANNER (2005), os maiores ganhos na massa corporal também ocorreram nas idades de maior ganho em estatura, sendo de 5,7 e 7,2 kg/ano para moças e rapazes, respectivamente, bem próximos aos apontados por GUEDES e GUEDES (1997). No estudo de WALTRICK e DUARTE (2000), os ganhos médios para a massa corporal acompanharam os ganhos etários para a estatura entre as moças, com diferença de 6,1 kg também aos 12 anos e, entre os rapazes, com ganhos médios de 6,5 $\mathrm{kg}$ aos 14 anos (13-14 anos).

Embora os valores das diferenças médias para a estatura entre os grupos etários sejam diferentes entre si e também mais baixas com relação ao presente estudo, elas ocorrem em idades muito próximas, indicando que o salto pubertário em estatura de crianças brasileiras ocorre no mesmo período, o mesmo acontecendo com relação à massa corporal. Deve-se 
considerar, neste caso, que os maiores ganhos nas duas variáveis do presente estudo deveu-se ao número mais baixo de indivíduos por grupo etário, sendo o tamanho da amostra, portanto, muito mais sensível à amplitude da distribuição dos valores em torno da média.

Segundo TANNER (1962), o salto pubertário do crescimento na adolescência ocorre entre os 10,5 a 13 anos para as moças e entre os 12,5 e 15 anos para os rapazes. O pico do estirão em estatura comumente ocorre aos 12 e 14 anos, sendo os ganhos médios na ordem de 8 e $10 \mathrm{~cm} / a n o$, respectivamente para moças e rapazes. As moças tendem, neste caso, a alcançarem seus picos de velocidade do crescimento em média dois anos antes dos rapazes, com uma mesma intensidade, porém com valores absolutos levemente abaixo deles. Contudo, segundo o mesmo autor, os ganhos na massa corporal estão na ordem 7 a $30 \mathrm{~kg} / \mathrm{ano}$, para ambos os sexos, mas ocorrem por volta de seis meses depois de terem alcançado o estirão na estatura. Esses dados corroboram com a idéia do salto pubertário ter ocorrido nesses dois períodos etários, entre as moças e rapazes rondonenses respectivamente

Os resultados da estatura e massa corporal dos rapazes e moças rondonenses demonstraram ter uma tendência semelhante em relação àqueles observados pelos autores, em outros estudos com amostras brasileiras, para todas as idades (ANJOS et al., 2003; BÖHME, 1995; GUEDES e GUEDES, 1993, 1997; GLANER, 2005; HOBOLD, 2003; MADUREIRA e SOBRAL, 1999; MARCONDES, 1989; PIRES e LOPES, 2004; POF/IBGE, 2003; WALTRICK e DUARTE, 2000), mesmo considerando a grande diferença no tamanho da amostra com relação à do presente estudo. Essa diferença no tamanho da amostra pode ter refletido nos valores das médias ligeiramente mais elevadas dos rapazes e moças, em quase todos os grupos etários, inclusive quando foram consideradas as medianas referentes à população estadunidense (HAMILL et al., 1979).

Três estudos relevantes envolvendo crianças e adolescentes paranaenses são o de GUEDES e GUEDES (1995), com uma amostra de 2189 rapazes e 2103 moças de Londrina; HOBOLD (2003), que investigou crianças e adolescentes rondonenses, com uma amostra de 1191 rapazes e 1146 moças - ambos os estudos envolvendo jovens em idade escolar (7 a 17 anos) -, e o estudo brasileiro denominado "Antropometria e análise do estado nutricional de crianças e adolescentes no Brasil” - Pesquisa de Orçamentos Familiares - com uma amostra envolvendo mais de 2600 crianças e adolescentes (1364 rapazes e 1300 moças) paranaenses, com idades entre 1 e 19 anos (IBGE, 2003). Embora o tamanho das amostras destes estudos tenham uma elevada representatividade da população de origem, os valores médios do 
presente estudo demonstraram uma tendência próxima quando observadas a estatura e a massa corporal ao longo dos anos.

TABELA 5 - $\underline{\text { Coeficientes de correlação entre as variáveis morfológicas e a idade milesimal }}$ de crianças e adolescentes de ambos os sexos.

\begin{tabular}{lrlrrrrrrr}
\hline & \multicolumn{3}{c}{ Rapazes } & \multicolumn{3}{c}{ Moças } & \multicolumn{3}{c}{ Ambos os Sexos } \\
\cline { 2 - 10 } Variáveis & Idade & MC & Est. & Idade & MC & Est. & Idade & MC & Est. \\
\hline Massa Corporal (MC) & $\mathbf{0 , 7 4}$ & & & $\mathbf{0 , 6 7}$ & & & $\mathbf{0 , 7 0}$ & & \\
Estatura (Est.) & $\mathbf{0 , 8 5}$ & $\mathbf{0 , 8 9}$ & & $\mathbf{0 , 7 5}$ & $\mathbf{0 , 7 8}$ & & $\mathbf{0 , 8 0}$ & $\mathbf{0 , 8 4}$ & \\
Gordura Relativa & $\mathbf{0 , 3 3}$ & 0,17 & $-0,15$ & $\mathbf{0 , 1 8}$ & $\mathbf{0 , 6 6}$ & $\mathbf{0 , 2 6}$ & $-0,06$ & $\mathbf{0 , 3 7}$ & 0,03 \\
Massa Magra & $\mathbf{0 , 7 9}$ & $\mathbf{0 , 9 5}$ & $\mathbf{0 , 9 0}$ & $\mathbf{0 , 7 2}$ & $\mathbf{0 , 9 2}$ & $\mathbf{0 , 8 1}$ & $\mathbf{0 , 7 5}$ & $\mathbf{0 , 9 2}$ & $\mathbf{0 , 8 6}$ \\
\hline
\end{tabular}

(valores em negrito são significantes, $\mathrm{p}<0,05$ )

Por outro lado, uma maior preocupação sobre a qualidade das informações está na importante relação entre a estatura e massa corporal, considerando os grupos tanto separadamente quanto simultaneamente. Segundo MALINA et al. (2004), a relação de ambas as medidas nos dois gêneros, deve ser sempre elevada. Os resultados do presente estudo, de fato, apresentaram-se moderados ou elevados, situando o mais baixo entre a estatura e a idade para as moças $(r=0,75)$ e o mais elevado entre a estatura e a massa corporal para os rapazes $(\mathrm{r}=0,89)$, e os demais coeficientes em níveis intermediários, para ambos os sexos (TABELA $5)$.

5.2.2 Gordura corporal absoluta $\left(\sum \mathrm{DC}\right)$ e relativa $(\% \mathrm{G})$, massa corporal magra $(\mathrm{MCM})$

Os dados concernentes ao comportamento da gordura corporal absoluta ( $\left.\sum \mathrm{DC}\right)$, gordura corporal relativa $(\% \mathrm{G})$ e da MCM estão apresentados na TABELA 6. Os valores médios da somatória das dobras cutâneas apresentam-se mais elevados nas moças para todas as idades que os rapazes. Contudo, dos 10 aos 12 anos as moças apresentaram valores médios muito semelhantes entre si. A partir dos 13 anos, os valores médios dos rapazes iniciam uma queda até os 16 , apresentando uma redução por volta de $27 \%$ para os valores absolutos (de 18,5 para $14,5 \mathrm{~mm}$ ), enquanto as moças começaram a aumentar os mesmos valores dos 14 aos 16 anos (de 22,5 para 26,1 mm), num aumento de mais de $13 \%$. 
TABELA 6 - Valores médios e desvios-padrão para a somatória de dobras (mm), gordura corporal relativa $(\%)$ e massa corporal magra $(\mathrm{kg})$ de crianças e adolescentes de ambos os sexos.

\begin{tabular}{ccccccc}
\hline & \multicolumn{2}{c}{$\begin{array}{c}\text { Somatório } \\
\text { de dobras }\end{array}$} & \multicolumn{2}{c}{$\begin{array}{c}\text { Gordura } \\
\text { Relativa }\end{array}$} & \multicolumn{2}{c}{$\begin{array}{c}\text { Massa } \\
\text { Magra }\end{array}$} \\
\cline { 2 - 7 } Idade & Rapazes & Mocas & Rapazes & Mocas & Rapazes & Mocas \\
\hline $\mathbf{1 0}$ & 18,5 & 21,6 & 16,2 & 19,4 & 29,0 & 28,7 \\
& $\pm 7,7$ & $\pm 6,6$ & $\pm 6,5$ & $\pm 5,3$ & $\pm 5,1$ & $\pm 4,2$ \\
$\mathbf{1 1}$ & 18,5 & 21,2 & 16,3 & 18,5 & 31,1 & 29,9 \\
& $\pm 9,3$ & $\pm 8,0$ & $\pm 6,6$ & $\pm 5,5$ & $\pm 4,4$ & $\pm 4,4$ \\
$\mathbf{1 2}$ & 18,5 & 22,5 & 15,7 & 19,2 & 34,3 & 36,0 \\
& $\pm 10,5$ & $\pm 11,6$ & $\pm 7,3$ & $\pm 6,9$ & $\pm 5,8$ & $\pm 5,4$ \\
$\mathbf{1 3}$ & 16,4 & $22,5^{*}$ & 15,8 & $20,1^{*}$ & 39,4 & 39,8 \\
& $\pm 5,2$ & $\pm 9,4$ & $\pm 4,9$ & $\pm 6,1$ & $\pm 8,9$ & $\pm 5,1$ \\
$\mathbf{1 4}$ & 15,5 & 27,0 & 13,8 & $22,0^{*}$ & $45,9^{*}$ & 41,7 \\
& $\pm 5,7$ & $\pm 12,1^{*}$ & $\pm 4,4$ & $\pm 5,2$ & $\pm 4,9$ & $\pm 6,4$ \\
$\mathbf{1 5}$ & 15,1 & 27,0 & 13,8 & $23,1^{*}$ & $50,8^{*}$ & 44,2 \\
& $\pm 4,7$ & $\pm 9,3^{*}$ & $\pm 4,9$ & $\pm 5,6$ & $\pm 7,1$ & $\pm 5,1$ \\
$\mathbf{1 6}$ & 14,5 & 26,1 & 13,3 & $23,1^{*}$ & $56,2^{*}$ & 46,8 \\
& $\pm 2,2$ & $\pm 7,3^{*}$ & $\pm 2,8$ & $\pm 4,9$ & $\pm 7,0$ & $\pm 5,5$ \\
$\mathbf{1 0} \mathbf{1 6}$ & 16,6 & $24,1^{*}$ & 14,9 & $20,8^{*}$ & 41,0 & 38,9 \\
& $\pm 6,9$ & $\pm 9,6$ & $\pm 5,5$ & $\pm 5,8$ & $\pm 11,1$ & $\pm 7,9$ \\
\hline (*0 $<0,05)$ & & & & & &
\end{tabular}

Enquanto a diferença relativa entre os sexos estava na ordem dos $14 \%$ aos 10 anos, a partir dos 13 anos estas aumentaram progressivamente para 44\%, até os 16 anos. Nesse sentido, as diferenças estatisticamente significantes entre rapazes e moças iniciaram a partir dos 13 até os 16 anos, provocadas em primeiro lugar pela redução nos valores absolutos de gordura corporal dos rapazes aos 13 anos e, em segundo lugar, pela elevação desses mesmos valores nas moças, a partir dos 14, diferenças estas se mantiveram até os 16 anos. Segundo LOHMAN (1987), as moças carregam mais gordura do que os rapazes em todas as idades, contudo, antes do início do salto pubertário as diferenças entre os sexos somente são significantes a partir deste período da vida.

Muitos estudos adotaram essas medidas como referenciais na população em idade escolar, pois conjuntamente explicam as mudanças na quantidade de gordura corporal entre eles. No Brasil, por exemplo, alguns estudos transversais procuraram descrever o comportamento da gordura corporal absoluta de crianças e adolescentes, nas idades de 7 a 17 anos, utilizando-se das dobras de tríceps e subescapular isoladamente, além de algumas outras 
dobras (BÖHME, 1996; FRANÇA, MATSUDO e SESSA, 1988; GUEDES e GUEDES, 1995; WALTRICK e DUARTE, 2000). Embora os resultados apresentados para cada uma das dobras cutâneas do tríceps e subescapular sejam diferentes, como no presente estudo, o comportamento entre elas com relação ao sexo e idade são muito semelhantes entre si. $\mathrm{Ou}$ seja, as variações médias observadas para cada grupo etário e sexo são reflexo das particularidades socioculturais de cada grupo populacional de que eles são provnientes. Porém, em todos eles, a variação e participação da dobra cutânea tricipital é maior do que a subescapular para todas as idades e sexo, e os valores médios delas são sempre mais elevadas que nas as moças.

No exterior, LOHMAN, BOILEAU e SLAUGHTER (1984) descreveram os resultados da adiposidade corporal total mediante o somatório dessas duas dobras cutâneas para crianças e adolescentes estadunidenses com idades de 6 a 17 anos. Em outro estudo, que envolveu crianças e adolescentes dos 10 aos 18 anos (NCYFS - National Children and Youth Fitness Study), os resultados médios para somatórias das dobras cutâneas nos mesmos grupos etários apareceram mais elevados que os do estudo anterior, principalmente entre os rapazes, com média de $2 \mathrm{~mm}$ a mais na espessura da dobra subcutânea para todas as idades (ROSS, DOTSON, GILBERT e KATZ, 1985). Em ambos os estudos o comportamento da gordura corporal está apresentado em valores medianos, contudo o comportamento das diferenças intra e interssexos mantiveram-se as mesmas. Não obstante, com o passar dos anos, houve uma mudança no comportamento da gordura corporal entre os sexos, pois esta se situava na ordem de 4 a $5 \mathrm{~mm}$ dos 6 aos 13 anos, passando para aproximadamente $10 \mathrm{~mm}$ a partir dos 14 anos de idade, com uma diferença da ordem de $40 \%$ em ambos os estudos. Estes valores demonstraram uma mudança no comportamento intra e interssexo muito próxima à do presente estudo, no qual as diferenças foram da ordem de $3 \mathrm{~mm}$ aos 12 anos, passando a mais de $12 \mathrm{~mm}$ aos 14 anos.

Outro aspecto é que as diferenças entre os sexos para as duas dobras cutâneas passam a ocorrer, frequentemente aos 14 anos de idade. Há um aumento acentuado na deposição de gordura na região tricipital entre as moças, iniciada aos 12 anos e diminuição entre os rapazes, iniciada aos 13 ou 14 anos de idade, com aumentos discretos na deposição de gordura corporal na região subescapular para ambos os sexos.

Por outro lado, a gordura relativa $(\% \mathrm{G})$ apresentou um comportamento muito semelhante ao demonstrado pelos valores absolutos (FIGURA 4), também apresentando um 
pequeno salto para as moças aos 14 anos, enquanto que no mesmo período houve uma queda nos valores médios entre os rapazes. Entre as moças, os valores médios se mantiveram na faixa de 19\% para as idades de 10 a 13 anos, já os rapazes mantiveram-se em uma mesma tendência dos 10 aos 12 anos, porém com valores médios na ordem de $16 \%$. A partir dos 14 anos para as moças, a gordura corporal relativa manteve-se na faixa dos $22,5 \%$, enquanto que os valores médios para os rapazes, os valores médios diminuíram em 2 pontos percentuais aos 14 anos, até alcançar o valor médio mais baixo aos 16 anos (13,3\%). Aos 16 anos de idade, as moças possuíam, proporcionalmente, e $70 \%$ mais de gordura corporal que os rapazes $(23,1$ contra 13,3\%).

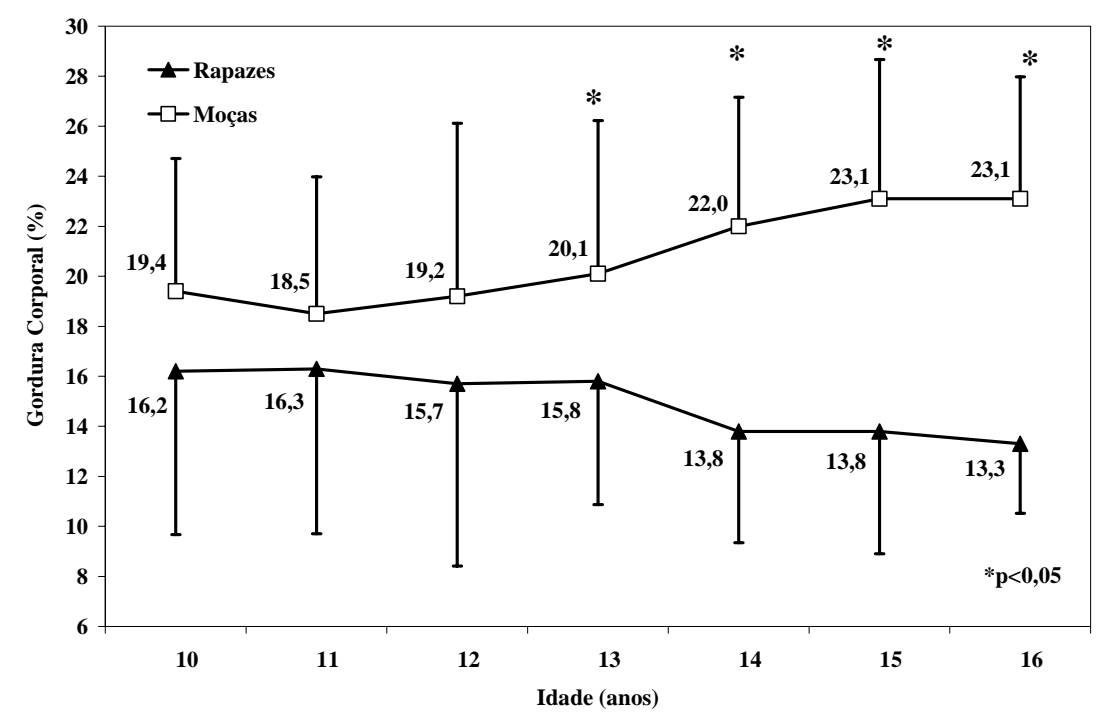

FIGURA 4 - Curvas de distância dos valores médios e desvios-padrão da gordura corporal relativa $(\% \mathrm{G})$ de crianças e adolescentes de ambos os sexos.

No caso do comportamento da gordura corporal relativa, pode-se perceber que as moças apresentaram valores médios estatisticamente mais elevados que os rapazes a partir dos 13 anos de idade. Os resultados semelhantes entre os sexos, nos níveis de gordura corporal nas idades mais precoces, e essas diferenças entre os sexos nos resultados dos valores percentuais são esperadas inclusive nas idades mais precoces, dos 6 aos 9 anos, porém com diferenças em pontos percentuais menos expressivas (LOHMAN, 1987). 
De maneira geral, pode-se observar que tanto as moças quanto os rapazes apresentaram valores médios de gordura corporal relativa dentro da faixa recomendada como saudável. Algumas faixas de valores percentuais da gordura corporal, que são consideradas adequadas para o sexo e idade, são apresentadas por LOHMAN (1987). Para este autor, meninos e meninas no período pré-pubertário, com idades entre seis e oito anos, deverão ter entre 13 a $15 \%$ e 16 a $18 \%$ de gordura corporal, respectivamente; no período da póspubescência (dos 14 aos 17 anos), rapazes e moças deveriam ter entre 10 a $12 \%$ e 21 a $23 \%$ de gordura corporal, respectivamente. Nesse sentido, tendo em vista que valores intermediários sejam considerados normais para o período pubertário, ou seja, nas idades de 9 a 13 anos, a faixa de 14 a $16 \%$ e 17 a 19\% de gordura para rapazes e moças deveria ser razoável. Essas faixas de valores consideradas recomendáveis para sexo e período do crescimento e desenvolvimento colocam as crianças e adolescentes do presente estudo dentro da média, ou seja essas crianças atingiram níveis muito adequados ou, segundo o mesmo autor, ótimos de gordura corporal.

Os estudos brasileiros descreveram o comportamento dos valores de percentual de gordura corporal para crianças e adolescentes ao longo dos anos, baseados em valores de espessuras das dobras cutâneas de tríceps e subescapular. Todos os estudos foram de características transversais, porém os valores percentuais foram determinados por diferentes modelos matemáticos (HOBOLD, 2003; GUEDES e GUEDES, 1995; MADUREIRA e SOBRAL, 1999; WALTRIC e DUARTE, 2000).

Outros estudos utilizaram-se de diferentes modelos matemáticos na determinação da gordura corporal de crianças ou adolescentes brasileiros, porém com grupos etários muito específicos ou são classificados por grupos maturacionais e não por idade, o que dificulta um entendimento acerca do comportamento esperado normal para essa população específica. Considerando apenas o comportamento da gordura corporal para cada grupo etário e sexo, GUEDES e GUEDES (1995) observaram que os valores de percentual de gordura corporal de rapazes e moças elevam-se com o passar dos anos. Contudo, nas idades mais precoces, tanto rapazes quanto moças apresentaram valores médios muito próximos entre si até por volta dos 11 anos, quando as tendências assumem caminhos opostos; as moças aumentando os seus valores médios até os 15 anos, e os rapazes diminuindo paulatinamente até os 16 anos, quando aparentemente ocorre uma estabilização ou até aumento nos valores na idade de 17 anos. 
MADUREIRA e SOBRAL (1999) e HOBOLD (2003) observaram comportamentos semelhantes dos 7 aos 17 anos, no qual ocorreram aumentos progressivos na quantidade de gordura corporal em ambos os sexos até os 11 ou 12 anos, quando as moças passaram a acumular uma maior quantidade de gordura corporal em relação aos rapazes já a partir dos 12 anos (MADUREIRA e SOBRAL, 1999) e dos 14 anos (HOBOLD, 2003), uma vez que por volta dos 13 anos nos rapazes de ambos os estudos, os valores médios mostraramse mais baixos com o passar dos anos. Porém, em ambos os estudos os autores observaram diferenças estatisticamente significantes em ambos os sexos para todas as idades, o que são resultados pouco comuns quando se observam outros estudos na literatura (MALINA et al., 2004).

Por outro lado, WALTRICK e DUARTE (2000), estudaram crianças e adolescentes de Florianópolis - SC, em duas formas de estudo: um longitudinal-misto e outro transversal. Com efeito, aos observarmos o comportamento dos valores medianos do estudo transversal (envolvendo 875 escolares de ambos os sexos), para cada sexo e idade, é possível perceber que ocorre um aumento desses valores para ambos os sexos, sendo estes maiores em todas as idades para as moças. Entre elas, um aumento acentuado ocorre precocemente nas idades de 8 para 9 anos, e mantém-se no mesmo patamar (entre 24,5 a 25,5\% de gordura) até os 17 anos; nos rapazes também ocorreu um aumento mais acentuado dos 11 para os 12 anos, quando a partir deste grupo etário, começaram a diminuir paulatinamente até os 16 anos, demonstrando apenas um leve aumento nos valores medianos aos 17 anos, conforme também foi observado por GUEDES e GUEDES (1995).

Em alguns estudos internacionais, os resultados do desenvolvimento da gordura corporal entre crianças e adolescentes obedecem, de forma geral, o mesmo comportamento observado no presente estudo. Um dos estudos mais importantes é apresentado por LOHMAN (1986), que oferece alguns resultados do NCHD (National Center of Health Statistics) dos Estados Unidos da América, publicado nos anos de 1972 e 1974 para dobras cutâneas de crianças e jovens, e os valores de percentual de gordura determinados pelo modelo de BOILEAU, LOHMAN e SLAUGHTER (1985). Segundo os resultados apresentados neste estudo, os rapazes e moças aumentam os seus valores de percentual de gordura, na mesma proporção dos aumentos dos valores das espessuras das dobras cutâneas de tríceps e subescapular. Os valores médios calculados para esse grupo à época do estudo demonstraram que aos 6 anos os meninos apresentavam em média $11 \%$ de gordura, enquanto que nas 
meninas esses valores estavam na ordem de $15 \%$. O incremento do nível de gordura corporal dos 6 aos 11 anos para os rapazes foi na ordem de 0,6 pontos percentuais, enquanto que entre as moças o aumento ocorreu até os 17 anos, na proporção média de 1 ponto percentual. Entre os rapazes, a partir dos 12 anos de idade, os valores médios diminuem paulatinamente até alcançar novamente os $11 \%$ de gordura observados na idade dos 6 anos.

Em um estudo mais recente, também em população estadunidense, National Children and Youth Fitness Study (NCYFS), de 1985, os autores publicaram os valores médios da somatória das dobras cutâneas de tríceps e subescapular (ROSS e GILBERT, 1985) para uma amostra populacional envolvendo mais de 8000 rapazes e moças de 10 a 18 anos, mas os valores em percentual de gordura também foram publicados por LOHMAN (1986), utilizando para tanto o mesmo modelo matemático proposto por BOILEAU et al. (1985). Os resultados observados demonstraram que os níveis de gordura corporal haviam aumentado em 1 ponto percentual para cada grupo etário de ambos os sexos, considerados a partir dos 10 anos de idade.

Embora o aumento da gordura corporal tenha mudado para níveis mais elevados, em menos de duas décadas em ambos os estudos, e gerado outras implicações acerca daquela população, os resultados apenas demonstram que mesmo com um aumento dos níveis de gordura, independentemente do sexo, eles mantiveram a mesma tendência nas diferenças etárias e sexuais, como podemos observar em estudos mais recentes (GUO, CHUMLEA, ROCHE e SIERVOGEL, 1997; MUELLER, HARRIST, DOYLE e LABARTHE, 2004; McCARTHY, COLE, FRY, JEBB e PRENTICE, 2006), a despeito de estes terem utilizado procedimentos de análise da composição corporal distinto dos anteriores, como por exemplo na utilização da impedância bioelétrica (BIO).

Um estudo longitudinal-misto, denominado Project HeartBeat!, envolveu 678 crianças e adolescentes estadunidense de ambos os sexos, separados em grupos por diferentes cores de pele (clara e escura), utilizando-se da BIO para determinar o percentual de gordura corporal em valores medianos (P50). O estudo envolveu três grupos de corte, um grupo iniciado aos 8 anos, outro aos 11 anos e o último aos 14 anos, acompanhados durante quatro anos por inúmeras medidas epidemiológicas obtidas a cada quatro meses. Desconsiderando os indivíduos de pele negra (por apresentarem maiores erros-padrão dos percentis), os resultados para os indivíduos de pele clara demonstraram um comportamento semelhante aos demais estudos publicados na literatura. Ou seja, as moças apresentaram medianas mais elevadas que 
os rapazes para todas as idades, o aumento do percentual de gordura corporal entre elas foi baixo, mas linear dos 8,5 aos 17,5 anos, enquanto que entre eles houve um aumento até os 11,5 anos e em seguida uma queda, porém pequena, até os 17,5 anos. Os valores medianos das moças ficaram em torno de $24 \%$ dos 8,5 aos 17,5 anos, enquanto que entre os rapazes esses valores contornaram os $17 \%$ no mesmo período.

Um estudo transversal recente apresentou valores medianos de 1985 crianças e adolescentes ingleses com idades entre 5 e 18 anos, de ambos os sexos, a partir das medidas de BIO (McCARTHY et al., 2006). Os valores medianos dos ingleses de ambos os sexos foram mais baixos que os observados em população estadunidense, contudo apresentaram o mesmo comportamento geral. O comportamento da gordura corporal foi similar em ambos os sexos até os 10 anos de idade, mas sempre com vantagem para as moças. A partir dessa faixa etária, as curvas assumem tendências distintas, em que as moças passam a ganhar mais gordura corporal relativa até os 18 anos, enquanto que os rapazes diminuem esses valores na mesma proporção até os 18 anos de idade e, segundo os autores, a diferença entre os sexos passa a ser de $60 \%$ a mais de gordura para as moças $(24,6$ contra $15,4 \%)$, diferença menor que a verificada no presente estudo.

Um dos estudos recentes mais importantes foi publicado por GUO et al. (1997), apresentando resultados longitudinais sobre o desenvolvimento da gordura corporal relacionada ao sexo, à idade e à maturação de crianças e adolescentes. A amostra envolveu 130 rapazes e 114 moças, com idades de 8 anos que foram avaliados a cada 2 anos, durante 12 anos consecutivos (dos 8 aos 20 anos). Os resultados de massa corporal gorda, massa corporal magra e percentual de gordura foram determinados por pesagem hidrostática (densitometria), além das medidas maturacionais mediante a idade esquelética. Os principais resultados demonstraram que para todas as idades as moças acumulam mais gordura que os rapazes, e que os valores aumentam com o passar dos anos para ambos os sexos em maior proporção entre elas. A média do percentual de gordura entre elas aumentou de 20 para $26 \%$ dos 8 aos 20 anos, enquanto entre eles aumentou de 14,8 para 17,6\% dos 8 aos 14 anos e depois diminuiu para 13\% aos 18 anos de idade. A partir dos 13 anos de idade, as diferenças na quantidade de gordura corporal entre os sexos tornam-se mais amplas, e estas são atribuídas a uma maior produção de estrogênio entre elas, enquanto no mesmo período ocorre uma maior produção de testosterona entre eles. Os autores ainda avaliaram a velocidade do ganho em gordura para moças e rapazes e demonstraram que entre elas a velocidade nos ganhos diminui com o passar 
dos anos enquanto que entre os eles a velocidade chegou a zero aos 12 anos, tornando-se negativa até os 18 anos para depois elvar-se em torno dos 20 anos. As moças apresentam aos 18 anos proporcionalmente quase o dobro (90\%) da quantidade de gordura corporal observada entre os rapazes $(15,2$ para $8,0 \mathrm{Kg})$, no mesmo período etário.

O comportamento da massa corporal magra (MCM) para ambos os grupos analisados foi linear com relação à idade, apresentado coeficientes de correlação na ordem de 0,75. Ao eliminarmos o fator gordura corporal, os valores médios apresentaram o mesmo comportamento já descrito tanto para a estatura quanto $(\mathrm{r}=0,86)$ para massa corporal $(\mathrm{r}=$ 0,92). Ou seja, apesar dos valores médios sejerem similares ao longo de todos os grupos etários de ambos os sexos, as moças apresentaram médias ligeiramente mais elevadas aos 10 , 12 e 13 anos, apresentando a mesma tendência observada tanto para a estatura quanto para massa corporal no mesmo período etário. Por outro lado, os rapazes apresentaram valores médios mais elevados nas demais idades, obtendo uma vantagem um pouco maior para a MCM já aos 14 anos, e sendo estatisticamente diferente a partir dos 14 anos.

Com relação aos ganhos relativos à MCM dos 10 aos 16 anos, para os rapazes o incremento se aproximou de $94 \%$ (de 29,0 a 56,2 $\mathrm{kg}$ ), enquanto para as moças os ganhos foram ligeiramente mais baixos, por volta de $57 \%$ (de 29,5 a 46,4 kg). Os maiores ganhos em valores absolutos intrassexo ocorreram aos 12 anos para as moças $(6,0 \mathrm{~kg} / \mathrm{ano})$ e aos 14 anos para os rapazes $(6,5 \mathrm{~kg} / \mathrm{ano})$, indicando que esses ganhos refletem os observados para a estatura e massa corporal de ambos os sexos, respectivamente. A MCM dos rapazes foi maior que das moças em apenas $10 \%$ aos 14 anos, mas aumentou em $15 \%$ aos 15 e 20\% aos 16 anos de idade.

No Brasil, GUEDES e GUEDES (1995) observaram que os ganhos da MCM ocorrem similarmente em ambos os sexos dos sete aos 14 anos, com vantagem sempre dos rapazes. Contudo os comportamentos em ambos os sexos apresentam-se um pouco diferentes. Por exemplo, entre as moças o aumento ocorreu linearmente dos sete aos 10 anos, enquanto que entre os rapazes foi até praticamente os 12 anos, quando as moças parecem acelerar seus ganhos de MCM até os 14 anos e estabilizam nessa idade, e os rapazes continuam a ganhar MCM até os 17 anos de idade. Finalmente, as diferenças entre os sexos na MCM somente foram observadas a partir dos 15 anos de idade.

Já no estudo de HOBOLD (2003), com crianças e adolescentes rondoneneses, a MCM também apresentou um comportamento linear com o passar dos anos, sempre em favor 
dos rapazes. Contudo, as diferenças entre os sexos ocorreram em idades muito precoces, sendo dos oito aos 10 anos, e mais adiante dos 15 aos 17 anos. Esses resultados ocorreram nas idades mais precoces provavelmente pelo modelo matemático adotado na determinação do percentual de gordura corporal, já que o autor utilizou-se de constantes interpoladas as de LOHMAN, produzidas por PIRES NETO e PETROSKI (1996). Nesse sentido, parece que valores de percentual de gordura muito baixos são artificialmente obtidos entre os rapazes com relação às moças pela utilização destas constantes, gerando, neste caso, valores de MCM mais elevados estatisticamente entre eles, em idades mais novas que aquelas observados na literatura.

No estudo Project HeartBeat!, a MCM também foi apresentada em valores medianos, para ambos os sexos. Os resultados demonstraram que os rapazes têm MCM mais elevada que as moças para todas as idades e que as diferenças entre os sexos podem ser de $8 \%$ aos 8 anos, chegando até $25 \%$ aos 17 anos entre os valores medianos. A MCM dos rapazes é proporcionalmente maior que a das moças em $34 \%(58,24$ contra $43,42 \mathrm{~kg})$. Os ganhos percentuais dos rapazes dos 10 aos 16 anos foram de 50\%, enquanto para as moças, no mesmo período, foi de $36 \%$. Os autores não avaliaram as diferenças entre os sexos nos diferentes grupos etários, contudo é possível notar que os valores medianos se assemelham dos 8 até aos 13 e 14 anos, quando os rapazes passam a alcançar valores medianos mais elevados que as moças até os 17 anos de idade.

Segundo GUO et al. (1997), as médias para a MCM, a estatura e a MC das crianças e adolescentes do estudo longitudinal de FELS são semelhantes entre os sexos até os 14 anos, ou seja, a partir dos 15 anos de idade os rapazes apresentaram a MCM estatisticamente maior que as moças. Assim, os ganhos absolutos em MCM foram semelhantes em ambos os sexos, com ganhos de $10 \mathrm{~kg}$ dos 8 aos 14 anos. Entretanto, após esse período etário, as moças acrescentaram apenas $9 \mathrm{~kg}$ até os 20 anos, enquanto que os rapazes ganharam em média $25 \mathrm{~kg}$ no mesmo período, refletindo os mesmos ganhos em estatura e massa corporal. 
5.3 Características do teste de esforço e dos parâmetros ventilatórios

5.3.1 Tempo de corrida (TC), freqüência cardíaca (FC) e quociente respiratório (QR)

As condições do ambiente laboratorial são de extrema importância quando se avalia a potência aeróbia considerando os parâmetros ventilatórios mensurados através de um analisador metabólico de gazes por meio de circuito aberto. No caso do analisador metabólico de gazes $\mathrm{VO}_{2000}{ }^{\circledR}$, todas as medidas ventilatórias foram obtidas por meio de parâmetros padronizados de temperatura e pressão, com ar seco (STDP), que são mais confiáveis quando a umidade relativa do ar e a temperatura ambiente estão em níveis adequados durante a realização do teste. Os valores médios da umidade relativa do ar e da temperatura estão apresentadas na Tabela 7

TABELA 7 - Valores médios e desvios-padrão da umidade relativa do ar (\%) e da temperatura do laboratório $\left({ }^{\circ} \mathrm{C}\right)$ durante o teste cardiopulmonar de esforço de crianças e adolescentes de ambos os sexos.

\begin{tabular}{ccccc}
\hline \multirow{2}{*}{ Idade } & \multicolumn{2}{c}{ Umidade } & \multicolumn{2}{c}{ Temperatura } \\
\cline { 2 - 5 } & Rapazes & Moças & Rapazes & Moças \\
\hline \multirow{4}{*}{10} & 53,2 & 52,6 & 22,3 & 22,6 \\
& $\pm 6,55$ & $\pm 5,03$ & $\pm 1,32$ & $\pm 1,07$ \\
& 54,6 & 56,1 & 22,2 & 22,5 \\
& $\pm 7,39$ & $\pm 5,83$ & $\pm 1,65$ & $\pm 1,37$ \\
12 & 55,1 & 56,7 & 22,1 & 22,4 \\
& $\pm 5,74$ & $\pm 5,77$ & $\pm 1,23$ & $\pm 1,59$ \\
13 & 52,3 & 52,7 & 22,1 & 22,3 \\
& $\pm 5,91$ & $\pm 6,88$ & $\pm 1,30$ & $\pm 1,52$ \\
14 & 53,6 & 52,1 & 22,3 & 22,2 \\
& $\pm 6,16$ & $\pm 6,32$ & $\pm 1,31$ & $\pm 1,75$ \\
15 & 50,2 & 50,9 & 22,0 & 22,8 \\
& $\pm 6,01$ & $\pm 5,90$ & $\pm 1,19$ & $\pm 1,27$ \\
16 & 51,9 & 51,9 & 22,6 & 22,7 \\
& $\pm 6,54$ & $\pm 7,34$ & $\pm 1,21$ & $\pm 0,99$ \\
$10-16$ & 52,9 & 53,3 & 23,3 & 22,5 \\
& $\pm 6,39$ & $\pm 6,43$ & $\pm 1,30$ & $\pm 1,40$ \\
\hline
\end{tabular}


O comportamento do TC para o teste cardiopulmonar de esforço em esteira para ambos os sexos, ao longo dos anos, está representado da FIGURA 5. Tanto os rapazes quanto as moças apresentaram resultados médios mais elevados com o passar dos anos. O TC dos rapazes foi estatisticamente maior que o das moças para todos os grupos etários analisados. Os rapazes aumentaram o tempo médio de corrida dos 10 aos 16 anos em 36\% (de 7,5 para 11,8 min), sendo mais discreto no mesmo período para moças, apenas $27 \%$ (de 5,5 para $7,5 \mathrm{~min}$ ). $\mathrm{O}$ tempo médio dos rapazes foi de 57 a $60 \%$ maior que o das moças entre os 15 e 16 anos, enquanto que aos 10 anos de idade as diferenças entre os sexos não ultrapassava os $38 \%$.

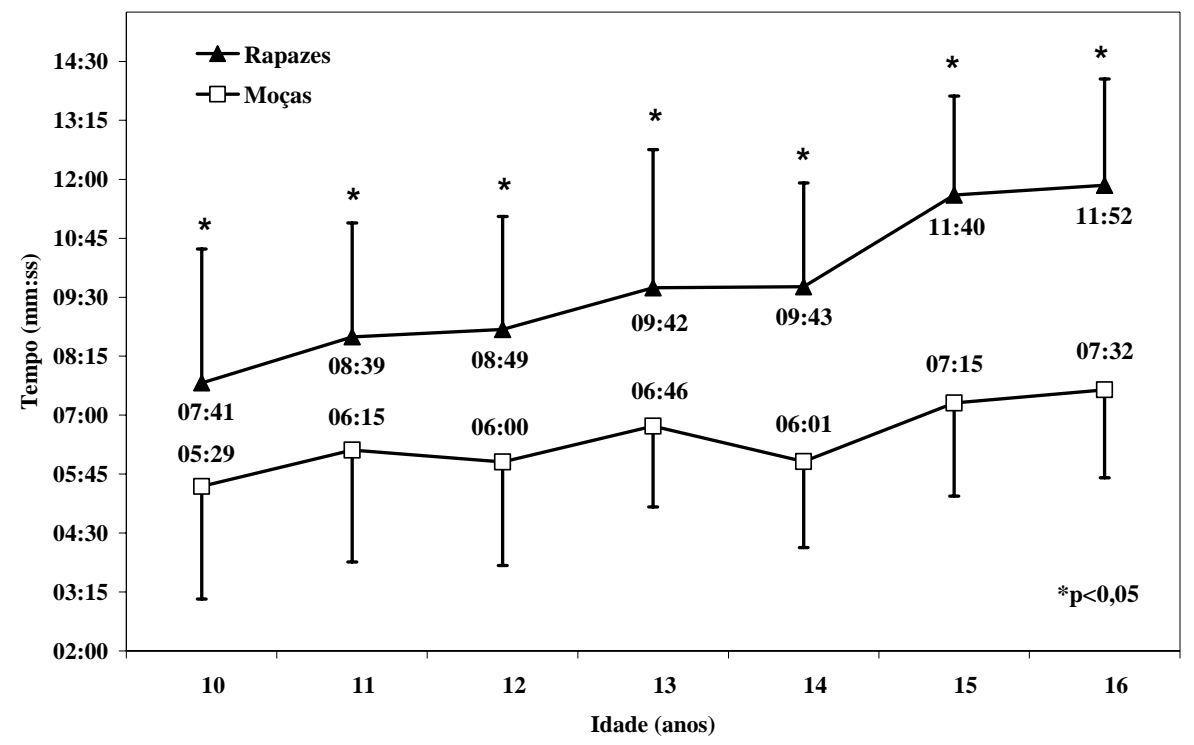

FIGURA 5 - Tempo médio de corrida para o teste cardiopulmonar de esforço de crianças e adolescentes de ambos os sexos.

A diferença média no TC entre os sexos ficou um pouco acima de 3 minutos, sendo paulatinamente mais elevada dos 10 aos 16 anos, para o sexo masculino, numa média de 20 segundos; a maior diferença alcançada entre os sexos foi aos 15 e 16 anos (mais de quatro minutos), e a menor aos 10 anos de idade, com um pouco mais de 2 minutos. O tempo médio obtido pelas moças demonstrou que a maioria completou o teste no mesmo grau de inclinação da esteira dos 11 aos 16 anos, ou seja, variando apenas no tempo de corrida para a inclinação de 7,5\% (FIGURA 6). Vale ressaltar que a variabilidade no TC das moças foi maior, pois os tempos mais baixos e mais elevados demonstraram que algumas moças aos 10 anos de idade já 
alcançaram um tempo de corrida superior a 10 minutos, seguido por poucas moças nos diferentes grupos etários, enquanto que o tempo mais baixo (por volta de 2 minutos) também ocorreu em todos os grupos etários. Entre os rapazes, o TC cima de 11 minutos ocorreu para os diferentes grupos etários, mas a elevação ocorreu dos 10 aos 16 anos.

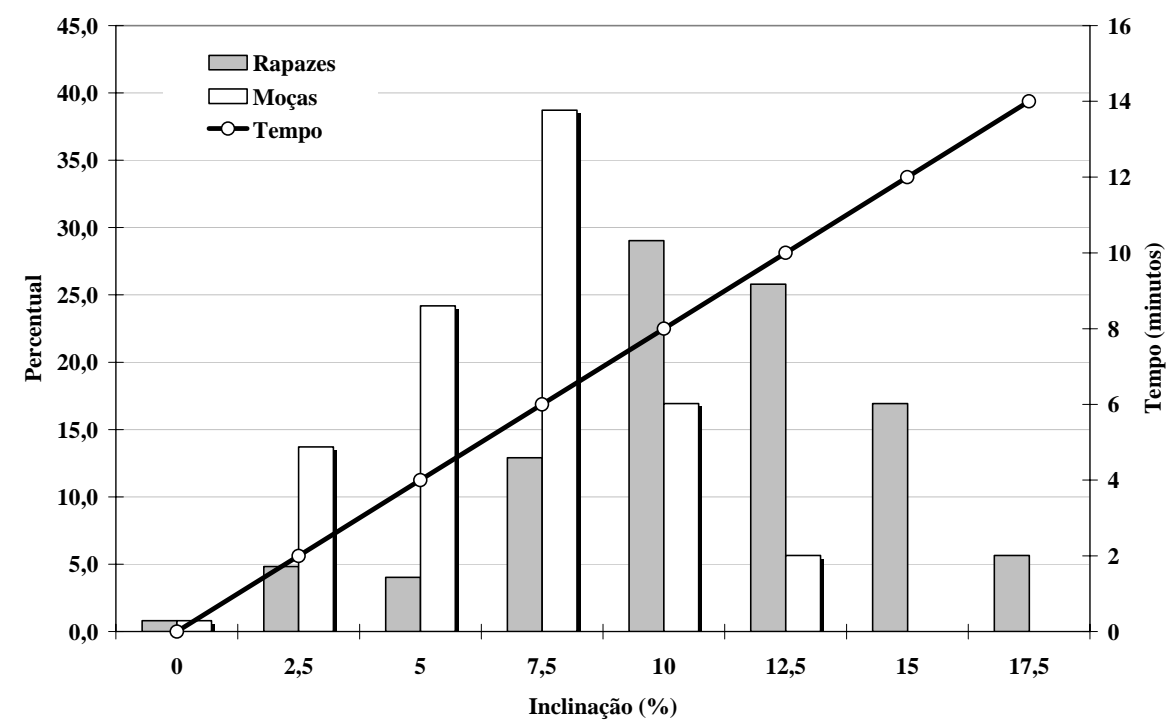

FIGURA 6 - Percentual de crianças e adolescentes, de ambos os sexos, que atingiram o $\underline{\mathrm{VO}}_{2}$ pico em cada estágio de inclinação da esteira com relação ao tempo de corrida.

Com relação às inclinações, ficou demonstrado que as mais elevadas foram alcançadas por um número muito pequeno de moças, mas distribuídas em todos os grupos etários. Ou seja, pouco mais de $15 \%$ atingiram o $\dot{\mathrm{V}} \mathrm{O}_{2}$ pico na inclinação de $10,0 \%$, enquanto que menos de $6,0 \%$ o alcançou em $12,5 \%$ da inclinação, sendo esta a maior inclinação alcançada por aquelas que permaneceram correndo por um tempo superior a 10 minutos (FIGURA 6).

Por outro lado, para os rapazes a carga de esforço média alcançada demonstrou que apenas um pequeno grupo (menos de $10 \%$ ), obteve o $\dot{\mathrm{VO}}_{2}$ pico nas inclinações mais baixas ( $5 \%$ da inclinação ou tempo inferior a 6 minutos). Nas inclinações de 7,5 e 10,0\% (tempos entre 6 e 10 minutos) a proporção foi superior a $41 \%$, envolvendo inclusive rapazes 
nas idades de 10 a 12 anos. Surpreendentemente, nas inclinações ainda mais elevadas (acima de $12,5 \%$ ) a quantidade de rapazes que atingiram o pico foi ainda maior (48\%), mas com idades superiores 13 anos.

Poucos são os estudos na literatura que apresentam valores médios de TC para um teste cardiopulmonar de esforço em função da idade e sexo. No Brasil, alguns estudos utilizaram teste progressivo de campo, no qual a potência aeróbia foi determinada indiretamente pelo número de voltas percorridas (PACER - Progressive Aerobic Cardiovascular Endurance Run). Em um estudo que envolveu este protocolo de teste em crianças e adolescentes rondonenses de 7 a 17 anos, HOBOLD (2003) observou que o número de voltas e, por extensão, o tempo de corrida, elevaram-se com o passar dos anos para ambos os sexos. Contudo, os rapazes apresentaram a média do número de voltas mais elevada estatisticamente que as moças, para todos os grupos etários analisados, repercutindo essas mesmas diferenças nos valores indiretos da potência aeróbia.

Com relação ao comportamento da potência aeróbia, através do mesmo teste, VASQUES et al. (2007) observaram as mesmas das médias do número de voltas para crianças e adolescentes catarinenses, de 10 a 15 anos. Pode-se observar que os ganhos médios do número de voltas assinalados para os rapazes foram de $80 \%$ (de 20,4 para 36,8 voltas), enquanto para as moças foi de $92 \%$ (de 19,1 para 36,7 voltas) no mesmo período. Esses ganhos foram bem mais elevados que os observados no presente estudo, mas não refletiram em mudanças na potência aeróbia que, no estudo citado, variou negativamente para ambos os sexos com o passar dos anos, a despeito do aumento do número de voltas, demonstrando um paradoxo dos resultados devido uma incoerência do modelo preditivo. Contudo, os autores não observaram diferenças estatisticamente significantes entre os sexos, resultados que também se refletiram nos valores médios da potência aeróbia.

Com relação à duração ideal do protocolo de teste cardiopulmonar de esforço, preconizada para se alcançar o $\dot{\mathrm{VO}}_{2}$ (pico ou máximo), a recomendação é de que seja entre 8 e 12 minutos nos indivíduos adultos (ROBERGS e ROBERTS, 1997), ou até o máximo de 14 minutos (THODEN, 1990), tanto para testes escalonados quanto para os de rampa. Essa recomendação é importante, segundo THODEN (1990), para que o teste não seja demasiadamente longo e que outras razões, como o desânimo ou dores localizadas impliquem na cessação do esforço antes da fadiga voluntária, ou que a determinação do máximo ou pico 
tenha sido obtida. Contudo, na literatura não há uma recomendação clara de tempo desejável para a determinação do $\dot{\mathrm{V}} \mathrm{O}_{2}$ pico para crianças e adolescentes, sendo necessário que todos os jovens avaliados sejam constantemente motivados pelos avaliadores a alcançarem a fadiga voluntária "verdadeira" (considerando os critérios de determinação do $\dot{\mathrm{V}}_{2}$ pico), independente do tempo de corrida.

Considerando a recomendação de tempo adotada para protocolos de teste em adultos, os resultados demonstraram que o protocolo adotado no presente estudo foi mais efetivo entre os rapazes, pois 54\% deles atingiram o pico entre 8 e 12 minutos de corrida, enquanto que apenas $22,6 \%$ das moças o atingiram na mesma faixa de tempo (FIGURA 6). A maioria das moças $(77,4 \%)$ terminou o teste em até os oito minutos, enquanto que apenas $23 \%$ dos rapazes terminaram no mesmo período. Por outro lado, o teste encerrou-se após os 12 minutos de corrida para mais de $22 \%$ dos rapazes, enquanto nenhuma das moças alcançou o $\dot{\mathrm{V}} \mathrm{O}_{2}$ pico acima desse tempo.

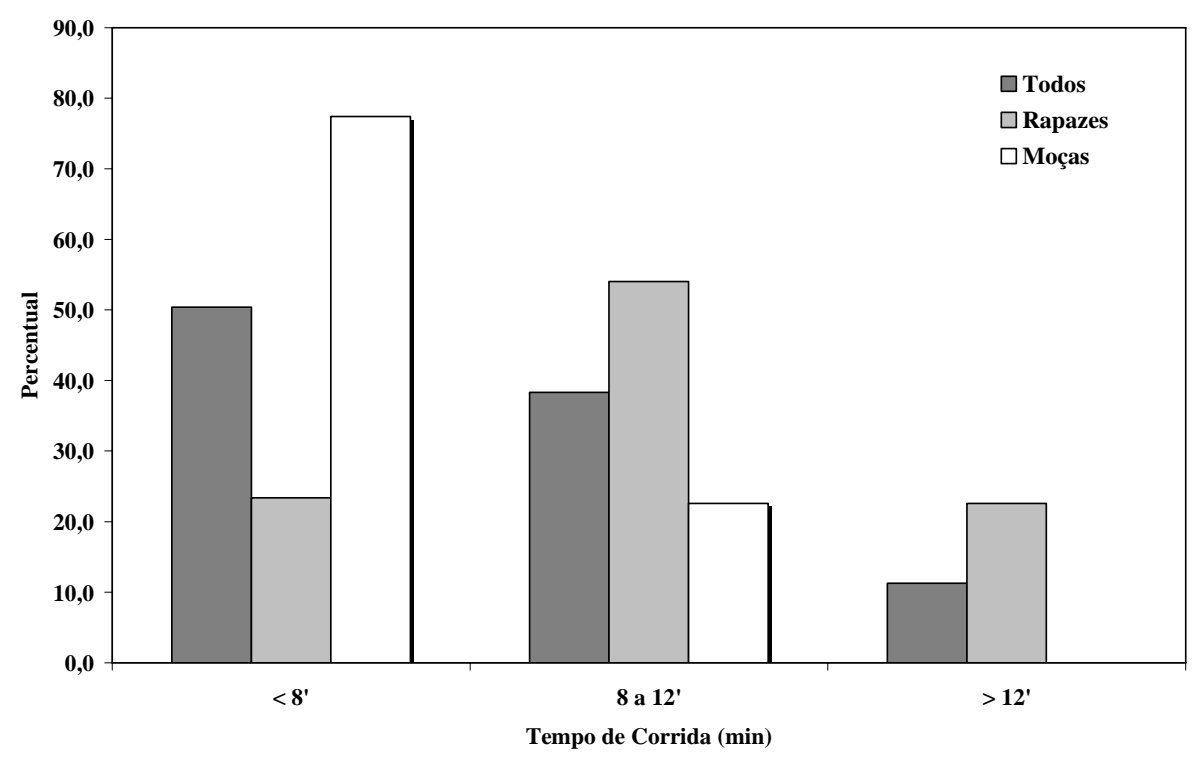

FIGURA 7 - Percentual de crianças e adolescentes, de ambos os sexos, que atingiram o $\underline{\mathrm{VO}}_{2}$ pico no período recomendado de 8 a 12 minutos durante o teste.

Os valores de frequência cardíaca $(\mathrm{FC})$ e do quociente respiratório $(\mathrm{QR})$ são imperativos quando estes são considerados isolados ou simultaneamente na determinação dos 
valores de do $\dot{\mathrm{VO}}_{2}$ pico. Ao considerarmos a interrupção do teste, por fadiga voluntária ou devido à verificação de um sinal ou sintoma de fadiga aguda, os valores do $\dot{\mathrm{V}}_{2}$ mais elevados são obtidos apenas a partir da determinação visual dos ventilatórios e hemodinâmicos. Portanto, para ser considerado o maior valor da potência aeróbia, ao menos um destes critérios foi alcançado.

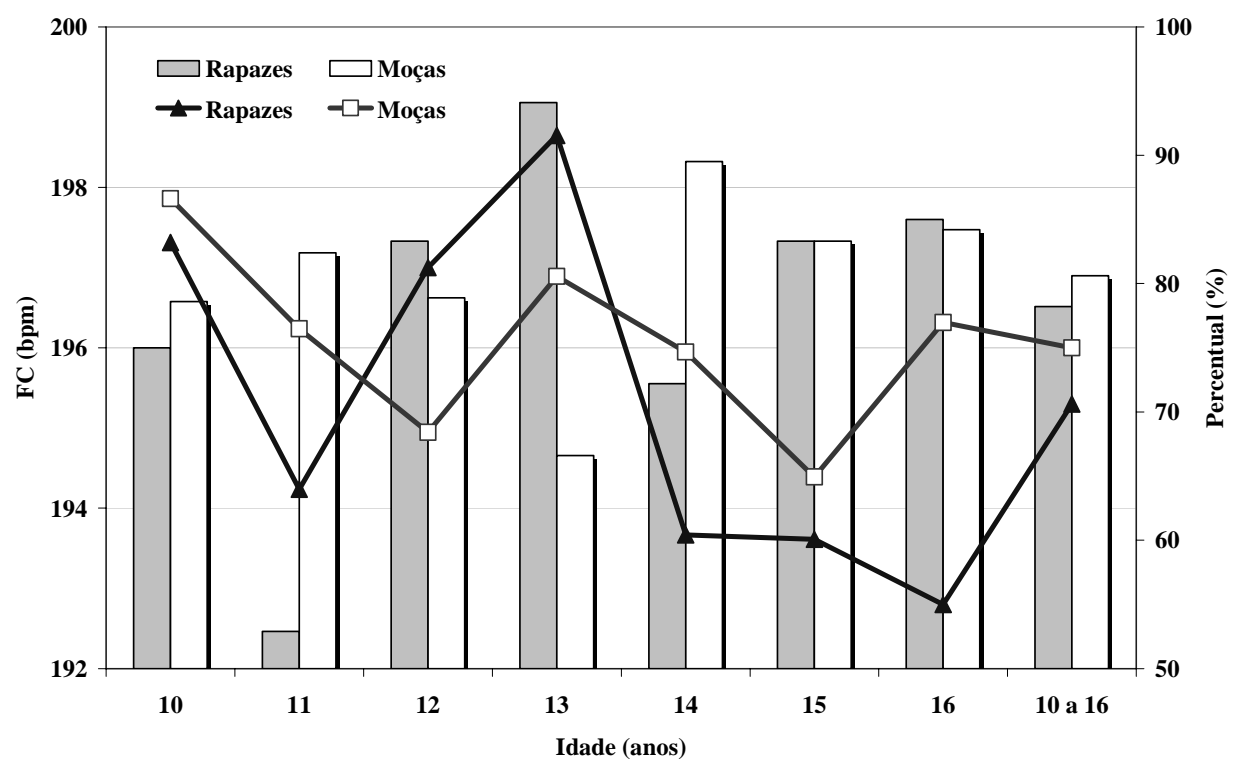

FIGURA 8 - Curvas de distância e valores do percentual de alcance da FCpico acima de 95\% da máxima prevista para a idade de crianças e adolescentes de ambos os sexos.

O comportamento e a frequência de alcance da FCpico de rapazes e moças são apresentados na Figura 8. Os rapazes apresentaram valores médios para FCpico com uma leve tendência à diminuição com o passar dos anos, mas entre as moças, pareceu ocorrer uma estabilização no mesmo período etário. Mesmo assim, considerando apenas um grupo por sexo, dos 10 aos 16 anos, a média da FCpico das moças foi ligeiramente mais elevada do que a dos rapazes (196,0 contra 195,3 para moças e rapazes respectivamente). Nas idades isoladamente, observou-se uma exceção aos 12 e 13 anos, em que as diferenças não ultrapassaram $4 \mathrm{bpm}$ em todas as idades (diferenças inferiores a $2 \%$ entre os sexos). Apesar de os rapazes apresentarem mais variabilidade nos resultados médios da FCpico ao longo dos 
anos, ficou demonstrado que a FC não constituiu diferenças marcantes entre os sexos para a determinação do $\dot{\mathrm{VO}}_{2}$ pico.

Assim, observando apenas os percentuais de alcance da FC como critério, ficou evidente que mais de $78,2 \%$ de todos os rapazes e $80,6 \%$ de todas as moças alcançaram uma FC $\geq 95 \%$ (208 - 0,7*idade), sendo o alcance mais baixo foi obtido aos 11 anos (52\%) entre os rapazes e aos 13 anos entre as moças (66\%); os valores percentuais mais elevados, ao contrário, foram obtidos aos 13 anos para os rapazes (94\%) e aos 14 anos para as moças (89\%). Durante os 10 aos 14 anos entre os rapazes, ficou evidente uma associação entre os valores médios da FCpico com o percentual de alcance do critério estabelecido, porém entre as moças não foi verificada a mesma tendência.

Poucos estudos apresentaram resultados médios da FC obtidos em testes de potência aeróbia de crianças e adolescentes, variando, entretanto, o número de indivíduos, o sexo e os grupos etários analisados. Em um desses estudos, ARMSTRONG, WILLIANS, BALDING, GENTLE e KIRBY (1991) avaliaram 113 rapazes e 107 moças com idades variando de 11 a 15 anos. No que tange a FCmáx, os resultados demonstraram que, no período etário analisado, a variação na média da FC foi de 199 a 202 bpm para o teste de esteira, independentemente do sexo, valores médios mais elevados que os observados entre eles no teste de cicloergômetro. Ao considerarem todos os indivíduos em um único grupo por sexo, os valores médios foram de 200 e $201 \mathrm{bpm}$, para rapazes e moças, respectivamente. Os valores médios ao longo dos anos foram ligeiramente mais elevados ao do presente estudo, contudo com a mesma tendência de as moças apresentarem resultados mais elevados que o dos rapazes.

Quanto aos valores médios do QRpico, ao longo dos anos, os comportamentos foram levemente opostos aos da FCpico (FIGURA 9), sendo mais estáveis com o passar dos anos, para ambos os sexos. No geral, dos 10 aos 16 anos, as moças apresentaram valores médios do $\mathrm{QR}$ mais elevados que o dos rapazes $(\mathrm{QR}=1,11$ e 1,07 para moças e rapazes, respectivamente), inclusive considerando todas as idades analisadas. Isso pode sugerir que o esforço entre elas foi ligeiramente mais exaustivo, considerando tanto a idade entre os sexos quanto o alcance do pico para uma mesma inclinação no teste de esforço, sendo os valores médios entre as moças 3\% superior ao dos rapazes. As diferenças entre os sexos, embora pequenas, foram estatisticamente significantes aos 10, 11 e 15 anos, mas essas diferenças 
podem estar relacionadas às diferenças no número de indivíduos para cada um desses grupos etários.

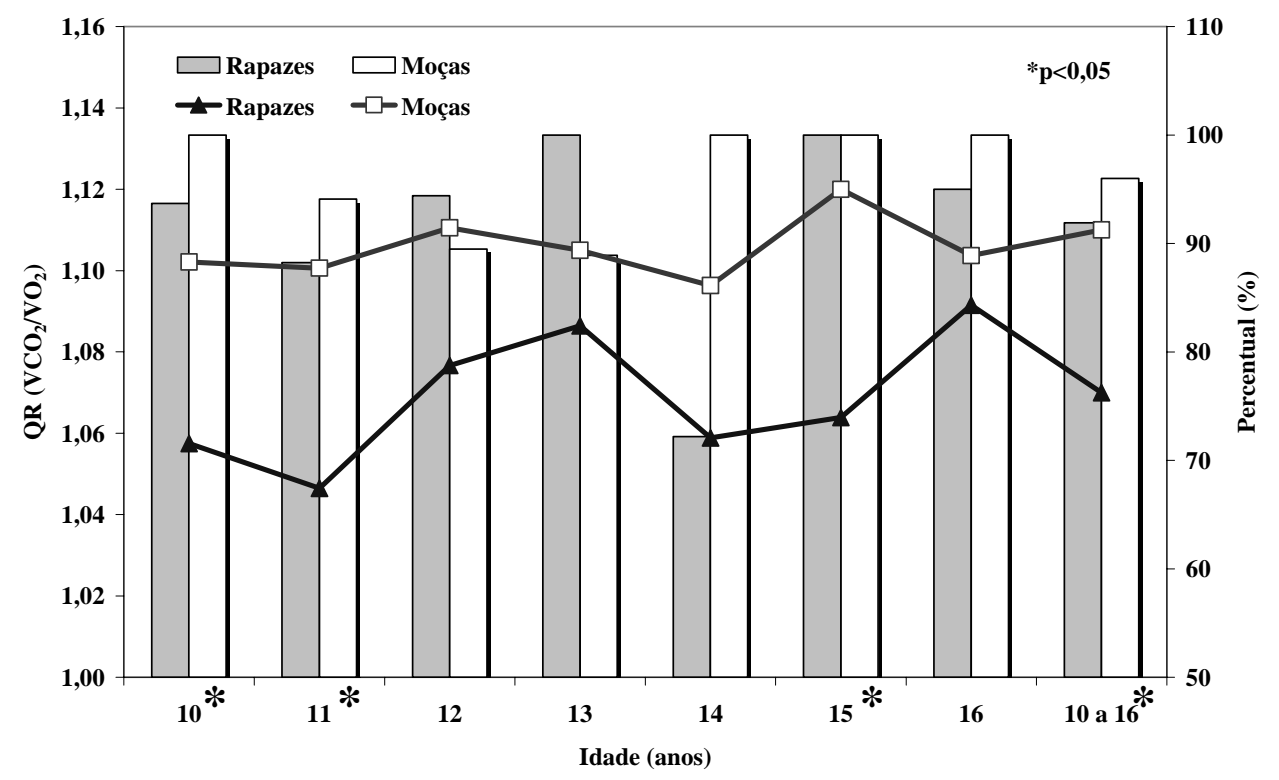

FIGURA 9 - Curvas de distância e valores do percentual de alcance do QRpico $\geq 1$ de crianças e adolescentes de ambos os sexos.

No caso do QRpico ( $\geq 1$ ) como critério, mais de 91,9\% de rapazes e 96\% das moças atenderam ao critério para o $\dot{\mathrm{VO}}_{2}$ pico (FIGURA 9), sendo o mais baixo percentual alcançado entre os rapazes aos 14 anos (72\%) e, entre as moças, aos 13 anos (88\%). A relação entre a FCpico e o QRpico variou entre 0,13 a 0,22 para moças e rapazes respectivamente, sendo de 0,17 quando foram analisados conjuntamente, demonstrando que o alcance de um critério não exerce uma relação recíproca com o outro. Ou seja, o mais importante, neste caso, é que ao menos um critério foi considerado na determinação do $\dot{\mathrm{VO}}_{2}$ pico, pois os valores percentuais observados em ambos os casos (FC e QR) foram distintos e, talvez por esse motivo, a relação entre eles tenha sido baixa.

Outro aspecto importante com relação a essas duas variáveis-critério em um teste cardiopulmonar de esforço, é que em nenhuma idade os indivíduos de ambos os sexos alcançaram $100 \%$ do critério da FC, e algumas poucas idades alcançaram a totalidade para o QR, embora quase todos eles tenham alcançado a fadiga voluntária, indicando que não é 
necessária a simultaneidade de ambos os critérios para considerar o $\dot{\mathrm{V}} \mathrm{O}_{2}$ pico como válido, no grupo etário analisado. Ao analisarmos os critérios de determinação conjuntamente, os resultados demonstraram que a simultaneidade não ocorreu entre todos eles, portanto uma análise dos critérios isoladamente se faz necessária para poder se interpretar como cada um deles ocorreu na presente amostra.

O estudo de RIVERA-BROWN et al. (1992) procurou avaliar a aplicabilidade dos critérios de determinação do $\dot{\mathrm{V}} \mathrm{O}_{2}$ máx mais utilizados na literatura (FC $\geq 95 \%$ máx; $\mathrm{QR} \geq$ $1,0)$, mediante a freqüência com que adolescentes ativos de ambos os sexos alcançaram os critérios para a determinação do $\dot{\mathrm{VO}}_{2}$. Para tanto, os autores submeteram 284 moças e 196 rapazes (média de 12,6 anos) a um teste cardiopulmonar de esforço em esteira, interrompido apenas quando a fadiga voluntária foi alcançada. Os autores observaram que o critério de alcance do QR foi obtido por $97 \%$ das moças e $93 \%$ dos rapazes. Ao considerarem a FC como critério, os resultados foram mais modestos, porém ainda elevados, pois $81 \%$ das moças e $75 \%$ dos rapazes ultrapassaram a marca de 95\% da FCmáx prevista para idade. Contudo, não houve uma avaliação de simultaneidade de alcance dos critérios, indicando também que apenas um deles pareceu ser suficiente para se considerar o $\dot{\mathrm{V}} \mathrm{O}_{2}$ pico como válido. No caso do alcance de um platô para determinação do $\mathrm{V}_{2}$ máx, apenas $11 \%$ dos adolescentes apresentaram essa condição, sendo $13 \%$ e $8 \%$ entre rapazes e moças respectivamente. Os autores concluíram que uma combinação de critérios subjetivos (fadiga voluntária) e objetivos $(\mathrm{QR} \geq 1$ ou $\mathrm{FC} \geq$ 95\%máx) pode ser aceito como suficiente para determinação do $\dot{\mathrm{V}}_{2}$ como válido.

Ao tentarem avaliar a reprodutibilidade do alcance de um platô do $\dot{\mathrm{V}} \mathrm{O}_{2}$ entre rapazes mais velhos (16 $\pm 1,3$ anos), RIVERA-BROWN e FRONTERA (1998) observaram que o teste em esteira apresentou os maiores índices de alcance do platô, contudo não superaram a marca de 50\% em ambos os testes, sem que houvesse uma simultaneidade entre os rapazes. Para terem certeza da ocorrência ou não de um platô entre os adolescentes, os autores testaram a reprodutibilidade apenas para aqueles que alcançaram o platô, e ficou demonstrado que ela não foi atingida em ambos os testes. Ou seja, evidenciou-se que o platô não é uma condição de validação dos resultados do teste em população jovem.

Em outro estudo, RIVERA-BROWN, ALVAREZ, RODRÍGUES-SANTANA e BENETTI (2001) avaliaram o alcance de platô na potência aeróbia de rapazes pré-púberes. Os 
resultados demonstraram que apenas 33\% do total alcançaram o platô, enquanto que todos eles (100\%) alcançaram o critério das trocas respiratória acima de $1(\mathrm{QR} \geq 1)$ e $95 \%$ alcançaram o critério preconizado para a freqüência cardíaca ( $\mathrm{FC} \geq 186$ bpm). Nas comparações entre os dois grupos (com e sem platô), nenhuma diferença foi observada entre as médias do $\mathrm{V}_{2}$ e demais variáveis analisadas. Os autores avaliaram a potência anaeróbia como possível determinante da ocorrência do platô, mas as médias entre os dois grupos não foram diferentes, eliminando esse fator como responsável pelo alcance ou não do platô.

5.3.2 Parâmetros ventilatórios: ventilação, potência aeróbia absoluta e relativa 5.3.2.1 Ventilação por minuto (VE)

O comportamento da ventilação por minuto (VE) de crianças e adolescentes de ambos os sexos é representada na Figura 10. Os resultados demonstraram que, em ambos os sexos, os valores médios foram mais elevados com o passar dos anos, apresentando um comportamento linear para os rapazes dos 10 aos 16 anos; as moças tiveram o mesmo comportamento apenas dos 10 aos 13 anos, quando apresentaram um nivelamento até os 14 anos seguido por um ligeiro aumento a partir dos 15 anos. Os valores médios dos rapazes foram superiores ao das moças para todos os grupos etários, mas as diferenças estatisticamente significantes somente apareceram a partir dos 14 anos de idade.

Os rapazes variaram os valores médios dos 10 aos 16 anos em aproximadamente $50 \%$, enquanto as moças, no mesmo período, apresentaram variações nas médias de $38 \%$. Isso implica que para os rapazes, no período analisado, os valores médios quase dobraram enquanto que, para as moças, houve um avanço de $68 \%$ em relação aos valores das idades iniciais. Contudo, ao analisarmos o período de 10 a 13 anos ambos os sexos, os aumentos foram semelhantes nos valores da VE $\left(\mathrm{L} \cdot \mathrm{min}^{-1}\right)$, sendo de 43 e $38 \%$ para rapazes e moças respectivamente, e as diferenças entre os sexos não ultrapassaram os $6 \%$ em cada grupo etário. Apenas a partir dos 14 anos de idade as diferenças médias tornaram-se importantes, pois aos 14 anos os rapazes ventilavam $15 \%$ a mais que as moças, sendo a maior diferença entre eles aos 16 anos, com uma magnitude de $25 \%$ em favor dos rapazes. 


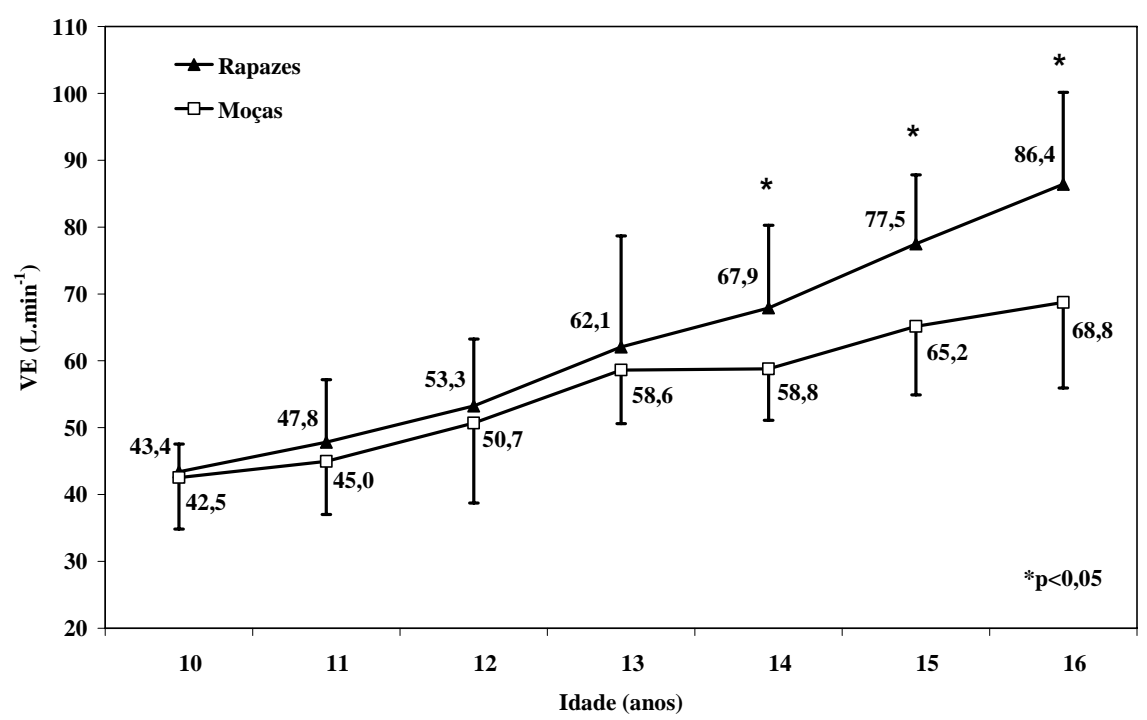

FIGURA 10 - Curvas de distância dos valores médios e desvio-padrão da ventilação por minuto - VE $\left(\mathrm{L} \cdot \mathrm{min}^{-1}\right)$ de crianças e adolescentes de ambos os sexos.

Um aspecto importante com relação aos valores ventilatórios deve ser notado na diminuição da velocidade dos ganhos ao longo dos anos, em ambos os sexos, pois entre as moças a velocidade sofreu uma desaceleração aos 14 anos, que foi menos acentuada para os rapazes, no mesmo período. Em ambos os sexos, aos 15 anos de idade, observou-se uma retomada na aceleração, elevando os valores médios da VE a níveis de ganhos semelhantes aos observados aos 13 anos de idade, apresentando a partir deste período um novo comportamento linear.

TABELA 8 - Coeficientes de correlação entre as variáveis ventilatórias e o tempo de corrida, idade, estatura e MC de crianças e adolescentes de ambos os sexos.

\begin{tabular}{|c|c|c|c|c|c|c|c|c|c|}
\hline \multirow[b]{2}{*}{ Variáveis } & \multicolumn{3}{|c|}{$\underline{\text { Rapazes }}$} & \multicolumn{3}{|c|}{ Moças } & \multicolumn{3}{|c|}{ Ambos os Sexos } \\
\hline & Idade & $\mathrm{MC}$ & Est. & Idade & $\mathrm{MC}$ & Est. & Idade & $\mathrm{MC}$ & Est. \\
\hline Tempo de Corrida (seg) & 0,50 & 0,18 & 0,32 & 0,27 & 0,02 & 0,23 & 0,32 & 0,06 & 0,24 \\
\hline Ventilação Minuto (VE) & 0,79 & 0,79 & 0,79 & 0,67 & 0,76 & 0,74 & 0,71 & 0,74 & 0,75 \\
\hline$\dot{\mathrm{V}} \mathrm{O}_{2}\left(\mathrm{~L} \cdot \mathrm{min}^{-1}\right)$ & 0,85 & 0,87 & 0,87 & 0,69 & 0,83 & 0,78 & 0,73 & $\mathbf{0 , 7 8}$ & 0,79 \\
\hline$\dot{\mathrm{V}} \mathrm{O}_{2}\left(\mathrm{~mL} \cdot \mathrm{MC}^{-1} \cdot \mathrm{min}^{-1}\right)$ & 0,26 & $-0,17$ & 0,04 & $-0,05$ & $-0,34$ & $-0,10$ & 0,09 & $-0,23$ & $-0,02$ \\
\hline$\dot{\mathrm{V}} \mathrm{O}_{2}\left(\mathrm{~mL} \cdot \mathrm{MC}^{-0,67} \cdot \mathrm{min}^{-1}\right)$ & 0,70 & 0,47 & 0,59 & 0,38 & 0,25 & 0,41 & 0,46 & 0,28 & 0,43 \\
\hline$\dot{\mathrm{V}} \mathrm{O}_{2}\left(\mathrm{~mL} \cdot \mathrm{MC}^{-0,75} \cdot \mathrm{min}^{-1}\right)$ & 0,63 & 0,34 & 0,49 & 0,29 & 0,11 & 0,30 & 0,38 & 0,17 & 0,33 \\
\hline$\dot{\mathrm{V}} \mathrm{O}_{2}\left(\mathrm{~mL} \cdot \mathrm{MCM}^{-1} \cdot \mathrm{min}^{-1}\right)$ & 0,23 & $-0,06$ & 0,04 & 0,12 & 0,06 & 0,11 & 0,14 & $-0,03$ & 0,05 \\
\hline
\end{tabular}


Considerando o nível de relação entre as variáveis (TABELA 8), dos 10 aos 16 anos, pareceu haver uma tendência nos ganhos da velocidade na VE, possivelmente por estar associada ao crescimento tanto da estatura $(r=0,75, p<0,001$ para ambos os sexos, $r=0,79$ e $0,74, \mathrm{p}<0,001$, para rapazes e moças respectivamente) quanto da $\mathrm{MC}(\mathrm{r}=0,74,[\mathrm{p}<0,001])$ para ambos os sexos; e $r=0,79$ e $0,76[p<0,001]$, para rapazes e moças respectivamente). Um aspecto importante no resultado é a baixa relação entre o TC e a potência aeróbia tanto nos valores absolutos quanto nos relativos a MCM, para rapazes e moças, pois a relação entre essas duas variáveis não explicou mais do que $18 \%$ e $30 \%$, respectivamente, do resultado dos testes de rapazes e moças. Contudo, no caso da correção da massa corporal apresentada em

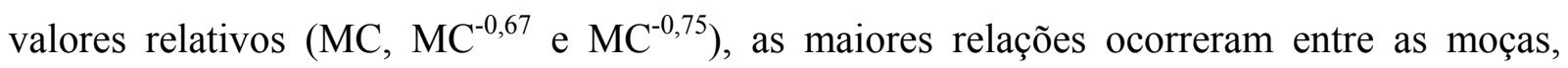
sugerindo que quem correu mais tempo apresentou uma MC mais elevada e, portanto, um estado maturacional determinante nos resultados entre elas.

Ainda são poucos estudos na literatura que apresentam valores ventilatórios médios para crianças e adolescentes, tanto numa abordagem longitudinal quanto transversal, com o passar dos anos. Em uma revisão da literatura, KRAHENBUHL et al. (1985) constataram que a ventilação por minuto máxima aumenta com o passar dos anos. Contudo, não foram apresentados valores médios que representem os ganhos anuais para cada sexo, bem como as possíveis diferenças entre eles ao longo dos anos. Com resultados longitudinais de crianças e adolescentes holandeses de 12 a 17 anos, KEMPER e VERCHUUR (1985) observaram que a VE aumentou mais acentuadamente entre os rapazes, variando de $70 \mathrm{~L} \cdot \mathrm{min}^{-1}$ aos 12 anos a um pouco mais de $100 \mathrm{~L} \cdot \mathrm{min}^{-1}$ aos 17 , enquanto que entre as moças os ganhos foram mais modestos, variando de 70 a $80 \mathrm{~L} \cdot \mathrm{min}^{-1}$ no mesmo período. Os autores não avaliaram as diferenças entre os sexos, porém as diferenças médias pareceram se acentuar a partir dos 14 anos. Uma informação importante, relacionada aos dados ventilatórios, é que a freqüência respiratória (fR) de rapazes e moças situavou-se na média de 55 aos 12/13 anos e diminuiu para aproximadamente 40 respirações/minuto aos 17 e 18 anos, ao mesmo tempo em que o volume tidal ${ }^{2}$ (VT) aumentou com o passar dos anos na mesma proporção da VE, sugerindo que a maior ventilação entre os rapazes deve-se ao seu maior tamanho corporal.

Em um estudo transversal, McMURRAY, BAGGETT, PENNELL, BANGDIWALA e HARRELL (2003) avaliaram as respostas ventilatória e de potência

\footnotetext{
${ }^{2} \mathrm{O}$ volume de ar inspirado em uma simples respiração durante um ciclo respiratório.
} 
aeróbia de 326 crianças e adolescentes de 8 a 18 anos, de ambos os sexos. Os valores ventilatórios foram obtidos para teste submáximo de caminha e corrida em velocidades fixas entre 4 a $8 \mathrm{~km} \cdot \mathrm{h}^{-1}$, e exercício em ciclo a $22,4 \mathrm{~km} \cdot \mathrm{h}^{-1}$, além das informações de repouso para controle. Considerando as respostas ventilatórias por minuto (VE) em todos os testes, os valores médios aumentaram com o passar dos anos, contudo não houve diferenças estatisticamente significantes entre os sexos e idades para os diferentes testes, provavelmente por todos eles desempenharem esforços submáximos. Por outro lado, os valores médios do VT aumentaram proporcionalmente à $\mathrm{VE}$, enquanto a $\mathrm{fR}$ também diminuiu no mesmo período, indicando que as respostas ventilatórias também são dependentes do tamanho.

\subsubsection{Potência aeróbia absoluta $\left(\dot{\mathrm{VO}}_{2}\right)$}

O comportamento da potência aeróbia em valores absolutos é apresentado na Figura 8. $\mathrm{O} \dot{\mathrm{V}}{ }_{2}$ pico apresentou-se crescente com o passar dos anos para ambos os sexos. Os maiores ganhos médios foram observados entre os rapazes a partir dos 12 até os 16 anos, enquanto que entre as moças o mesmo comportamento ocorreu entre as idades de 10 e 13 anos; após esse período, os valores médios da potência aeróbia elevaram-se mais discretamente. Os rapazes apresentaram valores médios $18 \%$ mais elevados que o das moças considerando todos os grupos etários, contudo as diferenças estatisticamente significantes ocorreram a partir dos 14 anos.

No presente estudo, dos 10 aos 16 anos, os ganhos médios na potência aeróbia mais que duplicou entre os rapazes (107\%), enquanto para as moças, foi de 66\%. A diferença entre os sexos foi de aproximadamente $10 \%$ dos 10 aos 13 anos, mas elevou-se em $18 \%$ (de 10 para 30\%) dos 14 aos 16 anos. Esses resultados estão diretamente associados àqueles observados para a ventilação pulmonar, no mesmo período etário, para ambos os sexos. Nesse caso, o coeficiente de correlação entre o $\mathrm{VO}_{2}$ pico e a VE, independentemente do sexo, foi de $0,91(\mathrm{p}<0,001)$; sendo ainda mais elevada para os rapazes $(\mathrm{r}=0,96, \mathrm{p}<0,001)$ em relação às moças $(\mathrm{r}=0,87, \mathrm{p}<0,001)$. 


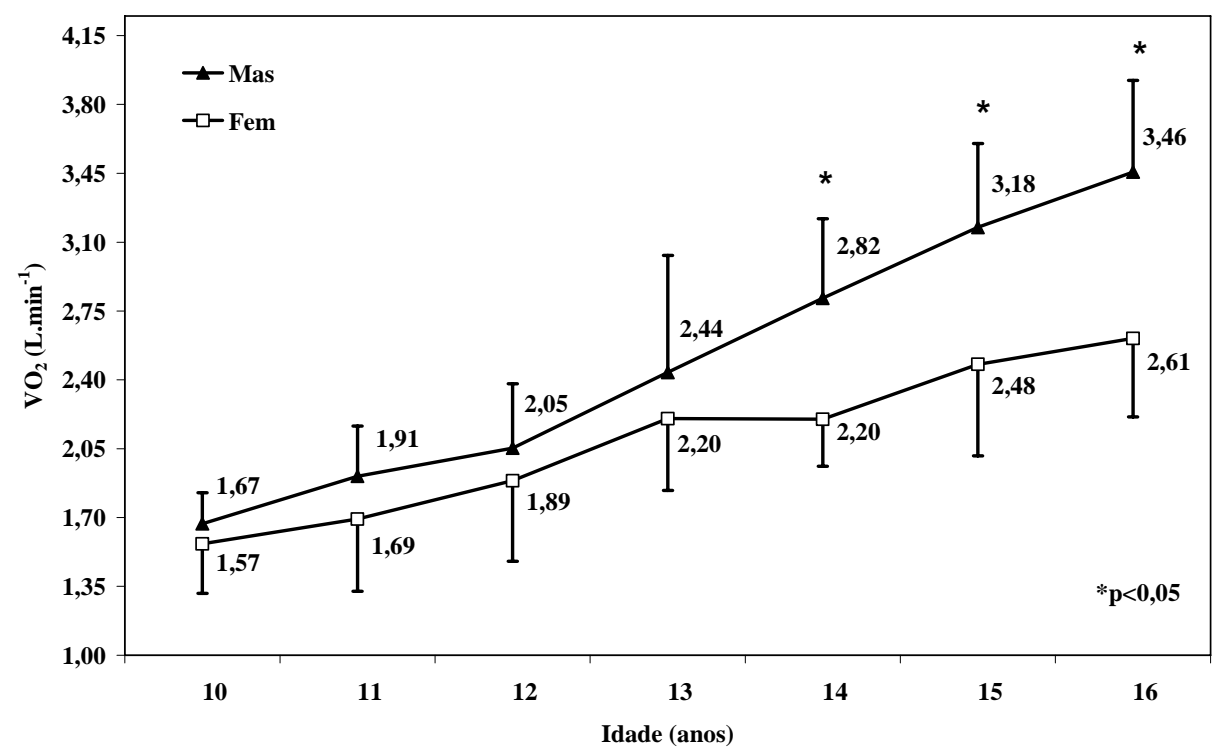

FIGURA 11 - $\underline{\text { Curvas de distância } \mathrm{VO}_{2}} \underline{\left(\mathrm{L} \cdot \mathrm{min}^{-1}\right) \text { de crianças e adolescentes de ambos os }}$ $\underline{\text { sexos. }}$

Em um estudo envolvendo crianças européias, de 12 a 17 anos de idade (102 rapazes e 131 moças), KEMPER e VERSCHUUR (1987) acompanharam por quatro anos os resultados da potência aeróbia absoluta e relativa, considerando as variações da idade cronológica e esquelética. O teste foi semelhante ao do presente estudo, realizado em esteira com velocidade fixa de $8 \mathrm{~km} \cdot \mathrm{h}^{-1}$, com incrementos na inclinação da esteira a cada 2 minutos, até a exaustão. Os resultados da potência aeróbia em relação à idade cronológica, entre os rapazes, apresentaram um aumento com o passar dos anos, com ganhos médios de aproximadamente $58 \%$ (de 2,41 a $3,81 \mathrm{~L} \cdot \mathrm{min}^{-1}$ ), enquanto que entre as moças, os ganhos foram menos acentuados no mesmo período, em torno de $17 \%$ (de 2,31 a 2,71 L·min ${ }^{-1}$ ). Embora o período etário tenha sido um pouco diferente do período contemplado pelo presente estudo, e ainda que os valores médios tenham sido mais elevados, no geral, os ganhos médios demonstraram um comportamento semelhante nos dois grupos amostrais, pois na presente amostra, os ganhos no mesmo período foram de $68 \%$ e $38 \%$, para rapazes e moças respectivamente.

Em um estudo longitudinal de cinco anos, envolvendo rapazes e moças prépúberes (dos 9 aos 13 anos), ROWLAND, VANDERBURGH e CUNNINGHM (1997) observaram que a partir dos 10 anos os rapazes apresentaram resultados médios 
estatisticamente mais elevados que os das moças. Quando foram analisados os ganhos dos 10 aos 13 anos, um aumento de $40 \%$ foi verificado entre eles, sendo de $31 \%$ para elas no mesmo período, enquanto que no presente estudo esses resultados foram de $46 \%$ e $40 \%$, para rapazes e moças, respectivamente. Aos 10 anos, as diferenças entre os sexos não superavam $21 \%$, diferença mais elevada aos 10 anos que no presente estudo (6\%), enquanto que aos 13 anos já ultrapassavam $29 \%$ e, no presente estudo, não chegavam aos $11 \%$. Esses resultados são distintos do presente estudo nas comparações interssexos, pois, neste estudo, as diferenças entre os sexos apareceram somente aos 14 anos, entretanto, os ganhos intrassexos podem ser considerados semelhantes em ambos os estudos. Isto se deveu provavelmente à enorme diferença de amostra (apenas 11 rapazes e 9 moças) do estudo em tela, não correspondendo a outros resultados na literatura.

No estudo transversal de ARMSTRONG et al. (1991), com rapazes e moças inglesas de 12 a 15 anos, o $\dot{\mathrm{VO}}_{2}$ pico mensurado no teste de esteira demonstrou resultados semelhantes aos do presente estudo. Os autores observaram que, com o passar dos anos para ambos os sexos, os ganhos foram mais acentuados entre os rapazes $(60 \%)$ do que para as moças (19\%). As diferenças médias entre os sexos ficaram na ordem de $22 \%$, em favor dos rapazes, e foram estatisticamente mais elevadas a partir dos 13 anos. Embora as médias no $\dot{\mathrm{VO}}_{2}$ absoluto do presente estudo sejam ligeiramente mais elevadas, o comportamento obtido em ambos os sexos foi semelhante, pois no mesmo período etário os ganhos médios entre os rapazes foram de $55 \%$ e entre as moças foram de $31 \%$.

JANZ, BURNS, WITT e MAHONEY (1998) avaliaram diretamente a potência aeróbia máxima de 53 rapazes (8 - 12 anos) e 57 moças (7 - 11 anos) por cinco anos. Considerando os valores do $\dot{\mathrm{VO}}_{2}$ absolutos, os rapazes apresentaram médias mais elevadas em relação às das moças, em todos os anos. Para eles os valores médios do $\dot{\mathrm{VO}}_{2}$ pico absoluto $\left(\mathrm{L} \cdot \mathrm{min}^{-1}\right)$ aumentaram todos os anos, porém os relativos $\left(\mathrm{mL} \cdot \mathrm{kg}^{-1} \cdot \mathrm{min}^{-1}\right)$ aumentaram significativamente até o terceiro ano de estudo (8-10 anos), quando continuou aumentando, mas discretamente, até o quinto ano (11-12 anos). Os resultados para as moças demonstraram que os aumentos também ocorreram nos valores absolutos, contudo, apenas até o quarto ano de estudo (7-10 anos), enquanto que nos valores relativos os resultados apresentaram uma diminuição a cada ano de estudo. 
Em outro estudo longitudinal, McMURRAY, HARRELL, BRADLEY, DENG e BANGDIWALA (2002) avaliaram a potência aeróbia indiretamente através de um teste escalonado em cicloergômetro (PWC 195) de 1279 moças e 1261 rapazes de 8 a 16 anos. Mesmo que o protocolo de estudo não se assemelhe aos diferentes estudos apresentados até o momento, sua relevância é devida ao grande número de indivíduos participantes e da faixa etária incluir a da presente amostra. Os resultados demonstraram que a potência aeróbia absoluta $\left(\mathrm{L} \cdot \mathrm{min}^{-1}\right)$ aumentou em ambos os sexos e grupos étnicos, sendo mais elevado entre os rapazes do que entre as moças, em qualquer idade. Entretanto, dos 10 aos 16 anos, os rapazes apresentaram um aumento médio de $81 \%$, enquanto que nas moças, o aumento foi de $28 \%$. No caso das moças, o aumento na potência aeróbia ocorreu apenas até os 14 anos (por volta de $32 \%$ ), quando os valores médios estabilizaram-se em aproximadamente $1,90 \mathrm{~L} \cdot \mathrm{min}^{-1}$. Esses resultados apresentaram valores médios mais baixos dentre os diferentes estudos, provavelmente, devido ao tipo de ergômetro utilizado e pelos valores serem obtidos indiretamente, entretanto, ao analisarmos o comportamento geral para ambos os sexos, os resultados apontam para um comportamento semelhante, em todos eles.

MALINA, BEUNEN, LEFREVRE e WOYNAROWSKA (1997) procuraram estabelecer a influência da maturação dos resultados da potência aeróbia de crianças e adolescentes poloneses, de ambos os sexos, mediante um estudo longitudinal-misto por quatro anos (11-15 anos). Os períodos foram estabelecidos considerando o pico de velocidade de crescimento em maturação precoce, média e tardia para rapazes; para a idade da menarca em precoce, média e tardia para as moças. Os resultados demonstraram que nos diferentes períodos maturacionais o $\dot{\mathrm{VO}}_{2}$ absoluto aumentou com o passar dos anos para, ambos os sexos, sendo mais acentuado entre os rapazes, enquanto que nos valores relativos, houve, uma queda em ambos os sexos, mais acentuadamente entre as moças.

Com relação aos períodos maturacionais, os rapazes com desenvolvimento precoce apresentaram valores médios de $\dot{\mathrm{VO}}_{2}$ pico absoluto mais elevados que os demais, enquanto que entre para os valores relativos ocorreu o inverso, ou seja, as médias mais baixas foram determinadas para o grupo com maturação mais avançado (precoce) ao longo dos anos. Para as moças, os resultados foram semelhantes, com médias mais elevadas para os valores absolutos e mais baixas para os relativos à massa corporal. Estes grupos com maturação precoce apresentaram médias mais elevadas em estatura e massa corporal que os demais 
grupos. Estes grupos apresentaram resultados opostos aos grupos precoces, com valores mais baixos para os rapazes e mais elevados para as moças. Os resultados sugerem que não ocorreu um efeito importante da maturação nos dados longitudinais do presente estudo, devido ao fato de não ter havido diferenças entre os diversos grupos maturacionais ao longo dos anos, maiores que os efeitos observados na idade cronológica. Vale ressaltar que no estudo em questão, os indicadores maturacionais entre os sexos foram distintos, idade no PVC e da menarca, para rapazes e moças respectivamente, podendo ser diferente quando uma mesma estratégia fosse adotada para determinar maturação em ambos os grupos.

\subsubsection{Potência aeróbia relativa à $\mathrm{MC}\left(\mathrm{mL} \cdot \mathrm{MC}^{-1} \cdot \mathrm{min}^{-1}\right)$}

O comportamento da potência aeróbia relativa à massa corporal total (MC), está representado na Figura 12. Os resultados demonstram que a potência aeróbia de rapazes e moças apresentou um comportamento distinto daqueles observados para os valores absolutos. Enquanto os rapazes apresentaram um aumento progressivo, porém discreto, do $\dot{\mathrm{VO}}_{2}$ com o passar dos anos, as moças apresentaram um comportamento com leve tendência a diminuição dos valores médios com o passar dos anos. Os rapazes apresentaram valores médios estatisticamente mais elevados do que as moças em todos os grupos etários analisados.

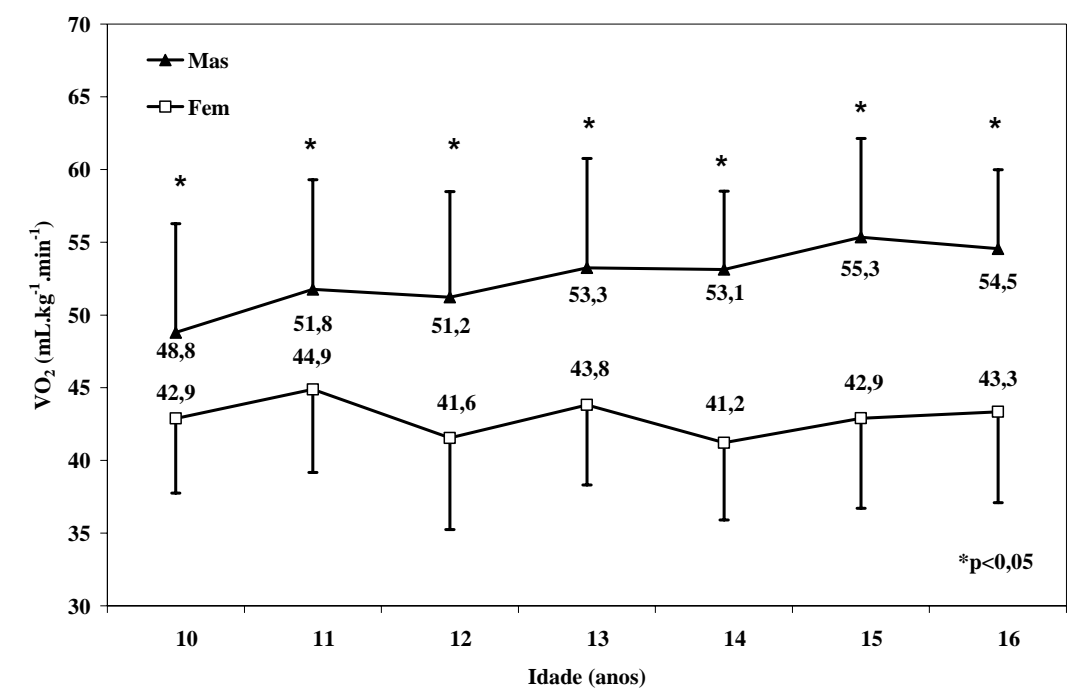

FIGURA 12 - Curvas de distância do $\mathrm{VO}_{2}\left(\mathrm{~mL} \cdot \mathrm{kg}^{-1} \cdot \mathrm{min}^{-1}\right)$ de crianças e adolescentes de ambos os sexos. 
Estes resultados parecem demonstrar um efeito espúrio da massa corporal nos resultados da potência aeróbia relativa, conforme alertou TANNER (1949), principalmente quando se analisa os resultados apresentados pelas moças. Isso porque a variação dos ganhos no $\dot{\mathrm{VO}}_{2}$ absoluto foi de $107 \%$ e $66 \%$, para rapazes e moças, respectivamente, contrastando enormemente com valores da potência aeróbia relativos à massa corporal, que foram de $12 \%$ para rapazes e, de apenas $1 \%$ para moças, no mesmo período analisado. Por outro lado, as diferenças entre os sexos, para cada grupo etário isoladamente, variaram na ordem de $15 \%$ aos 10 e 11 anos, $23 \%$ aos 12 e 13 anos, sendo mais elevadas do que nas idades de 10 a 14 anos para o $\dot{\mathrm{VO}}_{2}$ em valores absolutos; as mesmas diferenças proporcionais foram observadas entre 14 e 16 anos, na ordem de $28 \%$.

Esses resultados podem ser parcialmente explicados pela massa corporal ter sido mais elevada entre as moças na maior parte dos grupos etários, principalmente nas idades de 12 e 13 anos, ao mesmo tempo em que os valores médios do $\dot{\mathrm{VO}}_{2}$ absoluto terem sido mais baixos em todos os anos, em relação aos rapazes. Conseqüentemente, os valores médios da potência aeróbia absoluta foram estatisticamente mais elevados em todas as idades para os rapazes.

Um aspecto relevante está na relação dos valores do $\dot{\mathrm{VO}}_{2}\left(\mathrm{~L} \cdot \mathrm{min}^{-1}\right)$ e do tempo de corrida na esteira, pois foi encontrado um coeficiente de $0,56(p<0,001)$ entre os valores absolutos para os rapazes, e de $0,43(\mathrm{p}<0,001)$ para as moças. Por outro lado, quando os valores do $\dot{\mathrm{V}}{ }_{2}\left(\mathrm{~mL} \cdot \mathrm{kg}^{-1} \cdot \mathrm{min}^{-1}\right)$ foram analisados, ocorreu uma mudança entre as mesmas relações, pois os coeficientes saltaram para $0,79(\mathrm{p}<0,001)$ e $0,67(\mathrm{p}<0,001)$ para rapazes moças respectivamente. Enquanto o tempo de corrida exerceu uma relação moderada com os valores absolutos do $\dot{\mathrm{V}}_{2}$, essa relação passou a ser elevada para a potência aeróbia relativa, numa demonstração evidente de que um maior tempo de corrida pode estar associado a estágios maturacionais mais avançados, independentemente da idade. Ou seja, uma massa corporal mais elevada, para um mesmo grupo etário, permitiu ao executante do teste suportar maiores cargas do esforço.

$\mathrm{Na}$ literatura internacional, os resultados são distintos. Por exemplo, no estudo de ARMSTRONG et al. (1991), por exemplo, ao analisarem a relação da potência aeróbia relativa e a idade, verificaram que entre os rapazes não ocorreu qualquer relação, pois os 
valores médios apresentaram um comportamento estável. Por outro lado, entre as moças, essa relação foi negativa $(r=-0,26, p<0,05)$, ou seja, os valores médios tornaram-se mais baixos com o passar dos anos. No estudo de KEMPER e VERSCHUUR (1987), os resultados da potência aeróbia relativa a $\mathrm{MC}^{-1}$ demonstraram que entre os rapazes também não houve ganhos, enquanto que entre as moças as médias caíram em torno de 11\%, como observado nos estudos anteriores.

Numa outra perspectiva, McMURRAY, HARREL, BANGDIWALA e HU (2003), avaliaram a relação entre a potência aeróbia relativa e os níveis de atividade física. Os resultados demonstraram que para todas as idades as moças tinham níveis de atividade física e de $\dot{\mathrm{V}} \mathrm{O}_{2}\left(\mathrm{~mL} \cdot \mathrm{kg}^{-1} \cdot \mathrm{min}^{-1}\right)$ mais baixos que os rapazes. Mesmo entre as moças e rapazes mais ativos e com maiores níveis de potência aeróbia, a potência aeróbia relativa diminuiu paulatinamente com o passar dos anos, sendo mais acentuada entre as moças (18\%) que entre os rapazes $(7 \%)$.

No Brasil, poucos estudos apresentaram resultados da potência aeróbia para crianças e adolescentes mediante teste de esforço máximo, tanto em esteira quanto em cicloergômetro. Utilizando-se do primeiro tipo de ergômetro, RODRIGUES et al. (2006) apresentaram resultados médios da potência aeróbia relativa $\left(\mathrm{mL} \cdot \mathrm{kg}^{-1} \cdot \mathrm{min}^{-1}\right)$ para crianças e adolescentes de Vitória (ES). Foram avaliados 177 rapazes e 203 moças com idade de 10 a 14 anos, e os resultados indicaram que para todas as idades os rapazes apresentaram valores médios do $\dot{\mathrm{VO}}_{2}$ estatisticamente mais elevados que os das moças. No período, o ganho médio entre os rapazes foi de apenas $14 \%$, enquanto entre as moças ocorreu uma diminuição na ordem de $4 \%$. As diferenças entre os sexos variaram de $13 \%$ aos 10 anos e a $35 \%$ aos 14 anos (14\% e $28 \%$, respectivamente, no presente estudo). Quando os resultados para ambos os sexos foram analisados no mesmo período etário, os ganhos médios foram superiores ao do presente estudo em relação aos rapazes (14\% e 9\%), mas semelhantes entre as moças (diminuição de $4 \%$ em ambos os estudos). As diferenças entre os sexos foram proporcionalmente idênticas aos 10 anos e muito próximas aos 14 anos, demonstrando que o comportamento observado no presente estudo está de acordo com dados da literatura.

Utilizando-se dos segundo tipo de ergômetro, DUARTE e DUARTE (1989) observaram que os rapazes apresentaram valores médios mais elevados que as moças em todas as idades, porém com diferenças estatisticamente significantes a partir dos 14 anos, tanto em 
valores absolutos quanto relativos. No caso dos valores absolutos, os resultados demonstraram um aumento mais acentuado entre os rapazes com o passar dos anos, com ganhos médios de $91 \%$ dos 10 aos 18 anos e de $73 \%$ apenas até os 16 anos. Os ganhos médios para as moças foram de $20 \%$ aos 18 e de $26 \%$ aos 16 anos. Em termos relativos $\left(\mathrm{kg}^{-1}\right)$, os resultados inverteram a tendência, pois os rapazes mantiveram suas médias estáveis ao longo dos anos enquanto as moças as diminuíram no mesmo período, inclusive quando considerados os resultados dos 10 aos 16 anos. Exemplo disso é que o ganho médio para os rapazes foi de apenas $2 \%$, enquanto para as moças as perdas foram de quase $32 \%$ até os 18 anos, e $29 \%$ considerando os resultados até os 16 anos para as moças.

\subsubsection{Potência aeróbia relativa à $\mathrm{MCM}\left(\mathrm{mL} \cdot \mathrm{MCM}^{-1} \cdot \mathrm{min}^{-1}\right)$}

Ao se tentar minimizar um possível efeito negativo da massa corporal total, recorrendo aos valores da potência aeróbia relativa à $\mathrm{MCM}$, os resultados apresentaram comportamentos semelhantes ao anterior, porém ligeiramente mais elevados para ambos os sexos (FIGURA 13). Entre os rapazes, foi verificado um comportamento crescente da potência aeróbia até os 13 anos, que mantém seus valores médios até os 16 anos, enquanto que, entre as moças, houve um aumento mais discreto. Os ganhos observados entre os sexos foram na ordem de $8 \%$ e $6 \%$ para rapazes e moças, respectivamente. No estudo de KEMPER e VERSCHUUR (1987), os resultados do $\dot{\mathrm{VO}}_{2}$ pico, relativo à $\mathrm{MCM}^{-1}$, demonstraram que entre os rapazes os valores médios permaneceram constantes com o passar dos anos, enquanto que entre as moças as médias caíram em torno de 7\%. 


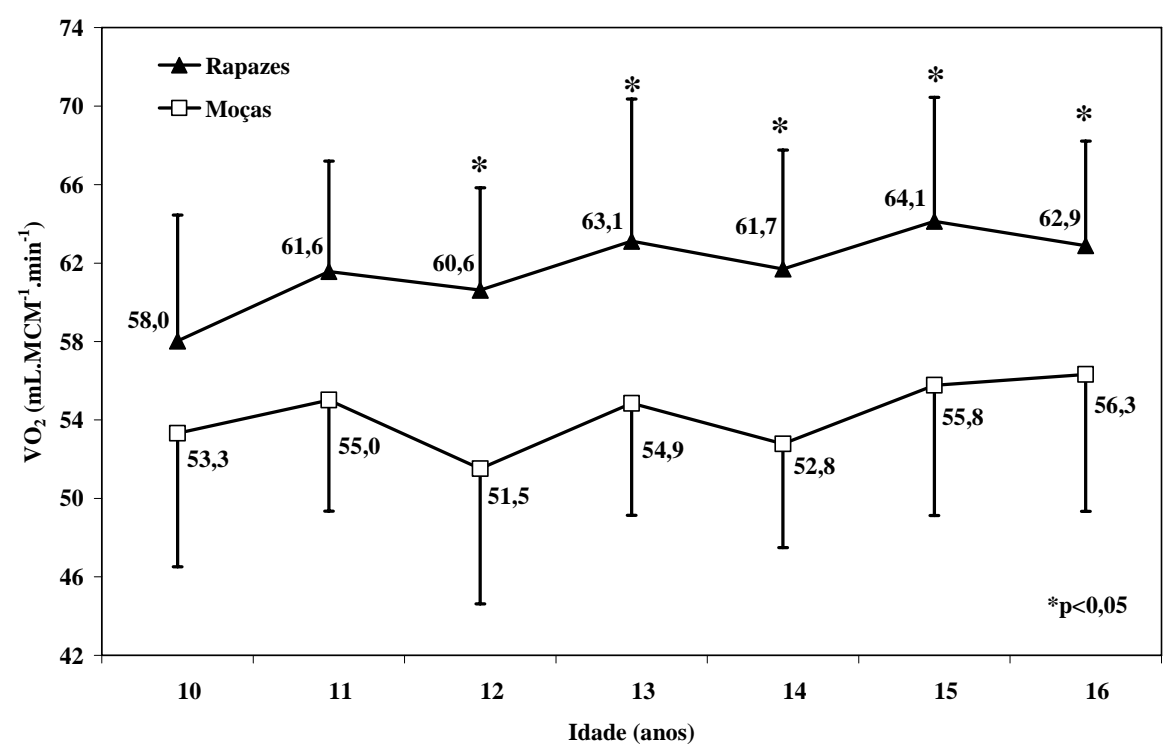

FIGURA 13 - Curvas de distância para o $\mathrm{VO}_{2}\left(\mathrm{~mL} \cdot \mathrm{MCM}^{-1} \cdot \mathrm{min}^{-1}\right)$ de crianças e adolescentes de ambos os sexos.

A média das diferenças do $\dot{\mathrm{VO}}{ }_{2}\left(\mathrm{~mL} \cdot \mathrm{MCM}^{-1} \cdot \mathrm{min}^{-1}\right)$ entre todos os grupos etários e sexos foi menos acentuada (apenas 14\%) do as observadas na potência aeróbia relativa a $\mathrm{MC}^{-1}$. As maiores diferenças, por outro lado, foram observadas dos 12 aos 15 anos (16\%), e relativamente mais baixas nas demais idades (11\%). Apenas nas idades de 10 e 11 anos não houve diferença estatisticamente significante entre os sexos. De maneira geral, os resultados na literatura apresentaram comportamentos semelhantes, tanto em estudos longitudinais quanto transversais quando os resultados foram analisados mediante a MCM.

\subsubsection{Potência aeróbia relativa: ajustes alométricos}

$\mathrm{O}$ comportamento da potência aeróbia relativa à $\mathrm{MC}$, na escala de potência de 0,67 e 0,75 é representado na Figura 14. Os resultados demonstraram que em ambos os sexos, para ambas as escalas de potência, o $\dot{\mathrm{VO}}_{2}$ pico elevou-se com o passar dos anos, mas foi mais acentuado entre os rapazes do que entre as moças, para a potência de 0,67 , sugerindo que o $\dot{\mathrm{VO}}_{2}$ pico poderá ser melhor ajustado pela potência baseada na lei de superfície corporal, mais 
recomendada para estudos longitudinais. Entretanto, os resultados da potência aeróbia com a MC elevada a 0,75 apresentou uma correlação com a idade moderada para os rapazes $(\mathrm{r}=$ $0,63, p<0,001)$, e baixa para as moças $(r=0,29, p<0,005)$, embora este expoente apresente relações para dados obtidos transversalmente para indivíduos adultos.

Contudo, a simultaneidade dos resultados entre as duas escalas de potência demonstrou que a utilização de uma escala, em detrimento da outra, dependendo da referência teórica adotada, apresentará rigorosamente os mesmos comportamentos de curvas de distância, pois, nos dois casos, os valores médios para cada grupo etário foram representativos da mesma unidade de medida do tamanho dos mesmos indivíduos. Ou seja, o mesmo efeito da massa corporal foi observado para todos os indivíduos.

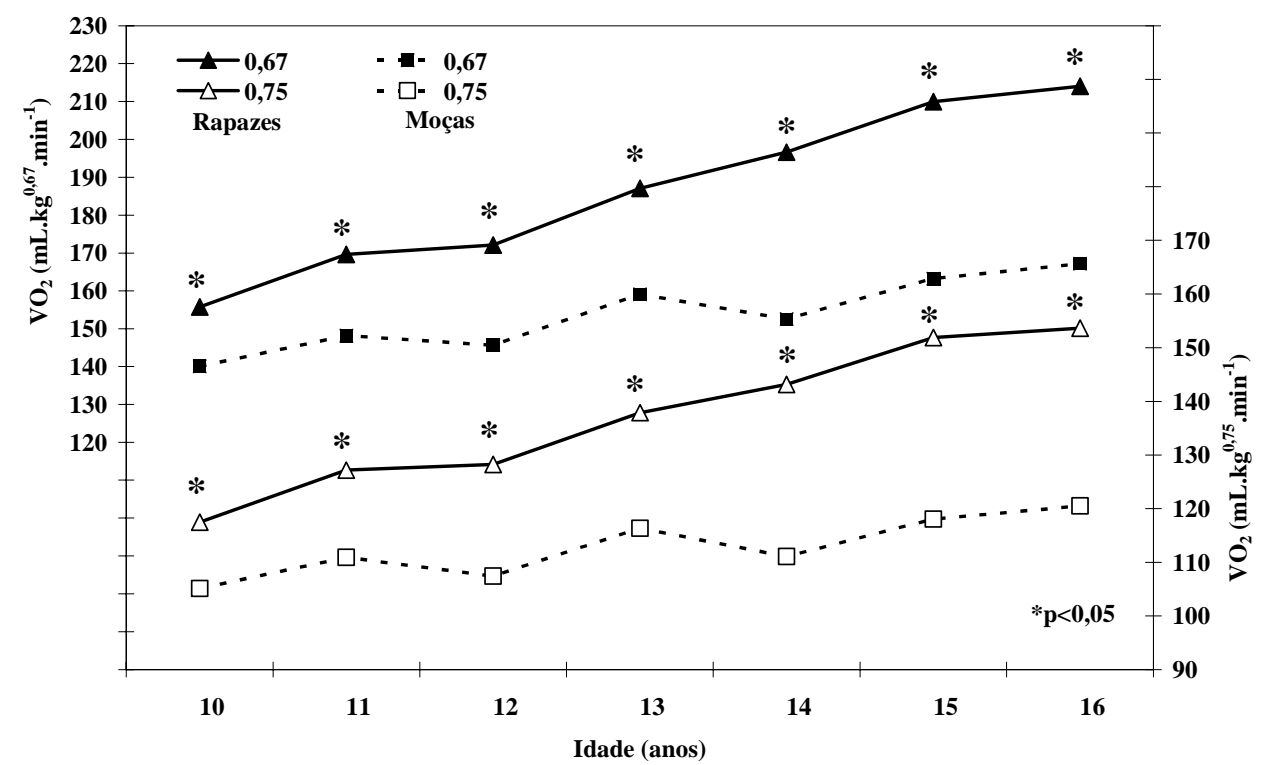

FIGURA 14 - Curvas de distância para os valores médios do $\mathrm{VO}_{2} \underline{\text { relativo à } \mathrm{MC} \text { em uma }}$ escala de potência de 0,67 e 0,75 de crianças e adolescentes de ambos os sexos.

Nesse sentido, nos casos de utilização de escala de potência, foram verificadas diferenças estatisticamente significantes para todos os grupos etários analisados, também observados quando o $\dot{\mathrm{VO}}_{2}$ pico estava relativo a $\mathrm{MC}^{1}$. As diferenças entre os sexos foram mais acentuadas para o $\dot{\mathrm{VO}}_{2}\left(\mathrm{MC}^{0,67}\right)$, devido a $\mathrm{MC}$ ser escalonada em uma proporção menor para 
cada indivíduo, elevando os valores médios da potência aeróbia de $140 \mathrm{~mL} \cdot \mathrm{kg}^{-0,67} \cdot \mathrm{min}^{-1} \operatorname{dos} 10$ aos 16 anos para $167 \mathrm{~mL} \cdot \mathrm{kg}^{-0,67} \cdot \mathrm{min}^{-1}$ para as moças, e de 117 para $153 \mathrm{~mL} \cdot \mathrm{kg}^{-0,75} \cdot \mathrm{min}^{-1}$, no mesmo período etário para os rapazes. Quando a mesma escala de potência é adotada para ambos os sexos, preservam-se as mesmas diferenças observadas anteriormente para o $\dot{\mathrm{V}} \mathrm{O}_{2}$ pico estava relativo à $\mathrm{MC}^{-1}$.

Os ganhos dos 10 aos 16 anos de idade, para ambos os sexos, foram de 37 e 19\%, relativos à $\mathrm{MC}^{0,67}$ e de 31 e $15 \%$ relativos à $\mathrm{MC}^{0,75}$ para rapazes e moças, respectivamente. As diferenças médias foram virtualmente idênticas para cada grupo etário, ou seja, os rapazes apresentaram valores médios superiores em $21 \%$ em relação às moças tanto para a $\mathrm{MC}^{0,67}$ quanto para $\mathrm{MC}^{0,75}$. As diferenças entre os dois grupos de escala de potência se deram para os valores absolutos, devido às diferenças na escala de potência da MC serem as mesmas anteriormente descritas.

No que diz respeito ao adequado uso de ajustes na potência aeróbia por meio de escala de potência, faz-se necessário, em primeiro lugar, verificar se o uso de modelos lineares para os ajustes funcionais satisfazem a condição de igualdade entre o coeficiente de correlação $\mathrm{r}_{\mathrm{xy}}$ e o quociente dos coeficientes de variação $\left(\mathrm{CV}_{\mathrm{x}} / \mathrm{CV}_{\mathrm{y}}\right)$, para ambos os sexos; em segundo lugar, se essas condições forem satisfeitas para os diferentes grupos etários, considerar o ajuste alométrico, em ambos os sexos e grupos etários, pela massa corporal total (MC) e a massa corporal magra (MCM), conforme sugeriu TANNER (1949). Nesse sentido, as Tabelas 9, 10 e 11 apresentam todos os coeficientes de variação $(\mathrm{CV})$ nos diferentes grupos etários e para ambos os sexos, envolvendo as variáveis do $\dot{\mathrm{VO}}_{2}$ pico $\left(\mathrm{L} \cdot \mathrm{min}^{-1}\right)$ para a $\mathrm{MC}(\mathrm{kg})$ e para a $\mathrm{MCM}$ $(\mathrm{kg})$. 
TABELA 9 - Valores dos coeficientes de variação $\left(\mathrm{CV}_{\mathrm{xy}}\right)$ e de correlação linear $\left(\mathrm{r}_{\mathrm{xy}}\right)$ para a potência aeróbia e MC relativo a idade e sexo, de crianças e adolescentes.

\begin{tabular}{|c|c|c|c|c|}
\hline \multirow[b]{2}{*}{ Idade } & \multicolumn{2}{|c|}{ Rapazes } & \multicolumn{2}{|c|}{ Moças } \\
\hline & $\begin{array}{l}\mathrm{MC}(\mathrm{CVx}) \\
\mathrm{VO}_{2}(\mathrm{CVy}) \\
\end{array}$ & $\begin{array}{c}\mathrm{CV}_{\mathrm{x}} / \mathrm{CV}_{\mathrm{y}} \\
\mathrm{r}_{\mathrm{xy}} \\
\end{array}$ & $\begin{array}{l}\mathrm{MC}(\mathrm{CVx}) \\
\mathrm{VO}_{2}(\mathrm{CVy}) \\
\end{array}$ & $\begin{array}{c}\mathrm{CV}_{\mathrm{x}} / \mathrm{CV}_{\mathrm{y}} \\
\mathrm{r}_{\mathrm{xy}} \\
\end{array}$ \\
\hline 10 & $\begin{array}{l}24,1 \\
09,4\end{array}$ & $\begin{array}{c}2,6 \\
0,64 *\end{array}$ & $\begin{array}{l}17,6 \\
16,0\end{array}$ & $\begin{array}{c}1,1 \\
0,72 *\end{array}$ \\
\hline 11 & $\begin{array}{l}20,1 \\
13,4\end{array}$ & $\begin{array}{c}1,5 \\
0,51^{*}\end{array}$ & $\begin{array}{l}18,5 \\
21,8\end{array}$ & $\begin{array}{c}0,84 \\
0,79 *\end{array}$ \\
\hline 12 & $\begin{array}{l}25,0 \\
15,9\end{array}$ & $\begin{array}{c}1,6 \\
0,77^{*}\end{array}$ & $\begin{array}{l}24,2 \\
21,7\end{array}$ & $\begin{array}{c}1,11 \\
0,78^{*}\end{array}$ \\
\hline 13 & $\begin{array}{l}24,2 \\
24,4\end{array}$ & $\begin{array}{c}0,99 \\
0,81^{*}\end{array}$ & $\begin{array}{l}19,4 \\
16,6\end{array}$ & $\begin{array}{c}1,17 \\
0,75^{*}\end{array}$ \\
\hline 14 & $\begin{array}{l}12,1 \\
14,4\end{array}$ & $\begin{array}{c}0,84 \\
0,69^{*}\end{array}$ & $\begin{array}{l}22,1 \\
10,9\end{array}$ & $\begin{array}{c}2,03 \\
0,75^{*}\end{array}$ \\
\hline 15 & $\begin{array}{l}17,9 \\
13,4\end{array}$ & $\begin{array}{c}1,33 \\
0,65^{*}\end{array}$ & $\begin{array}{l}15,5 \\
18,8\end{array}$ & $\begin{array}{c}0,82 \\
0,67^{*}\end{array}$ \\
\hline 16 & $\begin{array}{l}14,1 \\
13,5\end{array}$ & $\begin{array}{c}1,0 \\
0,72 *\end{array}$ & $\begin{array}{l}15,2 \\
15,3\end{array}$ & $\begin{array}{c}0,99 \\
0,61 *\end{array}$ \\
\hline $10-16$ & $\begin{array}{l}26,6 \\
17,3\end{array}$ & $\begin{array}{c}1,53 \\
0,87^{*}\end{array}$ & $\begin{array}{l}25,4 \\
24,2\end{array}$ & $\begin{array}{c}1,05 \\
0,83^{*}\end{array}$ \\
\hline
\end{tabular}

$\left({ }^{*} \mathrm{p}<0,05\right)$

No caso da MC (Tabela 9), os resultados mostraram que para todos os grupos etários, de ambos os sexos, nenhuma das variáveis satisfez a relação de linearidade proposta por TANNER (1949). Ou seja, o $\mathrm{V}_{2}$ pico não deverá ser normalizado considerando qualquer uma das variáveis, em uma escala de potência igual a $1\left(\mathrm{MC}^{-1}\right)$. A disparidade entre o quociente dos dois coeficientes de variação (CVx e CVy), com o coeficiente de correlação linear é enorme. Este efeito pode ser percebido pelos coeficientes de variação para a massa corporal e para $\mathrm{o} \mathrm{V}_{2}$ pico, principalmente nos resultados de 10 a 16 anos, considerando rapazes e moças, pois a diferença entre eles na $\mathrm{MC}$ foi inferior a $10 \%$, enquanto que na potência aeróbia foi superior a 39\%. Ou seja, as moças apresentaram muito mais variabilidade nos resultados do que os rapazes, embora os resultados médios fossem mais baixos. Entre todos os resultados, apenas uma exceção ocorreu nessas comparações, pois um valor muito próximo $(0,84$ e 0,79$)$ entre os coeficientes foi observado para as moças na idade de 11 anos (destacado em negrito na Tabela 10).

Por outro lado, ao ser considerada a $\mathrm{MCM}^{1}$ para o ajuste do $\dot{\mathrm{V}} \mathrm{O}_{2}$ pico (TABELA 10), houve uma maior disparidade entre os dois coeficientes, principalmente entre as moças 
nas idades de 11,13 e 16 anos $(0,98$ e 0,$91 ; 0,75$ e 0,$79 ; 0,71$ e 0,63 , respectivamente destacados em negrito na Tabela 10), influenciando no conjunto etário dos 10 aos 16 anos, uma menor discordância entre esses dois coeficientes $(0,83$ e 0,87$)$. Entre os rapazes, também ocorreram concordâncias entre o quociente dos coeficientes de variação e o de correlação, especificamente nas idades de 13 e 14 anos (0,95 e 0,88; 0,77 e 0,70, respectivamente), entr, isso não foi suficiente para aproximar os coeficientes no conjunto etário entre eles $(1,57$ e 0,93 respectivamente, dos 10 aos 16 anos).

TABELA 10 - Valores dos coeficientes de variação $(\mathrm{CV})$ e de correlação linear $\left(\mathrm{r}_{\mathrm{xy}}\right)$ para a potência aeróbia e MCM relativo à idade e ao sexo, de crianças e adolescentes.

\begin{tabular}{|c|c|c|c|c|}
\hline \multirow[b]{2}{*}{ Idade } & \multicolumn{2}{|c|}{ Rapazes } & \multicolumn{2}{|c|}{ Moças } \\
\hline & $\begin{array}{c}\mathrm{MCM}(\mathrm{Vx}) \\
\mathrm{VO}_{2}(\mathrm{Vy})\end{array}$ & $\begin{array}{c}\mathrm{V}_{\mathrm{x}} / \mathrm{V}_{\mathrm{y}} \\
\mathrm{r}_{\mathrm{xy}} \\
\end{array}$ & $\begin{array}{c}\mathrm{MCM}(\mathrm{Vx}) \\
\mathrm{VO}_{2}(\mathrm{Vy})\end{array}$ & $\begin{array}{c}\mathrm{V}_{\mathrm{x}} / \mathrm{V}_{\mathrm{y}} \\
\mathrm{r}_{\mathrm{xy}} \\
\end{array}$ \\
\hline 10 & $\begin{array}{c}17,9 \\
9,4\end{array}$ & $\begin{array}{c}1,9 \\
0,63^{*}\end{array}$ & $\begin{array}{l}14,4 \\
16,0\end{array}$ & $\begin{array}{c}0,90 \\
0,60^{*}\end{array}$ \\
\hline 11 & $\begin{array}{l}15,0 \\
13,4\end{array}$ & $\begin{array}{c}1,1 \\
0,75^{*}\end{array}$ & $\begin{array}{l}14,9 \\
21,8\end{array}$ & $\begin{array}{c}0,98 \\
0,91 *\end{array}$ \\
\hline 12 & $\begin{array}{l}16,8 \\
15,9\end{array}$ & $\begin{array}{c}1,06 \\
0,85^{*}\end{array}$ & $\begin{array}{l}15,2 \\
21,7\end{array}$ & $\begin{array}{c}0,70 \\
0,82 *\end{array}$ \\
\hline 13 & $\begin{array}{l}23,2 \\
24,4\end{array}$ & $\begin{array}{c}0,95 \\
0,88^{*}\end{array}$ & $\begin{array}{l}12,5 \\
16,6\end{array}$ & $\begin{array}{c}\mathbf{0 , 7 5} \\
\mathbf{0 , 7 9} *\end{array}$ \\
\hline 14 & $\begin{array}{l}11,2 \\
14,4\end{array}$ & $\begin{array}{c}\mathbf{0 , 7 7} \\
\mathbf{0 , 7 0}\end{array}$ & $\begin{array}{l}16,0 \\
10,9\end{array}$ & $\begin{array}{l}1,46 \\
0,74^{*}\end{array}$ \\
\hline 15 & $\begin{array}{l}13,8 \\
13,4\end{array}$ & $\begin{array}{c}1,02 \\
0,67^{*}\end{array}$ & $\begin{array}{l}11,2 \\
18,8\end{array}$ & $\begin{array}{c}0,59 \\
0,81^{*}\end{array}$ \\
\hline 16 & $\begin{array}{l}11,9 \\
13,5\end{array}$ & $\begin{array}{c}0,88 \\
0,78^{*}\end{array}$ & $\begin{array}{l}10,9 \\
15,3\end{array}$ & $\begin{array}{c}0,71 \\
0,63^{*}\end{array}$ \\
\hline $10-16$ & $\begin{array}{l}27,1 \\
17,3\end{array}$ & $\begin{array}{c}1,57 \\
0,93^{*}\end{array}$ & $\begin{array}{l}20,3 \\
24,2\end{array}$ & $\begin{array}{c}0,83 \\
0,87^{*}\end{array}$ \\
\hline
\end{tabular}

Quando considerado o critério de linearidade para cada grupo etário, independentemente do sexo, os resultados demonstraram maiores discrepâncias entre os coeficientes de variação e correlação relativos à $\mathrm{MC}$, porém, menores para alguns grupos em relação à MCM (destacadas em negrito na Tabela 11). Com efeito, nas idades de 11, 13 e 15 anos, os resultados foram menos discordantes entre os coeficientes $(0,76$ e 0,$81 ; 0,84$ e 0,80 ; 
0,70 e 0,76 , respectivamente), favorecendo, em grande medida, para que no conjunto dos grupos etários, envolvendo ambos os sexos (10 a 16 anos), a diferença entre eles fosse muito pequena $(0,84$ e 0,89$)$, sendo a mesma diferença absoluta observada para todas as moças em relação à $\operatorname{MCM}(0,83$ e 0,87$)$.

TABELA 11 - Valores dos coeficientes de variação $(\mathrm{CV})$ e de correlação linear $\left(\mathrm{r}_{\underline{x}}\right)$ da potência aeróbia, MC e MCM relativos à idade para crianças e adolescentes de ambos os sexos.

\begin{tabular}{|c|c|c|c|c|}
\hline \multirow[b]{2}{*}{ Idade } & \multicolumn{2}{|c|}{ MC } & \multicolumn{2}{|c|}{ MCM } \\
\hline & $\begin{array}{l}\mathrm{MC}(\mathrm{Vx}) \\
\mathrm{VO}_{2}(\mathrm{Vy})\end{array}$ & $\begin{array}{c}\mathrm{V}_{\mathrm{x}} / \mathrm{V}_{\mathrm{y}} \\
\mathrm{r}_{\mathrm{xy}}\end{array}$ & $\begin{array}{c}\mathrm{MCM}(\mathrm{Vx}) \\
\mathrm{VO}_{2}(\mathrm{Vy})\end{array}$ & $\begin{array}{c}\mathrm{V}_{\mathrm{x}} / \mathrm{V}_{\mathrm{y}} \\
\mathrm{r}_{\mathrm{xy}} \\
\end{array}$ \\
\hline 10 & $\begin{array}{l}20,9 \\
12,9\end{array}$ & $\begin{array}{c}1,62 \\
0,59^{*}\end{array}$ & $\begin{array}{l}16,1 \\
12,9\end{array}$ & $\begin{array}{c}1,24 \\
0,58^{*}\end{array}$ \\
\hline 11 & $\begin{array}{l}19,0 \\
18,4\end{array}$ & $\begin{array}{c}1,03 \\
0,62^{*}\end{array}$ & $\begin{array}{l}14,7 \\
18,4\end{array}$ & $\begin{array}{c}0,76 \\
0,81 *\end{array}$ \\
\hline 12 & $\begin{array}{l}24,9 \\
19,1\end{array}$ & $\begin{array}{c}1,30 \\
0,69^{*}\end{array}$ & $\begin{array}{l}16,1 \\
19,1\end{array}$ & $\begin{array}{c}0,84 \\
0,74^{*}\end{array}$ \\
\hline 13 & $\begin{array}{l}21,9 \\
21,5\end{array}$ & $\begin{array}{c}1,02 \\
0,68^{*}\end{array}$ & $\begin{array}{l}18,1 \\
21,5\end{array}$ & $\begin{array}{c}0,84 \\
0,80 *\end{array}$ \\
\hline 14 & $\begin{array}{l}19,9 \\
18,0\end{array}$ & $\begin{array}{c}1,11 \\
0,39^{*}\end{array}$ & $\begin{array}{l}14,1 \\
18,0\end{array}$ & $\begin{array}{c}0,78 \\
0,66^{*}\end{array}$ \\
\hline 15 & $\begin{array}{l}16,5 \\
19,9\end{array}$ & $\begin{array}{c}0,83 \\
0,52 *\end{array}$ & $\begin{array}{l}13,9 \\
19,9\end{array}$ & $\begin{array}{c}0,70 \\
0,76^{*}\end{array}$ \\
\hline 16 & $\begin{array}{l}14,6 \\
19,9\end{array}$ & $\begin{array}{c}0,73 \\
0,58^{*}\end{array}$ & $\begin{array}{l}14,2 \\
19,9\end{array}$ & $\begin{array}{c}0,71 \\
0,84 *\end{array}$ \\
\hline $10-16$ & $\begin{array}{l}26,6 \\
28,7\end{array}$ & $\begin{array}{c}0,92 \\
0,78^{*}\end{array}$ & $\begin{array}{l}24,2 \\
28,7\end{array}$ & $\begin{array}{c}0,84 \\
0,89 *\end{array}$ \\
\hline
\end{tabular}

No geral, esses resultados demonstraram que para todos os grupos etários, independente do sexo, ocorreram variabilidades elevadas entre a potência aeróbia para qualquer uma das duas variáveis morfológicas ( $\mathrm{MC}$ ou $\mathrm{MCM}$ ), além dos coeficientes de correlação linear apresentarem-se como os mais baixos. Contudo, os menores coeficientes de variação $(\mathrm{CV})$ e os maiores coeficientes de correlação linear $\left(\mathrm{r}_{\mathrm{xy}}\right)$ foram obtidos quando todo o conjunto etário foi testado (10 a 16 anos). Neste caso, o coeficiente de correlação linear mais elevado (próximo de 1) ocorreu entre os rapazes, para a MCM. 
Ou seja, os resultados demonstraram que de fato ocorreu um efeito "enganoso" quando a potência aeróbia foi ajustada linearmente com a $\mathrm{MC}^{-1}$, penalizando os indivíduos mais pesados em relação aos mais leves, para um mesmo nível de $\dot{\mathrm{V}}_{2}$ pico absoluto. Por outro lado, quando se analisou o ajuste linear para a $\mathrm{MCM}^{-1}$, um possível efeito negativo da elevada quantidade de gordura corporal foi reduzido, permanecendo a dos indivíduos mais pesados (verificar as Figuras 11 e 12), porém em menor magnitude.

No caso de um ajuste da potência aeróbia pela MCM, é importante destacar que o procedimento adotado para a determinação da quantidade de gordura corporal poderá contribuir na diminuição das possíveis discrepâncias dos resultados, pois aqueles procedimentos que geram maior quantidade de erro na determinação da gordura corporal inviabilizarão o ajuste adequado pela MCM, além da escolha de um protocolo de teste apropriado. Em razão dos ajustes lineares da MC na potência aeróbia não satisfazerem o pressuposto teórico apontados por TANNER (1949), os modelos das regressões alométricas para grupos etários dependentes e independentes do sexo são apresentados na Tabela 12.

TABELA 12 - Equações de regressão alométrica entre a potência aeróbia e a MC relativa à $\underline{\text { idade e ao sexo de crianças e adolescentes. }}$

\begin{tabular}{|c|c|c|c|}
\hline Idade & Rapazes & $\underline{\text { Moças }}$ & $\frac{\text { Ambos os }}{\text { sexos }}$ \\
\hline 10 & $\begin{array}{c}0,30 \mathrm{x}-0,57 \\
\mathrm{r}=0,70^{*}\end{array}$ & $\begin{array}{c}0,67 x-1,97 \\
r=0,76^{*}\end{array}$ & $\begin{array}{c}0,41 x-0,98 \\
r=0,62^{*}\end{array}$ \\
\hline 11 & $\begin{array}{c}0,37 x-0,69 \\
r=0,55^{\S}\end{array}$ & $\begin{array}{c}0,94 \mathrm{x}-2,89 \\
\mathrm{r}=0,79^{*}\end{array}$ & $\begin{array}{c}0,66 x-1,69 \\
r=0,62^{*}\end{array}$ \\
\hline 12 & $\begin{array}{c}0,53 \mathrm{x}-1,26 \\
\mathrm{r}=0,79^{*}\end{array}$ & $\begin{array}{c}0,78 x-2,35 \\
r=0,76^{*}\end{array}$ & $\begin{array}{c}0,56 x-1,45 \\
r=0,65^{*}\end{array}$ \\
\hline 13 & $\begin{array}{c}0,87 \mathrm{x}-2,45 \\
\mathrm{r}=0,83^{*}\end{array}$ & $\begin{array}{c}0,67 \mathrm{x}-1,85 \\
\mathrm{r}=0,74^{*}\end{array}$ & $\begin{array}{c}0,69 x-1,83 \\
r=0,69 *\end{array}$ \\
\hline 14 & $\begin{array}{c}0,81 \mathrm{x}-2,19 \\
\mathrm{r}=0,69^{*}\end{array}$ & $\begin{array}{c}0,41 \mathrm{x}-0,86 \\
\mathrm{r}=0,74^{*}\end{array}$ & $\begin{array}{c}0,49 x-1,04 \\
r=0,45^{*}\end{array}$ \\
\hline 15 & $\begin{array}{c}0,52 \mathrm{x}-0,96 \\
\mathrm{r}=0,69^{*}\end{array}$ & $\begin{array}{c}0,79 x-2,33 \\
r=0,65^{*}\end{array}$ & $\begin{array}{c}0,63 x-1,54 \\
r=0,50^{*}\end{array}$ \\
\hline 16 & $\begin{array}{c}0,73 \mathrm{x}-1,79 \\
\mathrm{r}=0,75^{*}\end{array}$ & $\begin{array}{c}0,56 x-1,37 \\
r=0,57^{*}\end{array}$ & $\begin{array}{c}0,79 x-2,16 \\
r=0,57^{*}\end{array}$ \\
\hline $10-16$ & $\begin{array}{c}0,91 x-2,61 \\
R=0,88^{*}\end{array}$ & $\begin{array}{c}\mathbf{0 , 8 2 x}-2,47 \\
\mathbf{R}=0,85^{*}\end{array}$ & $\begin{array}{c}\mathbf{0 , 8 5 x}-2,47 \\
r=0,81^{\#}\end{array}$ \\
\hline
\end{tabular}

$\left({ }^{\S} \mathrm{p}<0,05,{ }^{*} \mathrm{p}<0,01,{ }^{\#} \mathrm{p}<0,0001\right)$ 
Os resultados demonstraram que os expoentes alométricos obtidos variaram de 0,30 até 0,87 , nas idades de 10 e 13 anos para os rapazes, e de 0,41 a 0,94 aos 14 e 11 anos para moças. Ou seja, são inúmeras as diferenças entre os expoentes alométricos obtidos nos diferentes grupos etários e os seus respectivos coeficientes de correlação, pois as correlações variaram de elevada para baixa em ambos os sexos (TABELA 13). Isso permite inferir que em pequenos grupos de indivíduos, independentemente do grupo etário e sexo, os expoentes alométricos produzidos não são confiáveis. Quando analisados os grupos etários, independentemente do sexo, os expoentes variaram de 0,41 a 0,79 , aos 11 e aos 16 anos respectivamente, com expoentes intermediários na maioria dos grupos etários. Os coeficientes de correlação não apresentaram os mesmos resultados, sendo mais baixos entre os sexos do que para cada grupo etário isoladamente.

Quando o conjunto de indivíduos para cada sexo foi analisado por um único grupo etário (10 a 16 anos), os expoentes alométricos foram de 0,91 e 0,82 , apresentando os coeficientes de correlação mais elevados do que em qualquer idade isoladamente $(0,88$ e 0,85 , para rapazes e moças respectivamente). Na Figura 15, apresentamos o comportamento dos valores médios para potência aeróbia ajustada pelos expoentes $\mathrm{MC}^{-0,91} \mathrm{e} \mathrm{MC}^{-0,82}$ de rapazes e moças, respectivamente. Ao contrário do que fora observado em qualquer outra forma de ajuste do $\dot{\mathrm{VO}}_{2}$ pico, as moças apresentaram valores médios estatisticamente mais elevados que os dos rapazes, para todos os grupos etários. Contudo, considerando que a maioria dos estudos compõem o expoente alométrico para ambos os sexos, independentemente de haverem ou não diferenças nas propriedades intensivas, o expoente para o todo o grupo de 10 a 16 anos foi de $\mathrm{b}=0,85(\mathrm{r}=0,81, \mathrm{p}<0,001)$, sendo mais elevado que o teórico de 0,75 . 


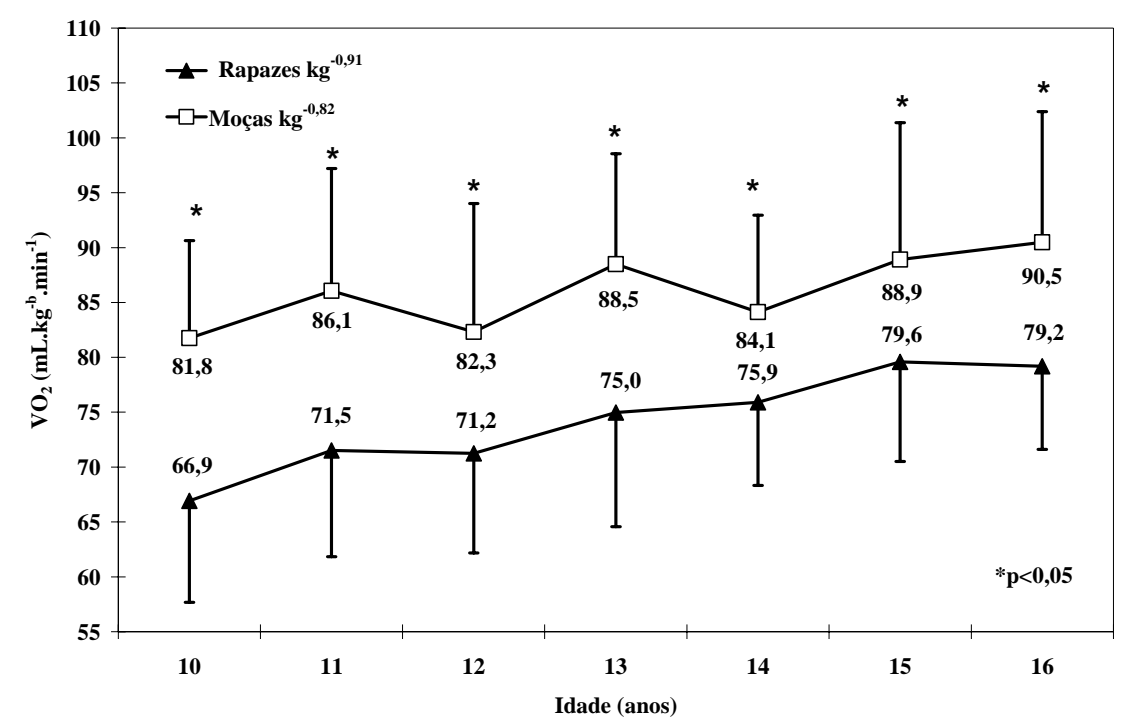

FIGURA 15 - Curvas de distância para os valores médios e desvio-padrão do $\mathrm{VO}_{2}$ relativo a $\mathrm{MC}^{0,91}$ e $\mathrm{MC}^{0,82}$ para rapazes e moças, respectivamente.

Este resultado somente pode ter ocorrido devido à massa corporal de rapazes e moças serem estatisticamente iguais em todos os grupos etários analisados. Nesse particular, entre as moças o comportamento do $\dot{\mathrm{VO}}{ }_{2}$ pico $\left(\mathrm{mL} \cdot \mathrm{kg}^{-0,82} \cdot \mathrm{min}^{-1}\right)$ foi crescente com o passar dos anos, mas variando positivamente para um pouco mais de $10 \%$ (de 81,8 para 90,5), dos 10 aos 16 anos. Porém, a magnitude dos ganhos entre os rapazes ficou acima da observada entre as moças no mesmo período etário, na ordem de $18 \%$ (de 66,9 para $79,2 \mathrm{~mL} \cdot \mathrm{kg}^{-0,91} \cdot \mathrm{min}^{-1}$ ), que foi influenciada pelo enorme aumento do $\dot{\mathrm{V}}_{2}$ pico em valores absolutos entre eles no mesmo período. A diferença proporcional das médias entre os sexos, nos diferentes grupos etários, foi de $16 \%$ em favor das moças, médias que foram diminuindo pouco a pouco (de 22 para 14\% dos 10 aos 16 anos).

Nos estudos analisados na literatura, verificou-se a tendência de apresentação de um único expoente considerado para ambos os sexos, independentemente dos grupos etários, sem que houvesse apresentação e discussão sobre os coeficientes alométricos obtidos para cada grupo. Por outro lado, a maioria dos estudos sobre a potência aeróbia ajustada por expoentes alométricos, independentemente de serem longitudinais ou transversais, apresenta cortes por faixa etárias que variam de indivíduos com idades de 6 e 7 anos (EIBERG, HASSELSTROM, GRONFELDT, FROBERG, SVENSSON e ANDRESEN, 2005), 7 a 9 
anos (ROGERS et al., 1995), 9 a 13 anos (ROWLAND et al., 1997), 11 a 13 anos (ARMSTRONG et al., 1999), 11 a 17 anos (ARMSTRONG e WELSMAN, 2001), 8 a 15 anos (EISENMANN, PIVARNIK e MALINA, 2001), 12 a 14 anos (PIVARNIK, TAYLOR CUMMINGS, 1998), 8 a 17 anos (PETTERSEN, FREDRIKSEN e INGJER, 2001) e até de crianças a adultos (MARCOVIC, VUCETIC e NEVILL, 2007; TOTH, GORAN, ADES, HOWARD e POEHLMAN, 1993).

Portanto, ao considerar ambos os sexos em um mesmo grupo etário (10 a 16 anos), o expoente alométrico obtido foi de $0,85(\mathrm{r}=0,81 \mathrm{p}<0,0001)$, sendo este expoente numa dimensão intermediaria considerando os valores obtidos para os rapazes e as moças separadamente. $\mathrm{O}$ comportamento da potência aeróbia relativa à $\mathrm{MC}^{0,85}$ para ambos os sexos, está apresentado na Figura 16. Os rapazes voltaram a apresentar valores médios mais elevados do que as moças para todos os grupos etários analisados, conforme foi verificado para os expoentes fixos de 0,67 e 0,75. Ou seja, os ganhos relativos entre os rapazes dos 10 aos 16 anos foram de $23 \%$, enquanto que, entre as moças, foram de apenas $9 \%$, sendo ao longo do período etário estudado mais baixo que os ganhos obsevados nos expoentes 0,67 e 0,75, devido a $\mathrm{MC}^{0,85}$ serem escalonada em uma dimensão mais elevada da $\mathrm{MC}$ de ambos os sexos. Contudo, as diferenças entre os grupos etários se mantiveram idênticas, por volta de $22 \%$, na elevando-se em favor dos rapazes, ao longo dos anos.

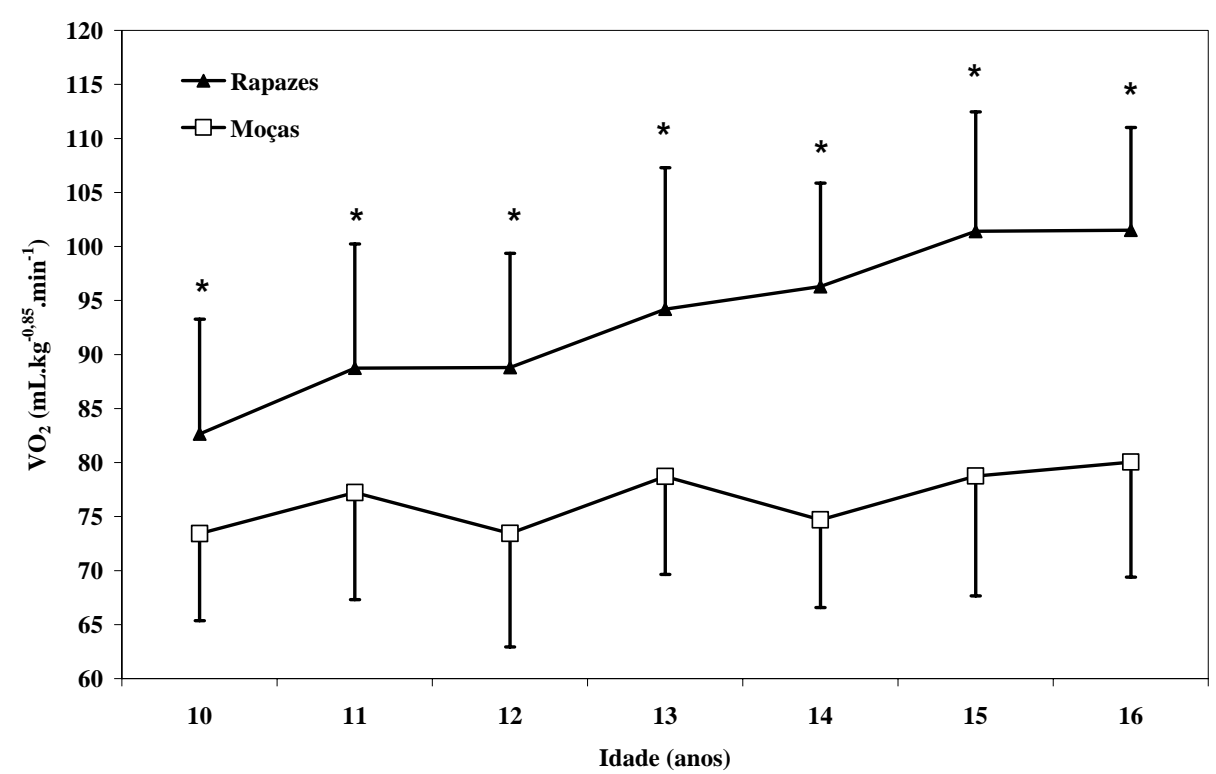

FIGURA 16 - Curvas de distância e valores médios e desvio-padrão do $\mathrm{VO}_{2}$ relativo à $\mathrm{MC}^{0,85}$ para ambos os sexos de crianças e adolescentes. 
$\mathrm{Na}$ tentativa de se encontrar expoentes que reflitam as mudanças nos diferentes períodos etários, foram realizadas sete composições com diferentes grupos etários (TABELA 13): duas com três grupos (10-12 anos; 14-16 anos); quatro com quatro grupos (10-13 anos; 11-14 anos; 12-15 anos; 13-16 anos); uma com cinco grupos (11-15 anos). Os resultados mostraram que as moças exibiram expoentes mais elevados que os dos rapazes nos grupos etários dos 10 aos 13 anos, enquanto os rapazes apresentaram expoentes elevados nos grupos etários de 14 a 16 anos. Esses resultados apontam para uma tendência interessante, onde o $\dot{\mathrm{VO}}_{2}$ pico para as moças sofreu uma maior influência da massa corporal nas idades mais precoces (até os 13 anos) do que nas idades mais avançadas (acima dos 13 anos). Para os rapazes ocorreu o inverso, já que o período de maior aumento em massa corporal aconteceu mais tarde em relação às moças e, deste modo, a massa corporal variou mais acentuadamente do que a do $\dot{\mathrm{VO}}_{2}$ pico a partir dos 14 anos.

TABELA 13 - Equações de regressão alométricas entre a potência aeróbia e a MC para diferentes grupos etários de crianças e adolescentes.

\begin{tabular}{|c|c|c|c|}
\hline $\begin{array}{l}\text { Grupos } \\
\text { Etários }\end{array}$ & Ranazes & & Ambos os \\
\hline $10-12$ & $\begin{array}{c}0,49 \mathrm{x}-1,13 \\
\mathrm{r}=0,70^{*}\end{array}$ & $\begin{array}{c}0,78 x-2,35 \\
r=0,79 *\end{array}$ & $\begin{array}{c}0,58 \mathrm{x}-1,55 \\
\mathrm{r}=0,67^{*}\end{array}$ \\
\hline $10-13$ & $\begin{array}{c}0,67 \mathrm{x}-1,75 \\
\mathrm{r}=0,77^{*}\end{array}$ & $\begin{array}{c}0,82 x-2,49 \\
r=0,83 *\end{array}$ & $\begin{array}{c}0,69 x-1,92 \\
r=0,74^{*}\end{array}$ \\
\hline $11-14$ & $\begin{array}{c}0,78 x-2,14 \\
r=0,82^{*}\end{array}$ & $\begin{array}{c}0,74 \mathrm{x}-2,16 \\
\mathrm{r}=0,81^{*}\end{array}$ & $\begin{array}{c}0,71 \mathrm{x}-1,96 \\
\mathrm{r}=0,73^{*}\end{array}$ \\
\hline $11-15$ & $\begin{array}{c}0,84 x-2,34 \\
r=0,85^{*}\end{array}$ & $\begin{array}{c}0,78 x-2,30 \\
r=0,82^{*}\end{array}$ & $\begin{array}{c}0,77 x-2,17 \\
r=0,75^{*}\end{array}$ \\
\hline $12-15$ & $\begin{array}{c}0,85 x-2,34 \\
r=0,85^{*}\end{array}$ & $\begin{array}{c}0,74 x-2,14 \\
r=0,76^{*}\end{array}$ & $\begin{array}{c}0,74 x-2,03 \\
r=0,70^{*}\end{array}$ \\
\hline $13-16$ & $\begin{array}{c}0,87 x-2,41 \\
r=0,85^{*}\end{array}$ & $\begin{array}{c}0,65 x-1,75 \\
r=0,70 *\end{array}$ & $\begin{array}{c}0,76 x-2,07 \\
r=0,66^{*}\end{array}$ \\
\hline $14-16$ & $\begin{array}{c}0,75 x-1,91 \\
r=0,77^{*}\end{array}$ & $\begin{array}{c}0,63 x-1,66 \\
r=0,65^{*}\end{array}$ & $\begin{array}{c}0,72 \mathrm{x}-1,91 \\
\mathrm{r}=0,58^{*}\end{array}$ \\
\hline
\end{tabular}

Ao considerarmos os grupos etários por sexo isoladamente, a média dos expoentes alométricos verificada entre as moças foi de 0,74 para todos os grupos, enquanto 
que para os rapazes, a média foi de 0,75 . Em ambos os casos, as médias foram virtualmente idênticas ao expoente teórico 0,75. Para os expoentes originados nos diferentes grupos etários para ambos os sexos, os expoentes mais baixos foram obtidos entre as idades de 10 a 13 anos (0,58 aos 10-12 anos; 0,69 aos 10-13 anos). Ou seja, o expoente mais próximo do teórico 0,67 ocorreu no grupo etário até os 13 anos. Por outro lado, quando a idade de 14 anos esteve presente em cinco grupos etários, os expoentes apresentaram valores mais elevados, de 0,71 a $0,77(\mathrm{r}=0,73$ a $0,75, \mathrm{p}<0,001)$, com média de 0,74 entre os grupos, um valor muito próximo do expoente teórico de 0,75 .

Num estudo envolvendo crianças de 8 a 11 anos, DENCKER, THORSSON, KARLSSON, LINDÉN, EIGBERG, WOLLMER e ANDERSEN (2006) avaliaram a potência aeróbia de rapazes e moças com idade aproximada de 10 anos, o expoente de 0,47 foi obtido para a massa corporal. No estudo de JANZ et al. (1998), os resultados foram semelhantes, pois o expoente alométrico determinado para um grupo de crianças pré-púberes (10,3 \pm 1 anos) foi de 0,49 e 0,57 para rapazes e moças respectivamente. Em ambos os estudos, os expoentes alométricos aproximaram-se do expoente 0,41 obtido para ambos os sexos na idade de 10 anos do presente estudo (Tabela 13).

Os resultados apresentados por ROGERS, OLSON e WILMORE (1995) para crianças, adolescentes e adultos de ambos os sexos reforçam essa premissa, pois entre os as crianças de ambos os sexos o expoente foi de 0,47 e, entre os adolescentes, o resultado foi um expoente $b=0,62$, porém, ainda mais baixo que o determinado entre os adultos $(b=1,02)$. Embora o número de indivíduos tenha sido diferentes nestes estudos, os resultados sugerem que nas idades até 12 ou 13 anos os expoentes são mais baixos que os encontrados em grupos etários mais elevados.

Uma forma de determinação dos expoentes alométricos, presente em alguns estudos, é mediante uma análise de covariância, com a prévia transformação logarítmica das variáveis dependente e independente ( $\dot{\mathrm{VO}}_{2}$ e $\left.\mathrm{MC}\right)$, resultando em uma análise das diferenças entre os variados coeficientes. Em um desses estudos, ARMSTRONG, WELSMAN e KIRBY (1998) avaliaram a potência aeróbia de 212 adolescentes (106 rapazes e 106 moças), também considerando os diferentes estágios maturacionais em que se encontravam para a mesma faixa etária (12,2 $\pm 0,4$ anos), ajustando a MC por análise de covariância, obtendo um expoente alométrico $b=0,65$ para ambos os sexos, estatisticamente iguais ao expoente teórico 0,67 . Os 
resultados demonstraram que os rapazes apresentaram valores médios de $\dot{\mathrm{V}}_{2}$ (absoluto e

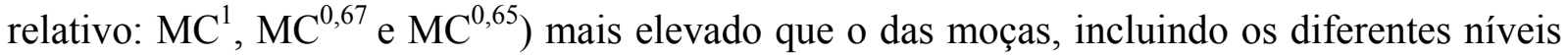
maturacionais. Nesse estudo, eles concluíram que o uso de um modelo alométrico para ajustar a massa corporal em adolescentes de 12 anos, produziu um importante efeito nas diferenças maturacionais, principalmente entre os rapazes.

No estudo longitudinal de JANZ et al. (1998), os expoentes alométrico foram determinados mediante quatro níveis maturacionais distintos: pré-púberes, púberes recentes, púberes tardios e pós-púberes. Os expoentes alométricos variaram para a massa corporal, respectivamente para rapazes e moças, em 0,49 e 0,54 nos pré-púberes; 0,42 e 0,58 para púberes recentes; 0,43 e 0,51 para púberes tardios e, 0,41 e 0,45 para os pós-púberes. Para todos os grupos maturacionais, nenhum expoente variou acima do expoente teórico de 0,67. Contudo, ao considerarem a MCM no ajuste do $\dot{\mathrm{VO}}_{2}$ pico, os expoentes apresentaram-se mais elevados em todos os grupos maturacionais, sendo entre 0,77 a 0,95 para ambos os sexos. Os expoentes femininos foram mais elevados que os masculinos em quase todos os casos analisados, com exceção do grupo pós-púbere, no qual os rapazes apresentaram um expoente de 0,81 e as moças de 0,77. Estes últimos resultados demonstraram que não houve diferenças entre os expoentes para MCM masculinos e femininos em relação aos estágios maturacionais. Ou seja, os expoentes alométricos ajustados à $\mathrm{MC}$ sofreram efeito da maturação, variando significativamente entre os rapazes à medida que maturavam, porém esse mesmo efeito não foi verificado entre as moças.

Mesmo considerando a existência de uma distribuição normal em uma variável, como a MC, essa mesma distribuição pode não ter ocorrido simultaneamente para a potência aeróbia, nos mesmos grupos etários, uma vez que a última é muito influenciada pelas condições socioculturais e ambientais. Além do mais, apesar de os expoentes estarem em torno dos expoentes teóricos para a $\mathrm{MC}^{0,67}$ ou $\mathrm{MC}^{0,75}$, como ocorreu em alguns grupos etários na presente amostra, o coeficiente de correlação linear alcançado por estes grupos foram ainda mais baixos do que nos demais, ainda que todos os coeficientes tenham significância estatística.

Os modelos das regressões alométricas, relativos a $\mathrm{MCM}$, para grupos etários são apresentados na Tabela 14. Os coeficientes obtidos nas equações log-lineares para a MCM são mais elevados que os obtidos para a MC. Além do mais, eles também apresentaram 
correlações mais fortes que as observadas anteriormente. Entre os rapazes, o expoente mais baixo ocorreu aos 10 anos $(b=0,44)$ e o mais elevado aos 13 anos $(b=1,00)$. Entre as moças, o expoente mais baixo foi obtido na idade de 14 anos $(b=0,60)$ e o mais elevado aos 15 anos $(\mathrm{b}=1,34)$. Entre as moças, nas idades 11, 12 e 15 anos, os expoentes ultrapassaram a unidade ( $b=1,32, b=1,22, b=1,34$, respectivamente), enquanto que entre os rapazes nenhum grupo etário chegou a ultrapassar esse valor. Ao considerarmos os grupos etários para ambos os sexos, os expoentes alométricos também apresentaram um valor intermediário em relação àqueles obtidos para os sexos separadamente, contudo nas idades de 11, 13, 14, 15 e 16 anos, eles estão próximos da unidade.

TABELA 14 - Equações de regressão alométricas entre a potência aeróbia e a MCM relativa a idade de crianças e adolescentes de ambos os sexos.

\begin{tabular}{|c|c|c|c|}
\hline Idade & $\underline{\text { Rapazes }}$ & Moças & $\frac{\text { Ambos os }}{\text { sexos }}$ \\
\hline 10 & $\begin{array}{c}0,44 \mathrm{x}-0,98 \\
\mathrm{r}=0,73^{*}\end{array}$ & $\begin{array}{c}0,74 x-2,04 \\
r=0,67^{*}\end{array}$ & $\begin{array}{c}0,57 x-1,44 \\
r=0,65^{*}\end{array}$ \\
\hline 11 & $\begin{array}{c}0,73 \mathrm{x}-1,85 \\
\mathrm{r}=0,76^{*}\end{array}$ & $\begin{array}{c}1,32 \mathrm{x}-4,03 \\
\mathrm{r}=0,91^{*}\end{array}$ & $\begin{array}{c}1,09 x-3,16 \\
r=0,82^{*}\end{array}$ \\
\hline 12 & $\begin{array}{c}0,82 \mathrm{x}-2,17 \\
\mathrm{r}=0,86^{*}\end{array}$ & $\begin{array}{c}1,22 \mathrm{x}-3,77 \\
\mathrm{r}=0,70^{*}\end{array}$ & $\begin{array}{c}0,91 x-2,56 \\
r=0,65^{*}\end{array}$ \\
\hline 13 & $\begin{array}{c}1,00 \mathrm{x}-2,79 \\
\mathrm{r}=0,89^{*}\end{array}$ & $\begin{array}{c}1,00 x-2,87 \\
r=0,75^{*}\end{array}$ & $\begin{array}{c}0,97 x-2,75 \\
r=0,81^{*}\end{array}$ \\
\hline 14 & $\begin{array}{c}0,97 \mathrm{x}-2,69 \\
\mathrm{r}=0,71^{*}\end{array}$ & $\begin{array}{c}0,60 x-1,44 \\
r=0,76^{*}\end{array}$ & $\begin{array}{c}0,97 x-2,76 \\
r=0,74^{*}\end{array}$ \\
\hline 15 & $\begin{array}{c}0,69 \mathrm{x}-1,57 \\
\mathrm{r}=0,73^{*}\end{array}$ & $\begin{array}{c}1,34 \mathrm{x}-4,19 \\
\mathrm{r}=0,82^{*}\end{array}$ & $\begin{array}{c}1,16 x-3,45 \\
r=0,81^{*}\end{array}$ \\
\hline 16 & $\begin{array}{c}0,87 \mathrm{x}-2,47 \\
\mathrm{r}=0,78^{*}\end{array}$ & $\begin{array}{c}0,79 x-2,04 \\
r=0,62^{*}\end{array}$ & $\begin{array}{c}1,09 x-3,19 \\
r=0,82^{*}\end{array}$ \\
\hline $10-16$ & $\begin{array}{c}1,00 x-2,76 \\
R=0,94^{*}\end{array}$ & $\begin{array}{c}1,01 x-2,95 \\
R=0,87^{*}\end{array}$ & $\begin{array}{c}1,02 x-2,94 \\
r=0,89^{*}\end{array}$ \\
\hline
\end{tabular}

Esses grupos etários, como aqueles observados para os expoentes da MC para ambos os sexos, apresentaram os maiores coeficientes de correlação linear, indicando que os expoentes alométricos mais elevados também apresentaram as correlações mais fortes. $\mathrm{Ou}$ seja, à medida que os coeficientes de correlação alcançaram relações mais fortes, os expoentes alométricos se aproximaram da unidade. Esses resultados demonstraram que a MCM, no caso 
de crianças e adolescentes, pode ser considerada como uma variável adequada para ajustar a potência aeróbia. Essa análise torna-se mais evidente quando verificamos os expoentes obtidos para cada sexo, dos 10 aos 16 anos de idade, pois foi de 1,00 para os rapazes e de 1,01 as moças. Além do mais, os expoentes também apresentaram os mais elevados coeficientes de correlação - 0,94 e 0,87 para rapazes e moças respectivamente - considerando todos os grupos etários, à exceção dos 16 anos para as moças (TABELA 14).

O comportamento da potência aeróbia, ajustada alometricamente pela MCM (expoente 1,0 para os rapazes e 1,01 para as moças), é apresentado na Figura 17. No geral, o comportamento entre os sexos foi semelhante ao observado pelo ajuste linear da potência aeróbia pela MCM. Contudo, as diferenças entre os sexos ocorreram para todos os grupos etários. Os ganhos relativos para os rapazes foram de 8\% dos 10 aos 16 anos e, para as moças, em torno de 5\%, resultados semelhantes aos dos ajustes lineares para a potência aeróbia. As diferenças médias entre os sexos ficaram em torno de 18\%, um pouco mais acentuada em relação ao ajuste linear da MCM, sendo as maiores diferenças entre os sexos também dos 12 aos 15 anos (20\%) em relação às demais idades (14\%).

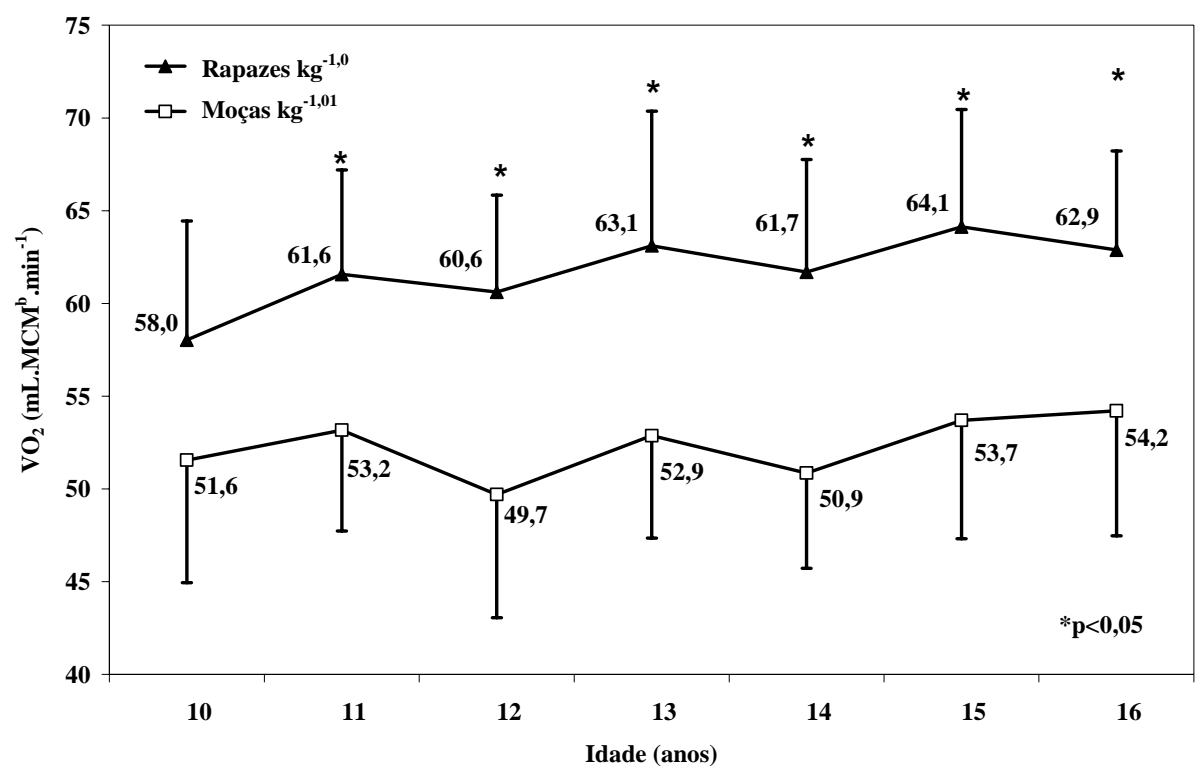

FIGURA 17 - Curvas de distância para os valores médios e desvios-padrão do $\mathrm{VO}_{2}$ relativo a $\mathrm{MCM}^{1,0}$ para rapazes e $\mathrm{MC}^{1,01}$ e para as moças. 
Ainda em relação a MCM para o conjunto de indivíduos, independentemente de grupos etários ou sexo, não se verificou diferenças estatisticamente significantes entre os expoentes dos rapazes e das moças ( $\mathrm{f}=447,8, \mathrm{p}>0,05)$, podendo utilizar um expoente alométrico para ambos os sexos, igual a 1,02 (Tabela 14), um valor bem próximo à unidade, confirmando a idéia de que a MCM pode se ajustar linearmente com o $\dot{\mathrm{VO}}_{2}$ pico, mesmo porque os coeficientes de variação e de correlação foram os que mais se aproximaram da igualdade, de todas as análises anteriormente realizadas (FIGURA 17). Os ganhos relativos da potência aeróbia dos 10 aos 16 anos para os rapazes e moças foram ligeiramente mais baixos dos observados pelo ajuste linear da MCM (7\% e 5\% respectivamente).

Contudo as diferenças relativas entre os sexos foram idênticas ao ajuste linear da MCM na potência aeróbia (14\%), sendo menores quando a MCM sofreu um ajuste para cada sexo. Neste caso, o uso de expoente específico produziu uma maior desvantagem para as moças, já que a massa corporal magra foi escalonada por um expoente acima de 1 , produzindo um efeito de aumento dos valores da MCM e, portanto, a diminuição dos valores médios da potência aeróbia. Entre os sexos, as diferenças ocorreram a partir dos 12 anos (FIGURA 18).

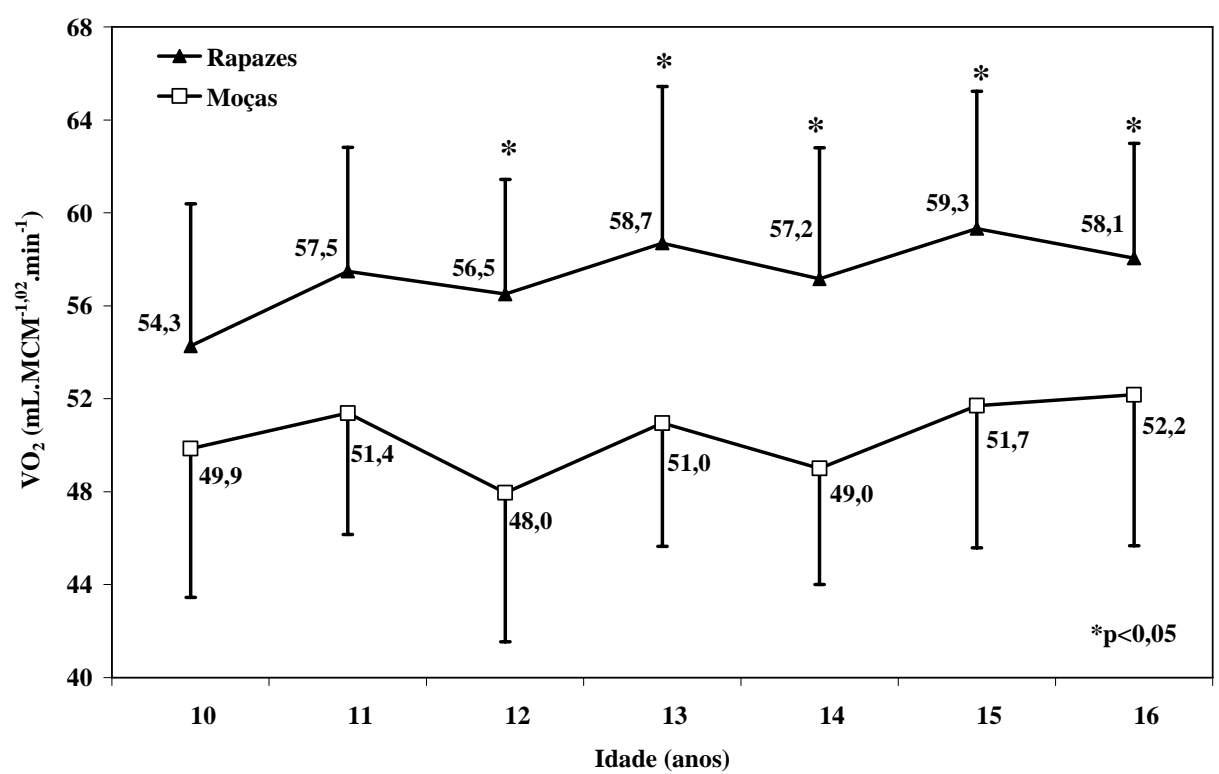

FIGURA 18 - Curvas de distância para os valores médios e desvios-padrão do $\mathrm{VO}_{2} \underline{\text { relativo a }}$ $\mathrm{MCM}^{1,02}$ para ambos os sexos. 
No estudo de JANZ et al. (1998) para a MCM no ajuste do $\dot{\mathrm{VO}}_{2}$ pico, os expoentes apresentaram-se mais elevados em todos os grupos maturacionais, sendo entre 0,77 a 0,95 para ambos os sexos. Os expoentes femininos foram mais elevados que os masculinos em quase todos os casos analisados, exceto do grupo pós-púbere, no qual os rapazes apresentaram um expoente de 0,81 e as moças de 0,77. Estes últimos resultados demonstraram que não houve diferenças entre os expoentes para MCM masculinos e femininos em relação aos estágios maturacionais.

O estudo de BEUNEN, ROGERS, WOYNAROWKA e MALINA (1997) avaliou as diferenças entre crianças de 11 a 14 anos de variados níveis maturacionais, além de obter expoentes alométricos para cada idade (expoentes interindividuais). Os autores verificaram que apenas na idade de 11 anos as moças apresentaram um expoente alométrico mais elevado que o dos rapazes (0,58 e 0,52 respectivamente), situação semelhante para o mesmo grupo etário do presente estudo. Os rapazes apresentaram maior variação nos expoentes (de 0,69 aos 12 anos para 1,02 aos 14 anos) enquanto as moças variaram menos (de 0,49 aos 13 anos para 0,65 aos 14 anos). Para cada grupo etário, os rapazes apresentaram um expoente intraindividual de 0,79 , estatisticamente mais elevado que o das moças, no mesmo período $(0,57)$. Na comparação entre os diferentes grupos maturacionais, os resultados apresentaram expoentes alométricos ainda mais diferentes, pois no grupo de rapazes e de moças com maturação precoce e na média para o PVC, o expoente obtido foi 0,80 e 0,57 ; já para o grupo de maturação tardia, os expoentes foram 0,57 e 0,42 , para rapazes e moças, respectivamente. Os autores concluíram que o efeito da massa corporal, em relação ao nível maturacional, para as moças explicou menos as diferenças do que aquelas observadas pela idade, mas pareceu exercer uma maior influência nos resultados da potência aeróbia entre os rapazes.

Com relação às moças, na tentativa de verificar outros indicadores maturacionais, THOMIS et al. (2000), avaliaram a potência aeróbia por quatro anos (dos 11 aos 14 anos), sendo que o indicador maturacional foi o tempo de 2 e 1 ano antes da menarca; no período próximo da menarca (seis meses antes e depois); e, por último, com 1 e 2 anos depois da menarca. Os expoentes alométricos intraindividuais não foram diferentes daqueles observados nos estudos anteriores. Por exemplo, eles variaram entre 0,42 com dois anos antes da menarca, até 0,59 para dois anos depois. De todos os expoentes, o mais baixo foi observado exatamente no período da menarca, sendo igual a 0,32 . Curiosamente quando o período de ocorrência da 
menarca foi retirado do modelo, os expoentes variaram de 0,46 a 0,59 , portanto diminuindo, portanto, a diferenças entre eles. Embora a variação tenha diminuído, todos os expoentes encontrados ficaram muito abaixo dos teóricos 0,67 ou 0,75 , sugerindo que a maturação também não explica os resultados da potência aeróbia entre as moças.

ROGERS et al. (1995) ao avaliarem o $\dot{\mathrm{VO}}_{2}$ pico de rapazes e moças pré-púberes (7-9 anos), encontraram expoentes alométricos mais próximos do teórico 0,67 no esforço submáximo $(0,65)$ do que no máximo $(0,52)$ para ambos os sexos. Embora os rapazes apresentassem valores médios mais elevados que as moças, os expoentes das moças apresentaram-se mais elevados, além de estatisticamente idêntico ao teórico $0,67(b=0,68)$, devido a proximidade maior do período maturacional do que os rapazes $(b=0,37)$, pois a $\mathrm{MC}$ estabeleceu uma importante relação com o pico de velocidade de crescimento. Ambos os expoentes encontrados para cada sexo aproximaram-se muito do observado aos 10 anos no presente estudo.

BEUNEN, BAXTER-JONES, MIRWALD, THOMIS, LEFEVRE, MALINA e BAILEY (2002) analisaram a influência da massa corporal na potência aeróbia de rapazes de oito a 16 anos, tanto longitudinal quanto transversal. Os expoentes interindividuais variaram de 0,62 aos 12 anos para 0,93 aos 15 anos. De maneira geral, os expoentes foram elevando-se com o passar dos anos, apresentando uma média de 0,78; valor bem próximo do teórico de 0,75. Os expoentes obtidos nas idades iniciais (8-9 anos) e finais (14-16 anos) eram significantemente mais elevados do que aqueles obtidos entre as idades de 9 a 13 anos $(\mathrm{b}=$ 0,70). Esse resultado aproxima-se do expoente teórico 0,67 e também daquele obtido para os rapazes de 10 a 13 anos do presente estudo. No estudo longitudinal, obteve-se o expoente 0,78 . Ou seja, os expoentes transversais e longitudinais diferiram dos expoentes teóricos, pois no primeiro caso aproximou-se de 0,67 enquanto no segundo aproximou-se de 0,75. Eles concluíram que a potência aeróbia ajustada pela massa corporal durante o crescimento demonstrou uma enorme variação.

No estudo de ARMSTRONG et al. (1999), com adolescentes de ambos os sexos, com idades variando de 11 a 13 anos, os autores utilizaram uma estatística de modelação multinível para determinar o efeito da idade, sexo, maturação e massa corporal no $\dot{\mathrm{VO}}_{2}$ pico. Os resultados demonstraram que ocorreu um efeito positivo no desenvolvimento da potência aeróbia entre os rapazes e moças, relacionados a idade, estatura, massa corporal e maturação 
em ambos os sexos. Para ambos os sexos, os coeficientes da modelação multi-nível mais elevados ocorreram para a massa corporal $(b=0,48)$ e estatura $(b=0,81)$, com maior contribuição dos rapazes, em que houve uma uma maior interação mais efetiva entre a idade e o sexo. Um aspecto importante apresentado pelos autores é a presença dos efeitos colineares entre as variáveis apresentadas no tratamento de modelação multinível. Ou seja, quando foi adicionada a estatura, o expoente diminuiu para 0,48 , porém aumentou com o adicionamento da adiposidade corporal $(0,86)$. Um efeito de colinearidade não pode ser apresentado no modelo da regressão log-linear, pois apenas uma variável de tamanho é apresentada para ajustar uma outra funcional. Nesse sentido, resultados com expoentes obtidos por regressões log-lineares e análise de covariância, poderão apresentar expoentes mais confiáveis aos outros modelos.

No estudo de COOPER et al. (1984), 58 rapazes e 51 moças tiveram sua potência aeróbia avaliada por meio de cicloergômetro. Rapazes e moças foram divididos em dois grupos para analisarem um possível efeito maturacional nos resultados (moças: 6-11 anos e 12-17 anos; rapazes: 6-13 anos e 14-17 anos). Considerando todos os grupos etários e sexo, o expoente encontrado para a potência aeróbia foi 1,01, sendo 1,09 para o sexo masculino e 0,83 para o feminino, ambos estatisticamente diferentes. O resultado para a potência anaeróbia revelou que os expoentes para a massa corporal para ambos os sexos foi 0,92 , sendo de 0,77 e 0,99 para moças e rapazes, respectivamente. Com esses expoentes, os autores avaliaram as possíveis diferenças entre os grupos etários e sexos e concluíram que no caso potência anaeróbia, a $\mathrm{MC}^{-1}$ não exerceu qualquer influência pela idade $(\mathrm{r}=0,13)$, passando a ser influenciado por esta quando substituída por $\mathrm{MC}^{-0,92}$. Com essa mudança de ajuste, nenhuma diferença estatisticamente significante foi observada entre os sexos nos diferentes grupos etários. Resultados semelhantes a esses foram encontrados entre a idade e o $\dot{\mathrm{VO}}_{2}$ pico, mas na análise da potência aeróbia $\left(\mathrm{mL} \cdot \mathrm{MC}^{-1,01} \cdot \mathrm{min}^{-1}\right)$ os rapazes passaram a ter médias mais elevadas que as moças. Quando os autores analisaram as diferenças na potência aeróbia para cada grupo etário, mediante seus expoentes específicos, diferenças ocorreram apenas no grupo de rapazes de 14-17 anos, pois estes apresentaram médias mais elevadas aos demais grupos.

No estudo de ŠPRINAROVÁ, PǍ̌ISKOVÁ e BUNC (1987), envolvendo rapazes de 11 a 18 anos, foram apresentados expoentes de amostras tanto transversais quanto longitudinais. No caso da amostra transversal, os expoentes variaram de 0,66 (11 anos) a 0,88 
(15 anos) para cada grupo etário, mas nos grupos etários dos 11, 12 e 13 anos, os expoentes não diferiram estatisticamente do expoente teórico 0,67, apenas os das idades de 14 e 15 anos foram mais elevados $(0,87)$. Para os dados obtidos longitudinalmente (dos 11 aos 15 anos), o expoente foi 1,10 , muito mais elevado que os demais, demonstrando a grande diferença de observações longitudinais e das transversais no mesmo grupo.

Segundo WELSMAN, NEVILL e KIRBY (1999), todos os achados sugerem que é inapropriado assumir que um ajuste expoentes alométricos fixos de 0,67 ou 0,75 controlará adequadamente as diferenças na potência aeróbia de crianças adolescentes. Ou seja, as variações absolutas no crescimento não são universais, mas as variações relativas entre crianças e adolescentes parecem ser mais generalizáveis, fundamentalmente quando são consideradas as variáveis de massa corporal e estatura.

Os expoentes produzidos no presente estudo estão distantes dos expoentes teóricos apresentados na literatura $(0,67$ e 0,75$)$. No primeiro caso, o expoente 0,67 deveria ser encontrado para indivíduos avaliados longitudinalmente, enquanto o segundo para os grupos avaliados transversalmente. De fato, os expoentes e os coeficientes de proporcionalidade produzidos para rapazes $(0,91 \mathrm{x}-2,61)$ e moças $(0,88 \mathrm{x}-2,47)$ de 10 a 16 anos são estatisticamente iguais ( $\mathrm{f}=285,8 ; \mathrm{p}>0,05)$ e aproximam-se mais do segundo expoente teórico interindividuos. Portanto, essa similaridade entre os expoentes para ambos os sexos reforça a idéia da utilização de um único expoente $(b=0,85)$, considerando que as diferenças relativas entre os sexos, dos 10 aos 16 anos, são da ordem de 6\% (a partir dos coeficientes de proporcionalidade). Segundo HEISNER (1985), essa condição satisfez a utilização de um expoente único, ou seja, que nos grupos fossem diferenciados apenas a partir das suas propriedades intensivas.

Nesse sentido, a grande variedade de expoentes alométricos apresentados na literatura, com valores acima ou abaixo dos expoentes alométricos teóricos, demonstra que o modelo teórico que ajusta a potência aeróbia ao $\mathrm{MC}^{-0,67}$ ou $\mathrm{MC}^{-0,75}$ não se aplica totalmente a crianças e adolescentes. As diferenças observadas no coeficiente de variação tanto da MC quanto do $\dot{\mathrm{V}}_{2}$ pico não podem ser explicadas apenas pelas variações inerentes do crescimento cronológico, da maturação ou do sexo. Outra característica da obtenção do expoente teórico 0,67 ou 0,75 é que nos estudos empíricos que geraram o expoente da lei da superfície corporal não foram diferenciados os animais machos das fêmeas. Portanto, um dos 
aspectos mais importantes na consideração das diferenças entre os sexos é que não há um dimorfismo sexual importante que explique as diferenças entre eles. No caso de seres humanos, durante o período do crescimento, as diferenças no tamanho são descritas de inúmeras maneiras, contudo as diferenças nas suas propriedades extensivas prevalecem as demais, como por exemplo, aquelas associadas ao crescimento somático.

Mesmo que todas as crianças e adolescentes cresçam e se desenvolvam com características muito semelhantes entre si, nos diferentes lugares do mundo, as sutis diferenças no tempo e na intensidade do crescimento, observadas no período pubertário ou fora dele, influirão nos resultados dos ajustes alométricos, principalmente se forem consideradas as influências socioculturais. O oferecimento ou oportunidade de práticas esportivas ou de exercícios físicos regulares, por exemplo, repercutirá no desempenho aeróbio máximo, podendo indicar uma situação socioeconômica adequada, refletida nos indicadores de composição corporal. Seria mais adequado que para cada grupo de crianças ou adolescentes, as diferenças fossem ajustadas com base na compreensão do significado das propriedades extensivas e intensivas e que a cada período de tempo, novas avaliações pudessem ser realizadas na tentativa de se corrigir diferenças apresentados no período, mesmo que os expoentes sejam obtidos transversalmente.

Alguns aspectos extrínsecos influenciadores do desempenho máximo - tais como a motivação e o nível de atividade física habitual - podem ser eliminados quando o desempenho submáximo é analisado alometricamente. Nesse sentido, alguns estudos sugerem que ajustes mais próximos dos teóricos são obtidos, fundamentalmente entre as crianças e adolescentes. Uma evidência desse efeito pode ser observada no $\dot{\mathrm{V}} \mathrm{O}_{2}$ pico para o tempo de corrida do presente estudo, já que muitos dos valores mais elevados da potência aeróbia foram obtidos com tempo de teste considerado baixo, inclusive por indivíduos mais velhos, demonstrando que um maior tempo de corrida não implica necessariamente em uma maior tolerância à fadiga aguda. Neste caso, os testes submáximos poderiam eliminar esse paradoxo. 
Diante dos resultados obtidos no presente estudo, relacionamos às seguintes conclusões:

a) Com relação às características do crescimento somático e da composição corporal, os resultados demonstraram que, para a estatura, as diferenças entre os sexos ocorreram a partir dos 14 anos de idade, favoravelmente para os rapazes; não foram observadas diferenças entre os sexos para a massa corporal; as moças apresentaram uma quantidade de gordura corporal superior aos rapazes em todas as faixas etárias do estudo, com diferenças a partir dos 13 anos; para a massa corporal magra, os rapazes apresentaram valores maiores que as moças em todos os anos;

b) Com relação aos parâmetros ventilatórios e da potência aeróbia absoluta $\left(\mathrm{L} \cdot \mathrm{min}^{-1}\right)$, os resultados mostraram uma estreita relação entre essas duas variáveis; os valores médios elevaram-se com o passar dos anos, tendo os rapazes apresentado valores superiores ao das moças, em todos os grupos etários analisados; as diferenças entre os sexos somente foram observadas a partir dos 14 anos de idade;

c) Com relação aos valores da potência aeróbia relativa à massa corporal e à massa corporal magra, os resultados mostraram diferenças estatisticamente significantes em favor dos rapazes, em todas as faixas etárias. Entre os rapazes a potência aeróbia $\left(\mathrm{mL} \cdot \mathrm{kg}^{-1} \cdot \mathrm{min}^{-1}\right)$ elevou-se discretamente com o passar dos anos, mas entre as moças o comportamento da potência aeróbia não se alterou dos 10 aos 16 anos; com relação aos valores relativos à massa corporal magra $\left(\mathrm{mL} \cdot \mathrm{MCM}^{-1} \cdot \mathrm{min}^{-1}\right)$, os resultados demonstraram um aumento mais proeminente para da potência aeróbia, para ambos os sexos, com o passar dos anos; 
d) Com relação aos resultados da potência aeróbia relativa aos expoentes alométricos fixos $\mathrm{kg}^{-0,67} \mathrm{e} \mathrm{kg}^{-0,75}$, os resultados, em ambos os casos, apresentaram comportamentos crescentes, tanto para o sexo feminino, quanto para o masculino. As diferenças entre os sexos ocorreram em todas as faixas etárias, favoravelmente aos rapazes, mas as diferenças relativas entre os sexos mantiveram-se idênticas para ambos os expoentes;

e) Com relação à determinação dos expoentes alométrico gerados no próprio grupo para a massa corporal, os expoentes 0,91 e 0,82 foram obtido para rapazes e moças, respectivamente; para ambos os sexos, o expoente 0,85 foi obtido dos 10 aos 16 anos, o que resultou em um comportamento crescente da potência aeróbia, com os ganhos mais expressivos para os rapazes (23 e $9 \%$ para rapazes e moças respectivamente), em relação à massa corporal. Os rapazes apresentaram valores médios mais elevados aos da moças em todos os grupos etários, mas as diferenças relativas foram idênticas àquelas observadas para os expoentes fixos; os expoentes obtidos pra os grupos etários específicos demonstraram que, para ambos os sexos, nas idades mais baixas assemelham-se ao expoente teórico de 0,67 e, para os grupos etários mais elevados, assemelham-se ao expoente teórico de 0,75;

f) Com relação à massa corporal magra, os expoentes aproximaram-se da unidade, sendo $b=1,00$ para os rapazes e $b=1,01$ para moças. Para ambos os sexos, o expoente obtido foi 1,02. Em todos os casos, os rapazes apresentaram valores mais elevados que as moças, ocorrendo uma elevação das médias da potência aeróbia crescente nos diferentes grupos etários.

A potência aeróbia de crianças e adolescentes apresentada em valores absolutos descreve mais adequadamente o comportamento das diferenças inter e intrassexos ao longo do crescimento. Os resultados corrigidos linearmente pela massa corporal produziram de fato desvantagens para ambos os sexos durante o crescimento, com desvantagens visivelmente mais acentuadas para as moças em todos os grupos etários. Os inúmeros expoentes 
alométricos obtidos para a massa corporal nos diferentes grupos etários demonstraram uma enorme variação das diferenças inter e intrassexos. O uso de expoentes alométricos que ajustaram adequadamente a potência aeróbia à massa corporal dependeu em grande parte dos grupos etários analisados, considerando sempre os expoentes obtidos e sua proximidade com os expoentes teóricos apresentados na literatura e os respectivos coeficientes de correlação, para ambos os sexos. Por outro lado, o expoente alométrico 0,85 obtido para a massa corporal de ambos os sexos, revelou ganhos para ambos os sexos ao longo dos anos, semelhante aos obtidos entre os expoentes teóricos. As mesmas diferenças foram adequadamente analisadas quando os valores absolutos foram ajustados linearmente à massa corporal magra, uma vez que o expoente obtido para ambos os sexos foi virtualmente igual a 1,0 e que as diferenças significantes entre os sexos ocorreram apenas a partir dos 12 anos de idade.

7

\section{RECOMENDAÇÕES}

Considerando algumas limitações do estudo, foram relacionadas as seguintes recomendações:

a) Que os estudos transversais possam envolver um amplo conjunto etário, para ambos os sexos (dos sete aos 17 anos), além de um o número superior de sujeitos ao da presente amostra;

b) Que medidas da maturação sejam obtidas para que as possíveis diferenças nas variações da potência aeróbia não sejam controladas apenas pela idade cronológica;

c) Que a composição corporal seja avaliada por procedimentos indiretos e não duplamente indiretos, garantindo a qualidade dos resultados da composição corporal;

d) Que as variáveis socioculturais também possam ser controladas, principalmente sobre a prática regular de exercícios físicos e a situação socioeconômica;

e) Se possível, que estudos longitudinais também possam ser desenvolvidos para 
que novos ajustes na potência aeróbia possam ser determinados para a população de jovens. 


\section{REFERÊNCIAS BIBLIOGRÁFICAS}

ABERNETHY, A.B.; MACKINNON, L.T.; NEAL, R.J.; KIPPERS, V.; HANRAHAN, S.J. The biophysical of human movement. Champaign: Human Kinetics Books, 1996.

ANJOS, L.A.; CASTRO, I.R.R.; ENGSTROM, E.M.; AZEVEDO, A.M. Crescimento e estado nutricional em amostra probabilística de escolares no Município do Rio de Janeiro, 1999. Cadernos de Saúde Pública, v.19, Supplemento 1, p.s171-9, 2003.

ASMUSSEN, E.; HEEBØLL-NIELSEN, K.R. A dimensional analysis of physical performance and growth in boys. Journal of Applied Physiology, v.7, p.593-603, 1955.

ARMSTRONG, N.; KIRBY, B.J.; MCMANUS, A.M.; WELSMAN, J.R. Aerobic fitness of prepubescent children. Annals of Human Biology, v.22, n.5, p.427-41, 1995.

ARMSTRONG, N.; KIRBY, B.J.; MCMANUS, A.M.; WELSMAN, J.R. Prepubescents' ventilatory responses to exercise with reference to sex and body size. $\underline{\text { Chest, }}$ v.112, n.6, p.1554-60, 1997.

ARMSTRONG, N.; WELSMAN, J.R.; NEVILL, A.M.; KIRBY, B.J. Modeling growth and maturation changes in peak oxygen uptake in 11-13 yr olds. Journal of Applied Physiology, v.87, n.6, p.2230-6, 1999.

ARMSTRONG, N.; WILliAnS, J.; BALDING, J.; GENTLE, P.; KIRBY, B.J. The peak oxygen uptake of British children with reference to age, sex and sexual maturity. European Journal of Applied Physiology and Occupational Physiology, v.62, n.5, p.369$75,1991$.

ARMSTRONG, N.; WELSMAN, J.R.; WINSLEY, R. Is peak VO2 a maximal index of children's aerobic fitness? International Journal of Sports Medicine, v.17, n.5, p.356-59, 1996. 
ASTRAND, P.-O.; RODAHL, K. Tratado de fisiologia do exercício. Rio de Janeiro: Interamericana, 1982.

BARBANTI, V.J. Aptidão física relacionada à saúde, manual de testes. Brasília: Secretaria de Educação e Desportos, MEC, 1983.

BATTERHAM, A.M.; BIRCH, K.M. Allometry of anaerobic performance: a gender comparison. Canadian Journal of Applied Physiology, v.21, n.1, p.48-62, 1996.

BATTERHAM, A.M.; GEORGE, K.P. Allometric modeling does not determine a dimensionless power function ratio for maximal muscular function. $\underline{\text { Journal of Applied }}$ Physiology, v.83, n.6, p.2158-66, 1997.

BATTERHAM, A.M.; GEORGE, K.P.; MUllinEAUX, D.R. Allometric scaling of left ventricular mass by body dimensions in males and females. Medicine and Science in Sports and Exercise, v.29, n.2, p.181-6, 1997.

BATTERHAM, A.M.; VANDERBURGH, P.M.; MAHAR, M.T.; JACKSON, A.S. Modeling the influence of body size on VO2 peak: effects of model choice and body composition. Journal of Applied Physiology, v.87, n.4, p.1317-25, 1999.

BARENBLATT, G.I. Scaling. Cambridge: Cambridge University Press, 2003.

BECQUE, M.D.; HATTORI, K.; KATCH, V.L.; ROCCHINI, A.P. Fat patterning of adolescents: allometry of fatfolds. American Journal of Human Biology, v.4, p.421-425, 1992.

BENEFICE, E.; NDIAYE, G. Relationships between anthropometry, cardiorespiratory fitness indices and physical activity levels in different age and sex groups in rural Senegal (West Africa). Annals of Human Biology, v.32, n.3, p.366-82, 2005. 
BEUNEN, G.; BAXTER-JONES, A.D.; MIRWALD, R.L.; THOMIS, M.; LEFEVRE, J.; MALINA, R.M.; BAILEY, D.A. Intraindividual allometric development of aerobic power in 8- to 16-year-old boys. Medicine and Science in Sports and Exercise, v.34, n.3, p.503-10, 2002.

BEUNEN, G.P.; ROGERS, D.M.; WOYNAROWSKA, B.; MALINA, R.M. Longitudinal study of ontogenetic allometry of oxygen uptake in boys and girls grouped by maturity status. Annals of Human Biology, v.24, n.1, p.33-43, 1997.

BÖHME, M.T.S. Aptidão física e crescimento físico de escolares de 7 a 17 anos de Viçosa MG: Parte I - resistência aeróbia, avaliação, desenvolvimento. Revista Mineira de Educação Física, v.2, n.1, p.27-41, 1994.

BÖHME, M.T.S. Aptidão física e crescimento físico de escolares de 7 a 17 anos de Viçosa MG: Parte IV - estatura, peso e perímetros (abdominal e de braço estendido). Revista Mineira de Educação Física, v.3, n.2, p.54-74, 1995.

BÖHME, M.T.S. Aptidão física e crescimento físico de escolares de 7 a 17 anos de Viçosa MG: Parte V - dobras cutâneas tricipital, subescapular e abdominal. Revista Mineira de Educação Física, v.4, n.1, p.45-60, 1996.

BOUCHARD, C.; DIONNE, F.T.; SIMONEAU, J.A.; BOULAY, M.R. Genetics of aerobic and anaerobic performances. Exercise and Sport Science Review, v.20, p.27-58, 1992.

BRADEN, D.S.; STRONG, W.B. Cardiovascular responses and adaptations to exercise in childhood. In: GISOLF, C.V.; LAMB, D.R. (Ed.). Perspective in exercise science and sports medicine. Indianopolis: Benchmark Press, v.2, 1989. p.293-329.

CALDER III, W.A. Size, function, and life history. Cambridge: Harvard University Press, 1984. 
CAPUTO, F.; STElla, S.G.; MELlO, M.T.; DENADAI, B.S. Índices de potência e capacidade aeróbia obtidos em cicloergômetros e esteira rolante: comparações entre corredores, ciclistas, triatletas e sedentários. Revista Brasileira de Medicina do Esporte, v.9, n.4, p.223-230, 2003.

COOPER, D.M.; WEILER-RAVELL, D.; WHIPP, B.J.; WASSERMAN, K. Aerobic parameters of exercise as a function of body size during growth in children. Journal of Applied Physiology, v.56, n.3, p.628-34, 1984.

CYRINO, E.S.; OKANO, A.H.; SILVA, K.E.S.; ALTIMARI, L.R.; DÓREA, V.R.; ZUCAS, S.M.; BURINI, R.C. Aptidão aeróbia e sua relação com processos de crescimento e maturação. Revista de Educação Física da UEM, v.13, n.1, p.17-26, 2002.

CZERWINSKI, S.A.; TOWNE, B. Methods for Study of the Genetics of Growth and Development. In: HAUSPIE, R.; CAMERON, N.; MOLINARI, L. (Ed.). Methods in Human Growth Research. Cambridge: Cambridge University Press, 2004. p.333-53.

DAVIES, M.J.; DALSKY, G.P.; VANDERBURGH, P.M. Allometric scaling of VO2max by body mass and lean body mass in older man. Journal of Aging and Physical Activity, v.3, p.324-331, 1995.

DAVIES, M.J.; MAHAR, M.T.; CUNNINGHAM, L.N. Running economy: comparison of body mass adjustment methods. Research Quarterly for Exercise and Sport, v.68, n.2, p.177-81, 1997.

DENCKER, M.; THORSSON, O.; KARLSSON, M.K.; LINDÉN, C.; EIBERG, S.; WOLLMER, P.; ANDERSEN, L.B. Gender differences and determinants of aerobic fitness in children aged 8-11 years. European Journal of Applied Physiology, v.99, n.1, p.19-26, 2007. 
DIBELLA, J.A.; JOHNSON, E.M.; CABRERA, M.E. Ramped vs. standard Bruce protocol in children: a comparasion of exercise responses. Pediatric Exercise Science, v.14, p.391400, 2002.

DOCHERTY, D. Measurement in pediatric exercise science. Champaign: Human Kinetics Books, 1996.

DUARTE, C.R.; DUARTE, M.F.S. Capacidade aeróbica em escolares de 10 a 18 anos: V02 e PWC170. Revista Brasileira de Ciência e Movimento, v.3, n.3, p.17-25, 1989.

DUNCAN, G.E.; MAHON, A.D.; HOWE, C.A.; DEL CORRAL, P. Plateau in oxygen uptake at maximal exercise in male children. Pediatric Exercise Science, v.8, p.77-86, 1996.

EIBERG, S.; HASSELSTRON, H.; GRONFELDT, V.; FROBERG, K.; SVENSSON, J.; ANDERSEN, L.B. Maximum oxygen uptake and objectively measured physical activity in Danish children 6-7 years of age: the Copenhagen school child intervention study. British Journal of Sports Medicine, v.39, n.10, p.725-30, 2005.

EISENMANN, J.C.; PIVARNIK, J.M.; MALINA, R.M. Scaling peak VO2 to body mass in young male and female distance runners. Journal of Applied Physiology, v.90, n.6, p.2172-80, 2001.

FARIAS, E.S.; SALVADOR, M.R.D. Antropometria, composição corporal e atividade física de escolares. Revista Brasileira de Cineantropometria e Desempenho Humano, v.7, n.1, p.21-9, 2005.

PFLUCK, L.D. Os aspectos naturais na propaganda da colonização de Marechal Cândido Rondon - Pr. In: VANDERLINDE, T.; DEITOS, N.J.; GREGORY, V. (Ed) Migrações e a Construção do Oeste do Paraná: século XXI em perspectiva. Cascavel: Coluna do Saber, 2007. p.119-42. 
FRANÇA, N.M.; MATSUDO, V.K.R.; SESSA, M. Dobras cutâneas em escolares de 7 a 18 anos. Revista Brasileira de Ciência e Movimento, v.2, n.4, p.7-16, 1988.

FREDRIKSEN, P.M.; INGJER, F.; NYSTAD, W.; THAULOW, E. Aerobic endurance testing of children and adolescents--a comparison of two treadmill-protocols. Scandinavian Journal of Medicine Science and Sports, v.8, n.4, p.203-7, 1998.

GLANER, M.F. Crescimento físico em adolescentes do norte gaúcho e oeste catarinense. Revista Brasileira de Ciência e Movimento, v.13, n.2, p.15-20, 2005.

GONÇALVES, H.R. Aspectos antropométricos e motores em escolares de 7 a 14 anos de alto nível sócio-econômico de Londrina - Pr. Revista da Associação dos Professores de Educação Física de Londrina, v.10, n.17, p.71-80, 1995.

GORDON, C.C.; CHUMLEA, W.C.; ROCHE, A.F. Stature, recumbent length and weight. In: LOHMAN, T.G.; ROCHE, A.F.; MARTORELL, R. (Ed.). Anthropometric standartization reference manual. Champaign: Human Kinetics Books, 1988. p.3-23.

GUEDES, D.P.; BARBANTI, V.J. Desempenho motor de crianças e adolescentes. Revista Paulista de Educação Física, v.9, n.1, p.37-50, 1995.

GUEDES, D.P.; GUEDES, J.E.R.P.; BARBOSA, D.S.; OLIVEIRA, J.A. Níveis de prática de atividade física habitual de adolescentes. Revista Brasileira de Medicina do Esporte, v.7, n.6, p.187-199, 2001.

. Atividade física habitual e aptidão física relacionada à saúde em adolescentes. Revista Brasileira de Ciência e Movimento, v.10, n.1, p.13-21, 2002.

GUEDES, J.E.R.P.; GUEDES, D.P. Crescimento e desempenho motor em escolares do município de Londrina, Paraná, Brasil. Cadernos de Saúde Pública, v.9, Supl.1, p.58-70, 1993. 
GUEDES, J.E.R.P.; GUEDES, D.P. Composição corporal em crianças e adolescentes do município de Londrina - Paraná. Revista da Associação dos Professores de Educação Física de Londrina, v.10, n.18, p.3-15, 1995.

GUEDES, J.E.R.P.; GUEDES, D.P. Crescimento físico de crianças e adolescentes do município de Londrina (PR), Brasil. Kinesis, v.18, p.91-106, 1997.

GUO, S.S.; CHUMLEA, W.C.; ROCHE, A.F.; SIERVOGEL, R.M. Age- and maturityrelated changes in body composition during adolescence into adulthood: The Fels Longitudinal Study. International Journal of Obesity, v.21, n.12, p.1167-75, 1997.

HAMILL, P.V.; DRIZD, T.A.; JOHNSON, C.L.; REED, R.B.; ROCHE, A.F.; MOORE, W.M. Physical growth: National Center for Health Statistics percentiles. American Journal of Clinical Nutrition, v.32, n.3, p.607-29, 1979.

HARRISON, G.G.; BUSKIRK, E.R.; CARTER, J.E.L.; JOHNSTON, F.E.; LOHMAN, T.G.; POLLOCK, M.L.; ROCHE, A.F.; WILMORE, J.H. Skinfold thickness and measurement technique. In: LOHMAN, T.G.; ROCHE, A.F.; MARTORELL, R. (Ed.). Anthropometric standardization reference manual. Champaign: Human Kinetics Books, 1988. p.55-70.

HEUSNER, A.A. Body size, energy metabolism, and the lungs. Journal of applied physiology: respiratory, environmental and exercise physiology, v.54, n.4, p.867-73, 1983.

HOBOLD, E. Indicadores de aptidão física relacionada à saúde de crianças e adolescentes de Marechal Cândido Rondon - Paraná, Brasil. 109p. Dissertação (Mestrado em Educação Física). Programa de Pós-Graduação em Educação Física. Universidade de Santa Catarina. Florianópolis, 2003. 
INSTITUTO BRASILEIRO DE GEOGRAFIA E ESTATÍSTICA. Pesquisa de orçamentos familiares 2002-2003: Antropometria e análise do estado nutricional de crianças e adolescentes no Brasil. Rio de Janeiro: IBGE, 2006.

INSTITUTO BRASILEIRO DE GEOGRAFIA E ESTATÍSTICA. Censo demográfico. Rio de Janeiro: IBGE, 2007.

JANZ, K.F.; BURNS, T.L.; WITT, J.D.; MAHONEY, L.T. Longitudinal analysis of scaling VO2 for differences in body size during puberty: the Muscatine Study. Medicine and Science in Sport and Exercise, v.30, n.9. p.1436-44, 1998.

KATCH, V.L.; KATCH, F.I. Use of weight-adjusted oxygen uptake scores that avoid spurious correlations. Research Quarterly, v.45, n.4, p.447-51, 1974.

KAUR, H.; HYDER, M.L.; POSTON, W.S. Childhood overweight: an expanding problem. Treatment in Endocrinology, v.2, n.6, p.375-88, 2003.

KEMPER, H.C.G.; VERSCHUUR, R. Maximal aerobic power in 13- and 14-year-old teenagers in relation to biologic age. International Journal of Sports Medicine, v.2, n.2, p.97-100, 1981.

KEMPER, H.C.G.; VERSCHUUR, R Maximal aerobic power. In: KEMPER, H.C.G. (Ed.) Growth, health and fitness of teenagers: longitudinal research in international perspective. Basel: Karger, 1985. p. 127-36

KEMPER, H.C.G.; VERSCHUUR, R. Longitudinal study of maximal aerobic power in teenagers. Annals of Human Biology, v.14, n.5, p.435-44, 1987.

KISS, M.A.P.D.; COLANTONIO, E.; REGAZZINI, V.M.; BARROS, R.V.; REGAZZINI, M. Variável aeróbia. In: KISS, M.A.P.D. (Ed.). Esporte e Exercício: Avaliação e Prescrição. São Paulo: Rocca, 2003. p.125-163. 
KRAHENBUHL, G.S.; SKINNER, J.S.; KOHRT, W.M. Developmental aspects of maximal aerobic power in children. Exercise and Sport Science Review, v.13, p.503-38, 1985.

LÉGER, L. Aerobic performance. In: DOCHERTY, D. (Ed.). Measurement in Pediatric Exercise Science. Champaign: Human Kinetics Books, 1996. p.183-223.

LOFTIN, M.; STRIKMILLER, P.; WARREN, B.; MYERS, L.; SCHROTH, L.; PITTMAN, J.; HARSHA, D.; SOTHERN, M. Comparison and relationship of VO2peak and physical activity patterns in elementary and high school females. Pediatric Exercise Science, v.10, p.153-63, 1998.

LOHMAN, T.G. The use of skinfold to estimate body fatness on children and youth. Journal of Physical Education, Recreation and Dance, v.58, n.9, p.98-102, 1987.

LOHMAN, T.G.; BOILEAU, R.A.; SLAUGTHER, M.H. Body composition in children and youth. In: BOILEAU, R.A. (Ed.) Advances in Pediatric Sport Science, Volume 1, Biological Issues. Champaign: Human Kinetics Books, 1984. p.26-57.

LOHMAN, T.G. Applicability of body composition techniques and constants for children and youths. Exercise and Sport Science Review, v.14, p.325-57, 1986.

LORENZI, T.C. Testes de corrida/caminhada de 6 e 9 minutos: validação e determinantes metabólicos em crianças e adolescentes. 104p. Dissertação (Mestrado em Educação Física) Programa de Pós-Graduação em Ciência do Movimento Humano. Universidade Federal do Rio Grande do Sul, Porto Alegre, 2006.

MACHADO, F.A.; GUGLIELMO, L.G.A.; DENADAI, B.S. Velocidade de corrida associada ao consumo máximo de oxigênio de meninos de 10 a 15 anos. Revista Brasileira de Medicina do Esporte, v.8, n.1, p.1-6, 2002.

McCARTHY, H.D.; COLE, T.J.; FRY, T.; JEBB, S.A.; PRENTICE, A.M. Body fat reference curves for children. International Journal of Obesity, v.30, n.4, p.598-602, 2006. 
McMURRAY, R.G.; HARRELL, J.; BRADLEY, C.B.; DENG, S.; BANGDIWALA, S. Predicted maximal aerobic power in youth is related to age, gender, and ethnicity. Medicine and Science in Sports and Exercise, v.34, n.1, p.145-51, 2002.

McMURRAY, R.G.; HARRELL, J.; BANGDIWALA, S.; HU, J. Tracking physical activity and aerobic power from childhood through adolescence. Medicine and Science in Sports and Exercise, v.35, n.11, p.1914-22, 2003.

McMURRAY, R.G.; BAGGETT, C.; PENNELl, M.; BANGDIWALA, S.; HARRELL, J. Gender differences in ventilatory responses of youth are related to exercise intensity. $22^{\circ}$ Pediatric Work Physiology Meeting. Universidade do Porto, Porto, Portugal. Revista Portuguesa de Ciências do Desporto, v.3, n.2, p.101-02, 2003.

MADUREIRA, A.S.; SOBRAL, F. Estudo comparativo de valores antropométricos entre escolares brasileiros e portugueses. Revista Brasileira de Cineantropometria e Desempenho Humano, v.1, n.1, p.53-9, 1999.

MALINA, R.M.; BOUCHARD, C. Growth, maturation, and physical activity. Champaign: Human Kinetics Books, 1991.

MALINA, R.M.; BOUCHARD, C.; BAR-OR, O. Growth, maturation, and physical activity. 2ed. Champaign: Human Kinetics Books, 2004.

MALINA, R.M.; BEUNEN, G.; LEFEVRE, J.; WOYNAROWSKA, B. Maturity-associated variation in peak oxygen uptake in active adolescent boys and girls. Annals of Human Biology, v.24, n.1, Jan-Feb, p.19-31, 1997.

MARCONDES, E. Distúrbios do crescimento e da nutrição: importância, conceito e classificação. In: MARCONDES, E. (Ed.). Crescimento normal e deficiente. São Paulo: Rocca, 1989. p.70-75. 
MORROW, J.R.; FREEDSON, P.S. Relationship between habitual physical activity and aerobic fitness in adolescents. Pediatric Exercise Science, n.6, 1994, p.315-29, 1994.

MUELLER, W.H.; HARRIST, R.B., DOYLE, S.R.; LABARTHE, D.R. Percentiles of body composition from bioelectrical impedance and body measurements in U.S. adolescents 8-17 years old: Project HeartBeat! American Journal of Human Biology, v.16, n.2, p.135-50, 2004.

NEDER, J.A.; LERARIO, M.C.; CASTRO, M.L.; SACHS, A.; NERY, L.E. Peak VO2 correction for fat-free mass estimated by anthropometry and DEXA. Medicine and Science in Sports and Exercise, v.33, n.11, Nov, p.1968-75, 2001.

NEVILL, A.M. The need to scale for differences in body size and mass: an explanation of Kleiber's 0.75 mass exponent. Journal of Applied Physiology, v.77, n.6, Dec, p.28702883, 1994.

NEVILL, A.M.; HOLDER, R.L.; BAXTER-JONES, A.; ROUND, J.M.; JONES, D.A. Modeling developmental changes in strength and aerobic power in children. Journal of Applied Physiology, v.84, n.3, Mar, p.963-70, 1998.

OLIVEIRA, P.R. Resistência aeróbica e sua relação com o crescimento e desenvolvimento físico de adolescentes. 91p. Dissertação. (Mestrado em Educação Física) Programa de Pós-Graduação em Educação Física. Universidade de São Paulo, São Paulo, 1982.

PATERSON, D.H.; MCLELLAN, T.M.; STELLA, R.S.; CUNNINGHAM, D.A. Longitudinal study of ventilation threshold and maximal $\mathrm{O} 2$ uptake in athletic boys. Journal of Applied Physiology, v.62, n.5, May, p.2051-7, 1987.

PETTERSEN, S.A.; FREDRIKSEN, P.M.; INGJER, F. The correlation between peak oxygen uptake (VO2peak) and running performance in children and adolescents. Aspects of different units. Scandinavian Journal of Medicine and Science in Sports, v.11, n.4, p.223-31, 2001. 
PIRES, E.A.G.; DUARTE, M.F.S.; PIRES, M.C.; SOUZA, G.S. Hábitos de atividade física e o estresse em adolescentes de Florianópolis, SC - Brasil. Revista Brasileira de Ciência e Movimento, v.12, n.1, p.51-6, 2004.

PIRES, M.C.; LOPES, A.S. Crescimento físico e características sócio-demográficas em escolares no município de Florianópolis - SC, Brasil. Revista Brasileira de Cineantropometria e Desempenho Humano, v.6, n.2, p.17-26, 2004.

PIRES NETO, C.S.; PETROSKI, E.L. Assuntos sobre equações da gordura corporal relacionadas a crianças e jovens. Comunicação, Movimento e Mídia na Educação Física, v.4, p. 21-30, 1996.

PIVARNIK, J.M.; TAYLOR, W.C.; CUMMINGS, S.S. Longitudinal assessment of aerobic fitness in middle school african-american girls. Pediatric Exercise Science, v.10, n.1, p.21-7, 1998.

PIVARNIK, J.M.; DWYER, M.C.; LAUDERDALE, M.A. The reliability of aerobic capacity (VO2max) testing in adolescent girls. Research Quarterly for Exercise and Sport, v.67, n.3, Sep, p.345-8, 1996.

PROGRAMA DAS NAÇÕES UNIDAS PARA O DESENVOLVIMENTO. Atlas do desenvolvimento humano no Brasil. 2007. Disponível na Internet via WWW. URL: http://www.pnud.org.br/atlas/. Arquivo capturado em 23 de agosto de 2008.

REISS, M.J. The allometry of growth and reproduction. Cambridge: Cambridge University Press, 1989.

RIVERA-BROWN, A.M.; ALVAREZ, M.; RODRÍGUES-SANTANA, J.R.; BENETTI, P.J. Anaerobic power and achievement of $\mathrm{VO}_{2}$ plateau in pre-pubertal boys. International Journal of Sports Medicine, v.22, n.2, p.111-15, 2001. 
RIVERA-BROWN, A.M.; FRONTERA, W.R. Achievement of plateau and reliability of $\mathrm{VO}_{2} \max$ in trained adolescents tested with different ergometers. Pediatric Exercise Science, v.10, n. 2, p.164-75, 1998.

RIVERA-BROWN, A.M.; FRONTERA, W.R.; RIVERA, M.A. Applicability of criteria for $\mathrm{VO}_{2}$ máx in active adolescents. Pediatric Exercise Science, v.4, n. 4, p.331-39, 1992.

ROBERGS, R.A.; ROBERTS, S.O. Exercise Physiology: Exercise, Performance, and Clinical Applications. Saint Louis: Mosby, 1997.

ROGERS, D.M.; OLSON, B.L.; WILMORE, J.H. Scaling for the VO2-to-body size relationship among children and adults. Journal of Applied Physiology, v.79, n.3, p.95867, 1995.

ROGERS, D.M.; TURLEY, K.R.; KUJAWA, K.I.; HARPER, K.M.; WILMORE, J.H. Allometric scaling factors for oxygen uptake during exercise in children. Pediatric Exercise Science, v.9, p.12-25, 1995.

ROSS, W.D.; MARFELL-JONES, M.J. Kinanthropometry. In: MACDOUGALL, J.D.; WENGER, H.A.; GREEN, H.J. (Ed.). Physiological testing of the elite athlete. New York: Movement Publications, 1982. p.75-115.

ROWLAND, T.W. Children's Exercise Physiology. Champaign: Human Kinetics Books, 2002.

ROWLAND, T.W. Children's Exercise Physiology. 2ed. Champaign: Human Kinetics Books, 2005.

ROWLAND, T.W. Aerobic exercise testing protocols. In: ROWLAND, T.W. (Ed.). Pediatric Laboratory Exercise Testing: Clinical Guidelines. Champaign: Human Kinetics Books, 1993. p.19-42. 
ROWLAND, T.W.; CUNNINGHAM, L.N. Oxygen uptake plateau during maximal treadmill exercise in children. Chest, v.101, n.2, Feb, p.485-9, 1992.

ROWLAND, T.W.; KLINE, G.; GOFF, D.; MARTEL, L; FERRONE, L. Physiological determinants of maximal aerobic power in health 12-year-old boys. Pediatric Exercise Science, v.11, p.317-26, 1999.

ROWLAND, T.W.; VANDERBURGH, P.M.; CUNNINGHAM, D.A. Body size and the growth of maximal aerobic power in children: a longitudinal analysis. Pediatric Exercise Science, v.9, p.262-274, 1997.

RODRIGUES, A.N.; PEREZ, A.J.; CARLETTI, L.; BISSOLI, N.S.; ABREU, G.R. Valores de consumo máximo de oxigênio determinados pelo teste cardiopulmonar em adolescentes: uma proposta de classificação. Jornal de Pediatria, v.82, n.6, p.426-30, 2006.

ROSS, J.M.; DOTSON, C.O.; GILBERT, G.G.; KATZ, S.J. The national children and youth fitness study. New standards for fitness measurement. Journal of Physical Education, Recreation and Dance, v.56, n.1, p.62-6, 1985.

ROSS, J.M.; GILBERT, G.G.; The national children and youth fitness study. A summary of findings. Journal of Physical Education, Recreation and Dance, v.56, n.1, p.45-50, 1985.

ROSS, W.D.; MARFELL-JONES, M.J. Kinanthropometry. In: MACDOUGALL, J.D.; WENGER, H.A.; GREEN, H.J. (Ed.). Physiological testing of the elite athlete. New York: Movement, 1982.

SCHIMIDT-NIELSON, K. Scaling: why is animal size so important? Cambridge: Cambridge University Press, 1984.

SALLIS, J.F.; PROCHASKA, J.J.; TAYLOR, W.C. A review of correlates of physical activity of children and adolescents. Medicine and Science in Sports and Exercise, v.32, n.5, May, p.963-75, 2000. 
SCHREINER, D.F., Cotidiano, trabalho e poder. A formação da cultura do trabalho no extremo oeste do Paraná. Toledo: EdT, 1997

SHEEHAN, J.M.; ROWLAND, T.W.; BURKE, E.J. A comparison of four treadmill protocols for determination of maximum oxygen uptake in 10- to 12-year-old boys. International Journal of Sports Medicine, v.8, n.1, Feb, p.31-4, 1987.

SILVA, A.E.L.; GAGLIARDI, J.F.L.; LOTUFO, R.F.M.; KISS, M.A.P.D. Ajustes lineares vs quadráticos da curva de consumo de oxigênio em teste progressivo. Revista Brasileira de Ciência e Movimento, v.11, n.4, p.1113-1118, 2003.

ŠPRINAROVÁ, Š; PAŘISKOVÁ, J; BUNC, V. Relantionships between body dimensions and resting and working oxygen consumption in boys aged 11 to 18 years. European Journal of Applied Physiology and Occupational Physiology, v.56, p.725-36, 1987.

TANAKA, H.; MONAHAN, K.D.; SEALS, D.R. Age-predicted maximal heart rate revisited. Journal of the American College of Cardiology, v.37, n.1, p.153-6, 2001.

TANNER, J.M. Fallacy of per-weight and per-surface area standards and their relation to spurious correlation. Journal of Applied Physiology, v.2, p.1-15, 1949.

THODEN, J.S. Testing aerobic power. In: MACDOUGALL, J.D.; WENGER, H.A.; GREEN, H.J.; SCIENCES., C.A.O.S. (Ed.). Physiological testing of the high-performance athlete. Champaign: Human Kinetics Books, 1990. p.107-73.

THOMIS, M.; ROGERS, D.M.; BEUNEN, G.P.; WOYNAROWSKA, B.; MALINA, R.M. Allometric relationship between body size and peak VO2 relative to age at menarche. Annals of Human Biology, v.27, n.6, Nov-Dec, p.623-33, 2000.

TOMASSONI, T.L. Conducting the pediatric exercise test. In: ROWLAND, T.W. (Ed.). Pediatric Laboratory Exercise Testing: Clinical Guidelines. Champaign: Human Kinetics Publishers, 1993. p.1-18. 
TOTH, M.J.; GORAN, M.I.; ADES, P.A.; HOWARD, D.B.; POEHLMAN, E.T. Examination of data normalization procedures for expressing peak VO2 data. $\underline{\text { Journal of Applied }}$ Physiology, v.75, n.5, Nov, p.2288-92, 1993.

TURLEY, K.R.; ROGERS, D.M.; HARPER, K.M.; KUJAWA, K.I.; WILMORE, J.H. Maximal treadmill versus cycle ergometry testing in children: differences, reliability and variability of responses. Pediatric Exercise Science, v.7, p.49-60, 1995.

VANDERBURGH, P.M.; MAHAR, M.T.; CHOU, C.H. Allometric scaling of grip strength by body mass in college-age man and women. Research Quarterly for Exercise and Sport, v.66, n.1, p.80-84, 1995.

VANDERBURGH, P.M.; KATCH, F.I.; SCHOENLEBER, J.; BALABINIS, C.P.; ELLIOTT, R. Multivariate allometric scaling of men's world indoor rowing championship performance. Medicine and Science in Sports and Exercise, v.28, n.5, May, p.626-30, 1996.

VANDERBURGH, P.M.; EDMONDS, T. The effect of experimental alterations in excess mass on pull-up performance in fit young man. Journal of Strength and Conditioning

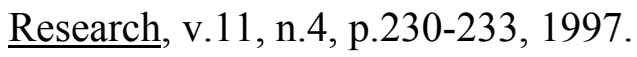

VASQUES, D.G.; SILVA, K.S.; LOPES, A.S. Aptidão cardiorrespiratória de adolescentes de Florianópolis, SC. Revista Brasileira de Medicina do Esporte, v.13, n.6, p.376-80, 2007.

VIDAL FILHO, J.C.B.; HERRERA, J.B.; BOTTARO, M. As respostas fisiológicas em préadolescentes durante o jogo de basquetebol. Revista Brasileira de Ciência e Movimento, v.11, n.2, p.19-23, 2003.

WALTRIC, A.C.A.; DUARTE, M.F.S. Estudo das características antropométricas de escolares de 7 a 17 anos - uma abordagem longitudinal mista e transversal. Revista Brasileira de Cineantropometria e Desempenho Humano, v.2, n.1, p.17-30, 2000. 
WELSMAN, J.R.; ARMSTRONG, N.; NEVILL, A.M.; WINTER, E.M.; KIRBY, B.J. Scaling peak VO2 for differences in body size. Medicine and Science in Sports and Exercise, v.28, n.2, p.259-65, 1996.

WINTER, E.M. Scaling: partitioning out differences in size. Pediatric Exercise Science, v.4, p.296-301, 1992.

. Importance and principles of scaling for size differences. In: BAR-OR, O. (Ed.). The child and adolescent athlete. Oxford: Blackwell Scientific Publications, 1996. p.673-679.

WINTER, E.M.; NEVILL, A.M. Scaling: adjusting for differences in body size. In: ESTON, R.; REILLY, T. (Ed.). Kinanthropometry and exercise physiology laboratory manual. London: E\&FN Spon, 1996. p.321-335.

. Importance and principles of scaling for size differences. In: BAR-OR, O. (Ed.). The child and adolescent athlete. Oxford: Blackwell Scientific Publications, 1996. p.673-679. 


\section{ANEXOS}

ANEXO I - Carta de Autorização da Direção da Escola

Prezado(a) Diretor(a), $\operatorname{Prof}(\mathrm{a})$.

Sou Professor do Curso de Educação Física da Universidade Estadual do Oeste do Paraná - Unioeste - e estou desenvolvendo uma pesquisa, no curso de doutorado, que envolverá crianças e adolescentes.

A pesquisa está intitulada como "Determinação da potência aeróbia de crianças e adolescentes a partir de ajustes alométricos". Este projeto, a ser iniciado em março de 2008 e com previsão de encerramento em novembro de 2008, tem o objetivo de descrever e comparar o comportamento da potência aeróbia de crianças e adolescentes rondonenses, com idades entre 10 e 16 anos de ambos os sexos, além de avaliar as características maturacionais, socioeconômicas e do nível de atividade física, que podem influenciar nos resultados.

Serão obtidas medidas antropométricas e de potência aeróbia (teste de esforço progressivo), além de avaliar o estado da maturação biológica, da atividade física habitual e do nível socioeconômico de cada sujeito participante. Considerando que nesta escola encontramse as crianças ou adolescentes com as idades estabelecidas na casuística do estudo, solicito uma autorização para visitar essa escola e convidar as crianças ou adolescentes para participarem do estudo e, àqueles interessados, entregar-lhes uma carta solicitando uma autorização (Termo de Consentimento) dos pais ou responsável. Para tanto, as visitas e convites aos alunos acontecerão prioritariamente durantes as aulas de Educação Física, e os professores responsáveis pelas turmas serão consultados sobre o dia e horário mais adequado à explicação e entrega da carta de autorização aos estudantes interessados.

Esclareço também que todas as informações sobre as crianças e adolescentes farão parte exclusivamente de um banco de dados para a referida pesquisa, respeitando o anonimato dos sujeitos quando forem analisados e publicados. Caso seja necessário, em caso de dúvidas ou notificação de acontecimentos não previstos declarados pelos pais ou pelas próprias crianças, deve-se procurar todos os esclarecimentos junto ao coordenador da pesquisa, pelo telefone 3284-7878 (Unioeste, Campus de Rondon), ou caso seja necessário outros esclarecimentos, consultar o Comitê de Ética em Pesquisa da Unioeste - CEP/Unioeste (Cascavel), através do telefone (45) 3220-3272.

Atenciosamente,

Prof. Gustavo André Borges

Coordenador da Pesquisa

Curso de Educação Física - Unioeste 


\section{ANEXO I (continuação) \\ Termo de Autorização da Direção da Escola}

Título do Projeto de Pesquisa:

"Determinação da potência aeróbia de crianças e adolescentes a partir de ajustes alométricos"

Pesquisador Responsável:

Prof. Gustavo André Borges

Prezado Professor,

Após ler a carta de intenção da pesquisa, e receber explicações sobre a mesma, a ser iniciada em março de 2008; além de entender os direitos assegurados de:

1. receber, junto do coordenador da pesquisa, resposta a qualquer pergunta ou esclarecimento necessário sobre os procedimentos, riscos, benefícios dos alunos ou outros assuntos relacionados à pesquisa;

2. retirar o consentimento dado pela direção da escola, a qualquer momento, da visita do coordenador da pesquisa;

3. sigilosidade, onde os alunos da escola não serão identificados, mantendo o caráter confidencial das informações relacionadas à sua privacidade;

4. procurar outros esclarecimentos junto ao Comitê de Ética em Pesquisa da Unioeste - CEP/Unioeste, através do telefone (45) 3220-3272 (Cascavel), em caso de dúvidas ou notificação de acontecimentos não previstos.

Declaro estar ciente dos procedimentos e AUTORIZO a visitação e participação dos alunos da escola, por interesse dos mesmos, no projeto de pesquisa em tela.

Marechal Cândido Rondon, de de 2008 . 


\section{ANEXO II - Carta de Intenção de Pesquisa}

\section{Senhores Pais ou Responsável,}

Sou professor do Curso de Educação Física da Unioeste e estou realizando uma pesquisa sobre o desenvolvimento físico de crianças e adolescentes, com idades entre 10 e 16 anos. Na pesquisa serão feitas medidas de estatura, do peso, da gordura corporal e da resistência aeróbica (teste de esforço em uma esteira elétrica com cargas progressivas), além de avaliar o estado pubertário, o nível de atividade física habitual e a condição socioeconômica. Após minha visita na escola do seu (sua) filho(a) e ter explicado a todos os jovens os objetivos da pesquisa, seu(sua) filho(a) demonstrou interesse. Nenhuma criança ou adolescente é obrigado a participar. A participação é voluntária.

Porém, é preciso explicar que o teste de condição aeróbica (Teste de Esforço Graduado) é o mais importante da avaliação e será feito por meio de uma corrida em esteira elétrica, no qual o esforço físico será aumentado durante a corrida até que seu(a) filho(a) ficar cansado e não conseguir continuar. $\mathrm{O}$ teste de esforço somente será interrompido quando forem alcançados os objetivos da avaliação ou quando seu(a) filho(a) pedir para parar. Saliento que há riscos à saúde apenas para crianças e adolescentes com problemas de saúde grave. Para crianças e adolescentes saudáveis, os riscos são muito pequenos. Entretanto, é comum entre os avaliados sentirem um mal-estar (dores de cabeça, tontura, mal-estar estomacal, dores nas pernas ou desconforto geral) depois da avaliação por causa do esforço da corrida até a exaustão.

Tudo será feito para evitar qualquer desconforto ou acidente, inclusive se necessário nós não realizaremos o teste de esforço. Caso o(a) Senhor(a) autorize o seu(sua) filho(a) a participar da pesquisa, ele(a) ainda poderá desistir quando quiser, por sua própria motivação, sem qualquer prejuízo ao mesmo. A avaliação será realizada em um único dia, com uma duração total de aproximadamente $60 \mathrm{~min}$. A avaliação será feita nas dependências da Unioeste em dia e horário marcados, fora do período de aula. Caso não haja a possibilidade do seu(sua) filho(a) se deslocar até a Unioeste, será providenciado transporte de ida e volta, sem custos adicionais. $\mathrm{O}$ (a) Senhor(a) tem o direito de acompanhar pessoalmente toda avaliação do seu(sua) filho(a), caso ache necessário.

Asseguro que todas as informações obtidas sobre seu(sua) filho(a) durante a avaliação serão utilizadas apenas para a pesquisa, respeitando o anonimato dele(a) quando os resultados forem publicados. Em caso de dúvidas, o(a) Senhor(a) tem o direito pedir esclarecimentos ao coordenador da pesquisa pelo telefone 8821-9543 (particular), ou consultar a direção da escola que ele(a) estuda ou também junto ao Comitê de Ética em Pesquisa da Unioeste, através do telefone (45) 3220-3272 (Cascavel).

É necessário que o(a) Senhor(a) autorize a avaliação pela assinatura do documento que acompanha esta carta (TERMO DE CONSENTIMENTO), para ser devolvido ao professor de Educação Física da escola que ele(a) estuda.

Atenciosamente,

\section{Prof. Gustavo André Borges \\ Coordenador da Pesquisa}

Curso de Educação Física - Unioeste

R. Pernambuco, no. 1777, Marechal Cândido Rondon - Paraná F: 3284-7878 


\section{ANEXO III - Termo de Consentimento}

\section{EXPLICAÇÃO DO TESTE DE ESFORÇO GRADUADO}

Eu compreendo que meu(minha) filho(a) irá correr em uma esteira em teste de esforço com cargas progressivas. Se meu(minha) filho(a) sentir desconforto ou estiver em perigo em algum momento do teste, este será interrompido. Caso meu(minha) filho(a) não apresente qualquer problema de saúde, o teste de esforço graduado será finalizado quando os objetivos forem alcançados ou quando meu(minha) filho(a) pedir para parar, por exaustão.

\section{RISCOS E DESCONFORTOS}

Todo empenho será feito pelos avaliadores para que qualquer desconforto durante o teste não ocorra ou coloque meu(minha) filho(a) em risco. Estou ciente de que testes de esforço em crianças e adolescentes têm baixo risco à saúde. Contudo, sei que será feito o possível para que não haja qualquer risco a integridade física dele(a) durante o teste. Caso seja encontrado algum sinal de risco, meu(minha) filho(a) não realizará o teste, e o motivo deverá ser comunicado mim. Contudo, fui esclarecido(a) que após o teste poderão surgir desconfortos tais como dores de cabeça, tonturas, mal-estar estomacal, dores nas pernas ou desconforto geral, como conseqüência do esforço físico realizado durante o teste.

\section{OBJETIVOS E BENEFÍCIOS ESPERADOS}

Estou esclarecido(a) que o teste tem como objetivo avaliar a resistência aeróbica de crianças e adolescentes As informações obtidas no teste serão usadas para efeito de pesquisa científica sobre o desenvolvimento das crianças e adolescentes de Marechal Cândido Rondon. Foi-me garantido o total anonimato dos resultados do teste do meu (minha) filho(a).

\section{CONSSENTIMENTO LIVRE E ESCLARECIDO}

Eu e meu(minha) filho(a) tivemos a chance de sermos esclarecidos(as) a respeito do teste e eu tenho o direito de tirar qualquer dúvida sobre a avaliação realizada no(a) meu(minha) filho(a) com o coordenador do estudo, a qualquer momento.

Portanto, AUTORIZO a participação do(a) meu(minha) filho(a) na pesquisa, considerando o seu próprio interesse em participar, mas na condição de que ele(a) poderá pedir para não participar mais da avaliação em qualquer momento, por motivação própria, e que esse direito lhe será assegurado(a).

Nome do(a) filho(a):

Nome do pai, mãe ou responsável:

Telefone para contato: Idade:

Assinatura:

Data: / 2008. 
ANEXO IV - Termo de Aprovação do Comitê de Ética em Pesquisa

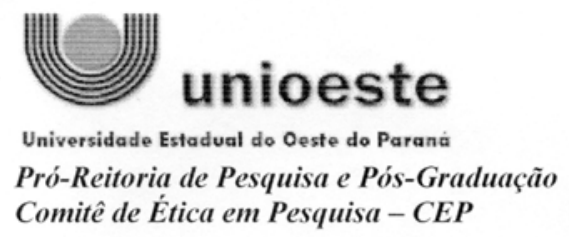

Comitê de Ética em Pesquisa-CEP

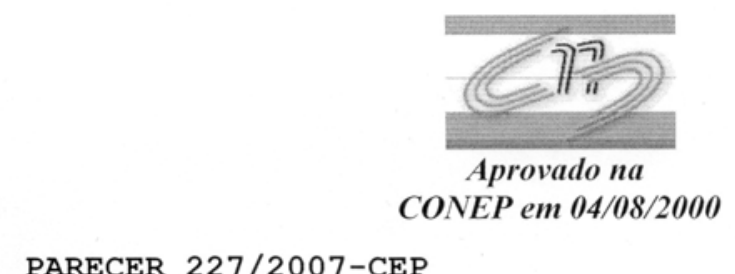

PARECER 227/2007-CEP

Súmula: Avaliação de proposta de projeto de Tese de doutoramento, tendo como pesquisador responsável Gustavo André Borges.

- Comitê de Ética em Pesquisa da Universidade Estadual do Oeste do Paraná, analisou na continuação da sessão ordinária do dia 16/08/2007, realizada no dia 30/08/07, Ata 008/2007 - CEP, o processo CR n 21449/2007, referente ao projeto de Tese de doutoramento intitulado "Determinação da potência aeróbia de crianças e adolescentes a partir de ajustes alométricos" tendo como pesquisador responsável Gustavo André Borges, cujo objetivo é entre outros, "Descrever e comparar o comportamento da potência aeróbia ( $\left.\mathrm{VO}_{2} \mathrm{pico}\right)$, em base em medidas diretas, relativas à idade, sexo, maturacional e nível socioeconômico".

Assim, mediante a importância social e cientifica que o projeto apresenta, a sua aplicabilidade e conformidade com os requisitos éticos, somos de parecer favorável à realização do projeto classificando-o como APROVADO, pois 0 mesmo atende aos requisitos fundamentais da Resolução $196 / 96$ e suas complementares do Conselho Nacional de Saúde.

$$
\text { Deverá ser encaminhado ao CEP ○ relatório final da }
$$

pesquisa e/ou a publicação de seus resultados, para acompanhamento, bem como comunicada qualquer intercorrência ou a sua interrupção.

\author{
Cascavel, 31 de Agosto de 2007.

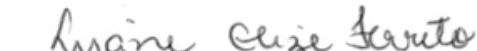 \\ LIRANE ELIZE FERRETO \\ Coordenadora do CEP/Unioeste
}


ANEXO V - Ficha de coleta dos dados

Data Avaliação:

Nome:

Sexo: ( ) M ( ) F Data do Nascimento:

IM:

Medidas Antropométricas:

Peso (kg):

Estatura (cm):

Dobras Cutâneas (mm):

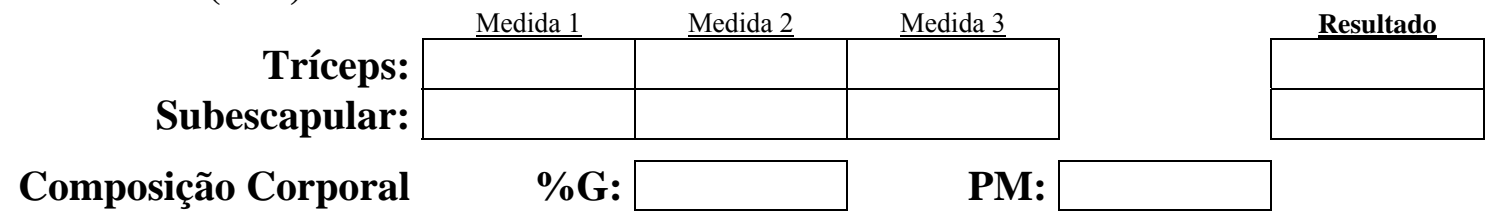

Parâmetros Hemodinâmicos de Repouso:

FCrepouso:

PAS:

PAD:

Protocolo de Esforço: (Balke Modificado)

Características do teste: Velocidade: $8 \mathrm{~km} / \mathrm{h}$ - Inclinação: $2,5 \%$ (a cada $2 \mathrm{~min}$ ).

Valores obtidos no VO $\mathrm{VO}_{2}$ PICO:

\begin{tabular}{|c|c|c|c|c|c|c|}
\hline \hline \multicolumn{3}{|c|}{ Teste } & \multicolumn{4}{c|}{ Valores Ventilatórios } \\
\hline $\begin{array}{c}\text { Tempo } \\
\text { (min) }\end{array}$ & $\begin{array}{c}\text { Inclin. } \\
(\%)\end{array}$ & $\begin{array}{c}\text { FC } \\
(\mathbf{b p m})\end{array}$ & QR & $\begin{array}{c}\text { VE } \\
(\mathrm{L} / \text { min) }\end{array}$ & $\begin{array}{c}\mathrm{VO}_{2} \\
(\mathrm{~L} / \mathbf{m i n})\end{array}$ & $\begin{array}{c}\mathrm{VCO}_{2} \\
(\mathrm{~L} / \mathrm{min})\end{array}$ \\
\hline & & & & & & \\
\hline
\end{tabular}

Características do Ambiente Laboratorial:

Temperatura da Sala $\left({ }^{0} \mathrm{C}\right)$ : Umidade Relativa (\%):

Parâmetros do Analisador de Gases VO2000 para a realização do teste:

\begin{tabular}{|c|c|}
\hline \multicolumn{2}{|c|}{ (CHANNEL VOLTMETER) } \\
\hline FLO & Temp. \\
\hline O2 & Presão At. \\
\hline CO2 & \\
\hline
\end{tabular}

